Daniel Luiz Rodrigues Junior

\title{
EFEITO DA DEFORMAÇÃO PLÁSTICA SOBRE AS PROPRIEDADES MAGNÉTICAS EM AÇOS PARA FINS ELÉTRICOS
}


Daniel Luiz Rodrigues Junior

\section{EFEITO DA DEFORMAÇÃO PLÁSTICA SOBRE AS PROPRIEDADES MAGNÉTICAS EM AÇOS PARA FINS ELÉTRICOS}

Tese apresentada à Escola

Politécnica da Universidade de São Paulo para obtenção do título de doutor em engenharia

Área de concentração: Engenharia Metalúrgica e de Materiais.

Orientador: Professor Doutor Fernando José Gomes Landgraf 
Este exemplar foi revisado e corrigido em relação à versão original, sob responsabilidade única do autor e com a anuência de seu orientador.

São Paulo, de fevereiro de 2015.

Assinatura do autor

Assinatura do orientador

Catalogação-na-publicação

Rodrigues Junior, Daniel Luiz

Efeito da deformação plástica sobre as propriedades magnéticas em aços para fins elétricos / D.L. Rodrigues Junior. versão corr. -- São Paulo, 2015.

$120 \mathrm{p}$.

Tese (Doutorado) - Escola Politécnica da Universidade de São Paulo. Departamento de Engenharia Metalúrgica e de Materiais.

1.Aço elétrico 2.Deformação plástica 3.Perdas magnéticas I.Universidade de São Paulo. Escola Politécnica. Departamento de Engenharia Metalúrgica e de Materiais II.t. 
Alos MEUS pAIs, ФANIEL LUI\% Rodrigues e NeUSA pereIrA ROdRIGUES. Sন̃̄O ELES OS MEUS MATIORES EXEMJLOS, MELHORES AMIGOS E GRANDES INCENTIVATORES. DEDICO TAMBÉM AOS NUMEROSOS AMIGOS QUE FI\% AO LONGO DESSA JORNATDA. 


\section{Agradecimentos}

Ao professor Dr. Fernando José Gomes Landgraf, orientador desse trabalho.

À Coordenação de Aperfeiçoamento de Pessoal de Nível Superior - CAPES pelo apoio financeiro.

À Brasmetal Waelzholz SA pela doação de matéria prima utilizada na realização desse trabalho.

Ao Instituto de Pesquisas Tecnológicas - IPT por gentilmente disponibilizar equipamentos para a realização de parte do procedimento experimental desse trabalho.

Instituto de Física da USP.

Funcionários do laboratório de metalografia Hubertus Colpaert.

Ao professor Dr. André Paulo Tschptschin que viabilizou parte da etapa de caracterização microestrutural.

Aos amigos do "Grupo de materiais magnéticos", equipe de trabalho dedicada a investigar as relações entre microestrutura e propriedades magnéticas.

Aos amigos da turma 031 do curso de Materiais Processos e Componentes Eletrônicos (MPCE) da FATEC-SP. 


\section{Resumo}

Este trabalho avalia o efeito da deformação plástica sobre as propriedades magnéticas em amostras de aço elétrico de grão não orientado. O material sob estudo foi extraído de uma bobina de aço elétrico GNO, com $0,8 \% \mathrm{Si}$, em estado recozido, com densidade $7781 \mathrm{~kg} / \mathrm{m}^{3}$ e tamanho de grão $20 \mu \mathrm{m}$. As chapas extraídas foram laminadas a frio para a produção de amostras com deformação real entre 0,03 e 0,29.

A densidade de discordâncias desses corpos de prova foi estimada através de difração de raios-X. Através da análise da largura à meia altura dos picos de difração foi possível estimar a densidade de discordâncias das amostras. Os resultados descreveram maior taxa de aumento da densidade de discordâncias para pequenas deformações. A partir de 0,12 de deformação real o incremento foi pequeno.

No que tange à caracterização magnética, para os ciclos de histereses obtidos em regime quase estático, verificou-se aumento da perda histerética com o crescimento da deformação plástica. Essa relação foi descrita de acordo com a lei de dependência onde a perda histerética cresce com a raiz quadrada da deformação real. Sobre o efeito da frequência de excitação na dissipação de energia por perdas magnéticas, o material não deformado mostrou-se mais sensível que os laminados a frio ao aumento da frequência. Pois se constatou que os materiais laminados apresentaram perda de excesso desprezível. Este comportamento pode ser explicado assumindo-se que com a deformação plástica eleva-se o número de paredes de domínio por unidade de volume, diminuindo assim as perdas de excesso. Dessa forma, para a faixa de 
frequências analisada, a perda histerética é a parcela que mais contribuiu para o aumento da perda magnética com a deformação.

Palavras-chave: aço elétrico, deformação plástica, propriedades magnéticas. 


\section{Abstract}

This study evaluates the effect of plastic deformation on the magnetic properties of electrical steel in electrical steel samples. The material under investigation was obtained from a coil of non-oriented electrical steel sheets, $0.8 \% \mathrm{Si}$, annealed, with density $7781 \mathrm{~kg} / \mathrm{m}^{3}$ and grain size of $20 \mu \mathrm{m}$. The material was cold rolled in order to produce samples with true strain ranging from 3 to $29 \%$.

The specimens' dislocation density was estimated by X-ray diffraction. Analyzing the full width at half maximum of the diffraction peaks was possible to estimate the dislocation density of the samples. The results described a large increasing rate of dislocation density for small deformations and from $12 \%$ true strain the increment was small.

On the magnetic characterization, the hysteresis loops obtained at quasi static regime shown a hysteresis loss increasing with true strain. This relationship is described according to the law of dependence where the increasing is linear with the square root of the true strain.

All samples suffered total loss increasing with the frequency growth. It was observed that the hysteresis loss was the main contribution for the energy dissipation, for any true strain level. The undeformed material exhibited greather sensibility to frequency excitation than any strained sample. This result occurs due to the cold rolled sheets presented negligible excess loss. This behavior can be explained assuming the hypothesis that the number of domain walls per unit volume increase due to grain fragmentation, thus reducing excess loss. Keywords: electrical steel, plastic deformation, magnetic properties. 


\section{Índice de figuras}

Figura 1: Exemplos de peças usadas na construção de núcleos de motores e transformadores elétricos .................................................. 2

Figura 2: Distribuição da participação no volume de produção das diferentes classes de materiais magneticamente moles. ............................ 3

Figura 3: Gráfico indicando a redução da energia dissipada pelos melhores aços elétricos comerciais para transformadores ao longo do tempo.

Figura 4: Ilustração mostrando as correntes de Foucault induzidas pela variação da indução magnética......................................... 9

Figura 5: Perdas totais e suas componentes para aços com teor de silício e processamento diferentes................................................ 10

Figura 6: Monocristal de ferro desmagnetizado pela formação de estruturas de domínios. ....................................................................... 12

Figura 7: Estrutura de domínios observada em amostra de FeSi não orientado.

.................................................................................. 12

Figura 8: Mudança gradual na orientação dos dipolos através da parede de domínio. ........................................................................ 13

Figura 9: Parede de domínio encurvada sob a ação do campo magnético aplicado............................................................................... 14

Figura 10: Esquema ilustrando a modificação da estrutura de domínios ao longo do processo de magnetização. ...................................... 15

Figura 11: Ciclo de histerese magnética e seus principais pontos ................. 17

Figura 12: Subdivisão do ciclo de histerese em regiões de alta e baixa indução. 19

Figura 13: Imagem obtida por microscópio Lorentz de um precipitado atuando como empecilho à movimentação de uma parede de domínio. .... 20

Figura 14: Curva de indução e o ruído Barkhausen detectado por uma bobina sensora. ........................................................................ 21

Figura 15: Energia dissipada por histerese em função da indução máxima para a aplicação do campo magnético em três orientações distintas. .. 23

Figura 16: Energia dissipada por histerese em função da indução máxima apresentando os diferentes intervalos de variação de $B_{\max }$ e suas leis de potência. ................................................................. 24

Figura 17: Evolução do campo coercivo em função do aumento da indução máxima. 25

Figura 18: Representação esquemática das diferentes linhas deslizamento no interior de um grão. ................................................... 28

Figura 19: Ilustração das estruturas formadas durante o processo de fragmentação dos grãos em razão da deformação plástica......... 31

Figura 20: Estrutura deformada observada por microscopia eletrônica de transmissão em amostra de níquel..................................... 31

Figura 21: Micrografia de uma amostra de cobre com grãos grosseiros subdivididos em bandas de deformação. ............................... 32

Figura 22: Subestruturas formadas durante deformação plástica de aço........ 33

Figura 23: Efeito da deformação plástica, fornecida por laminação a frio, sobre o limite de escoamento de um aço elétrico GNO com $2 \%$ de silício. 
Figura 24: Gráfico relatando o aumento da densidade de discordâncias com o aumento da deformação real para amostras de ferro com diferentes tamanhos de grão. 35

Figura 25: Gráfico relatando o aumento da densidade de discordância com a deformação para amostras de aço livre de intersticial (IF) e de carbono ultra baixo (ULC). ................................................ 36

Figura 26: Exemplos de arranjos de discordâncias mostrados no trabalho de Kronmüller................................................................. 39

Figura 27: Arranjo da magnetização espontânea no campo de tensão de uma discordância em cunha. ...................................................... 40

Figura 28: Definição dos parâmetros característicos de um campo de forças atuando sobre uma parede de domínio................................ 41

Figura 29: Perfil da extremidade de corte por puncionamento de uma amostra de aço elétrico $2 \%$ Si completamente processado. .................. 43

Figura 30: Ilustração mostrando as regiões que compõem a superfície lateral de uma lâmina cortada por puncionamento............................. 45

Figura 31: Contornos de baixo ângulo formados por arranjos de discordâncias decorrentes de poligonização................................................ 50

Figura 32: Efeito do tratamento térmico de recuperação sobre o limite de escoamento em amostras de alumínio de diferentes tamanhos de grão............................................................................ 51

Figura 33: Variação do limite de escoamento ( $\left.R^{\prime}\right)$ e da perda total $(R)$ para amostras com diferentes valores de deformação real ao longo do recozimento de recuperação. ................................................ 53

Figura 34: Largura à meia altura dos picos de difração em função da deformação real. 61

Figura 35: Micrografia da secção longitudinal de uma amostra com deformação real de 0,29, extraída por meio de microscopia óptica................ 64

Figura 36: Detalhe mostrando grãos deformados em amostra com deformação real 0,29 . Imagem extraída na secção longitudinal por microscopia eletrônica de varredura. 65

Figura 37: Microestrutura de um aço GNO 1,25 \% Si com 50 \% de redução por laminação a frio 65

Figura 38: Gráfico das curvas de magnetização das amostras deformadas por laminação a frio. 66

Figura 39: Gráfico das curvas de magnetização das amostras de aço não orientado 3 \% Si deformado a frio. ..................................... 67

Figura 40: Gráfico da indução B50 em função da deformação...................... 68

Figura 41: Curvas B50 em função da deformação real observadas por Fukuhara e para as amostras $0,8 \%$ Si do presente trabalho. ...... 68

Figura 42: Gráfico indicando a permeabilidade relativa e função do campo magnético para as amostra deformadas. ................................69 69

Figura 43: Ciclos de histereses quase estáticos? de algumas das amostras deformadas para indução máxima de 1,0 T............................ 70

Figura 44: Ciclos de histerese (quase estáticos) obtidos para amostras deformadas por laminação................................................. 70

Figura 45: Gráfico da energia dissipada por histerese quase estática em função da deformação real para diferentes valores de indução máxima. . 71

Figura 46: Gráfico indicando aumento linear da energia dissipada por histerese (em regime quase estático) com a raiz quadrada da deformação. 72 
Figura 47: Gráfico publicado por Hou e Lee indicando aumento da perda histerética com a raiz quadrada da deformação........................ 73

Figura 48: Comparação entre os resultados desse trabalho $(0,7 \% \mathrm{Si})$ e os dados apresentados por Fukuhara (2 e 3,1\% Si). ..................... 74

Figura 49: Evolução da perda histerética com o crescimento da densidade de discordâncias estimada por meio de difração de raios $X$............ 75

Figura 50: Variação da inclinação e do coeficiente linear das retas obtidas no gráfico da Figura 46. ......................................................... 76

Figura 51: Indução de máxima permeabilidade em função da deformação real. ................................................................................. 77

Figura 52: Energia dissipada por histerese na região de baixa indução, $L_{w h}$, em função da deformação real. ................................................ 78

Figura 53: Gráfico da energia dissipada na região de baixa indução, Lwh, (indução máxima de 1,5 T) em função da raiz da densidade de discordâncias estimadas por raios $X$..................................... 78

Figura 54: Energia dissipada por histerese na região de alta indução em função da deformação real.

Figura 55: Efeito da deformação sobre as componentes da perda histerética. 80

Figura 56: Gráfico do crescimento linear do campo coercivo com a raiz da deformação real para diferentes valores de indução. ................. 81

Figura 57: Crescimento linear do campo coercivo medido em regime quase estático em indução máxima de 1,5 T com a raiz da densidade de

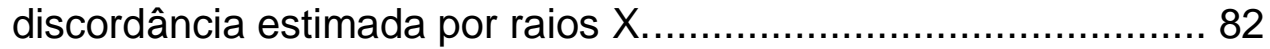

Figura 58: Gráfico mostrando a perda total em função da frequência para as amostras deformadas...................................................... 83

Figura 59: Gráfico indicando a variação da energia dissipada na forma de perda parasita (Wp) em função da frequência para as amostras deformadas. ................................................................... 84

Figura 60: Evolução das perdas de excesso em função da frequência para amostras com diferentes quantidades de deformação. ............... 85

Figura 61: Imagem da estrutura de domínios ao longo da superfície de um dente de estator produzido por corte por puncionamento e sem recozimento posterior................................................... 86

Figura 62: Processo de separação de perdas aplicado à amostras com deformação real $(\varepsilon)$ 0,03 e 0,06 posteriormente recozidas a $500^{\circ} \mathrm{C}$ por 90 minutos.

Figura 63: Gráfico do tamanho de grão calculado através da Equação 17 em função da deformação real..................................................... 88

Figura 64: Mapa de EBSD/OIM para uma amostra de aço laminada a frio com deformação real 0,29. 89

Figura 65: Micrografia indicando a variação dos ângulos de misorientação na microestrutura de uma amostra com 29\% de deformação real.... 90

Figura 66: Mapa de orientações obtidas por EBSD em uma amostra com deformação 0,29 recozida a $500^{\circ} \mathrm{C}$ durante uma hora. ............. 91

Figura 67: Tensão de Barkhausen em função do campo magnético para amostras com diferentes quantidades de deformação. ............... 92

Figura 68: Envolventes do sinal de Barkhausen para amostras de ferro Armco submetidas a diferentes níveis de deformação a frio.................. 93

Figura 68: Área integrada dos picos de Barkhausen em função da deformação real. 
Figura 69: Gráfico mostrando a razão entre área integrada dos picos de Barkhausen e a espessura das amostras em função da deformação

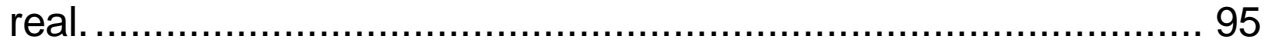




\section{Sumário}

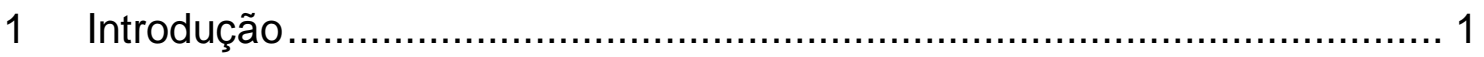

1.1 Aços elétricos de grão não orientado e sua importância tecnológica ... 1

1.2 Dissipação de energia e os novos desafios ................................... 4

1.2.1 O tratamento das perdas magnéticas: o procedimento de separação das perdas.............................................................. 7

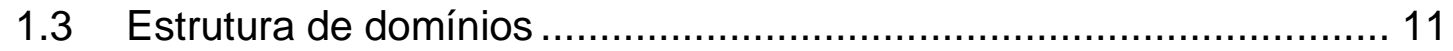

1.3.1 O processo de magnetização em termos da estrutura de domínios 13

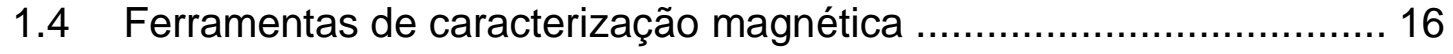

1.4.1 O ciclo de histerese ................................................ 16

1.4.2 O ruído de Barkhausen............................................... 19

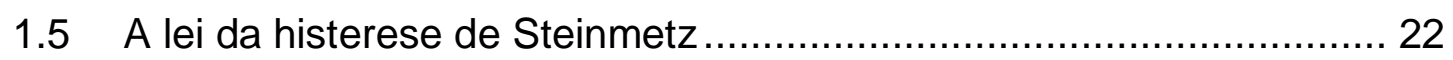

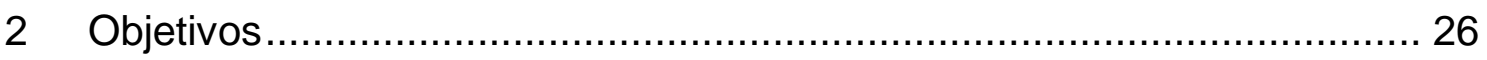

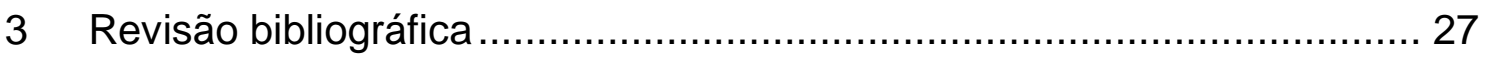

3.1 O estado deformado ...................................................... 27

3.1.1 Arranjos de discordâncias: subdivisão dos grãos ..................... 27

3.1.2 A menor escala de subdivisão: células de discordâncias............ 29

3.1.3 Subdivisão por microbandas e blocos de células..................... 30

3.1.4 Microestruturas de grandes deformações............................. 32

3.1.5 A difícil nomenclatura das estruturas de deformação................. 32

3.2 O efeito do trabalho a frio sobre as propriedades mecânicas............. 34

3.3 Deformação plástica e propriedades magnéticas: a concepção de

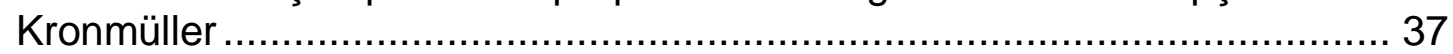

3.3.1 Parâmetros característicos da estrutura de discordâncias ........... 38

3.3.2 Interações fundamentais entre discordância e magnetização...... 39

3.3.3 Determinação da relação entre densidade de discordâncias e tensão aplicada.

3.3.4 A questão da ação da deformação plástica sobre a dissipação de energia 42

3.3.5 Combinação entre propriedades magnéticas e mecânicas em aços elétricos .................................................................................. 44

3.4 O fenômeno de recuperação .............................................. 48 
3.4.1 Migração e aniquilação das discordâncias durante a recuperação 49

3.4.2 Propriedades afetadas pela recuperação ................................... 51

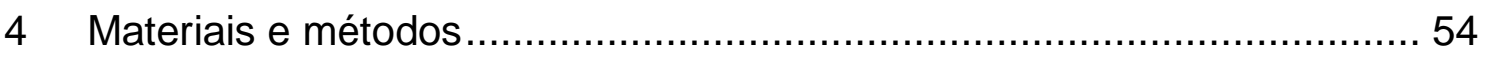

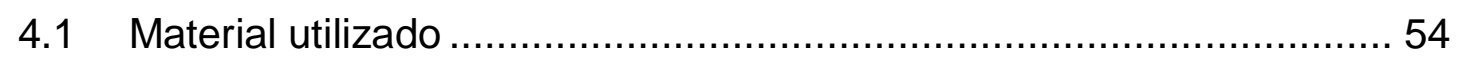

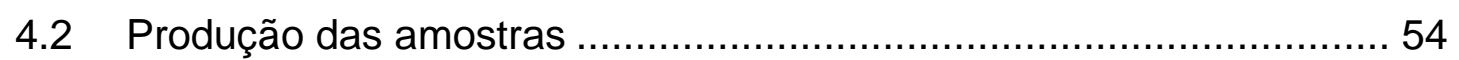

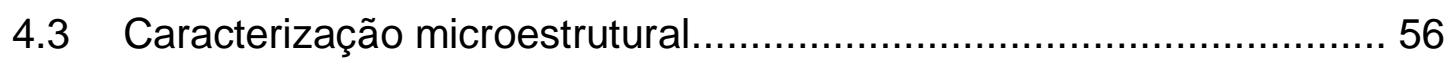

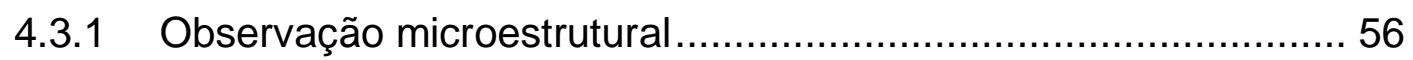

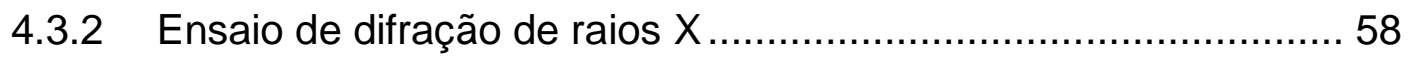

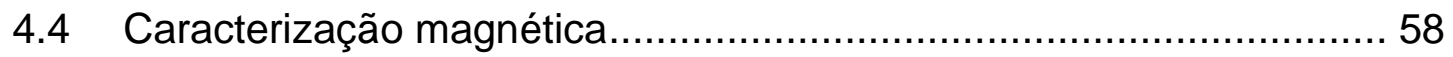

4.4.1 Medição da perda histerética.................................................... 58

4.4.2 Medição das perdas totais e separação das perdas …………..... 59

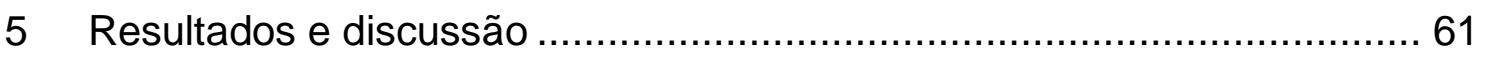

5.1 O ensaio de raios $X$ para estimativa da densidade de discordâncias . 61

5.1.1 Estrutura de grãos do material laminado ................................... 63

5.2 A ação da deformação sobre a curva de magnetização ...................... 66

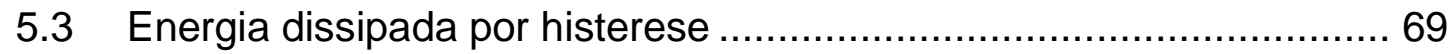

5.3.1 Ação da deformação plástica sobre o campo coercivo ................. 81

5.4 Importância da frequência de excitação …………............................. 82

5.4.1 Análise de ruídos de Barkhausen ............................................. 91

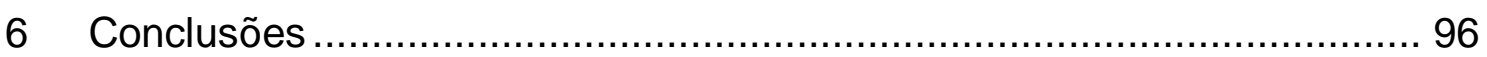

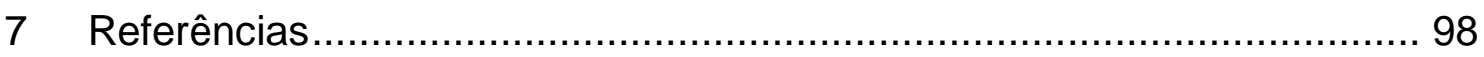




\section{Introdução}

\subsection{Aços elétricos de grão não orientado e sua importância tecnológica}

Aços elétricos são materiais magneticamente moles, ou seja, destacamse por apresentar baixo campo coercivo (campo magnético necessário para desmagnetizar o material) e elevada permeabilidade magnética. Esta última característica refere-se à capacidade de amplificar um campo magnético externamente aplicado. Esse conjunto de propriedades garante aos aços elétricos aplicação extensa na produção de dispositivos elétricos, tornando-os matéria-prima fundamental tanto na geração quanto na utilização de energia elétrica. Esse tipo de aço foi desenvolvido no início do século 20 e rapidamente se tornou o material mais utilizado para a construção de núcleos de dispositivos elétricos. Apesar de sua utilização intensa por mais de um século, muitos aspectos da relação entre microestrutura e propriedades não estão quantitativamente estabelecidos.

Diferentes classes de aços elétricos são usadas na forma de chapas laminadas que após corte por puncionamento são empilhados e dão origem às peças (semelhantes às mostradas na Figura 1) usadas para a construção de rotores, estatores (para motores e geradores elétricos) e núcleos de transformadores. 


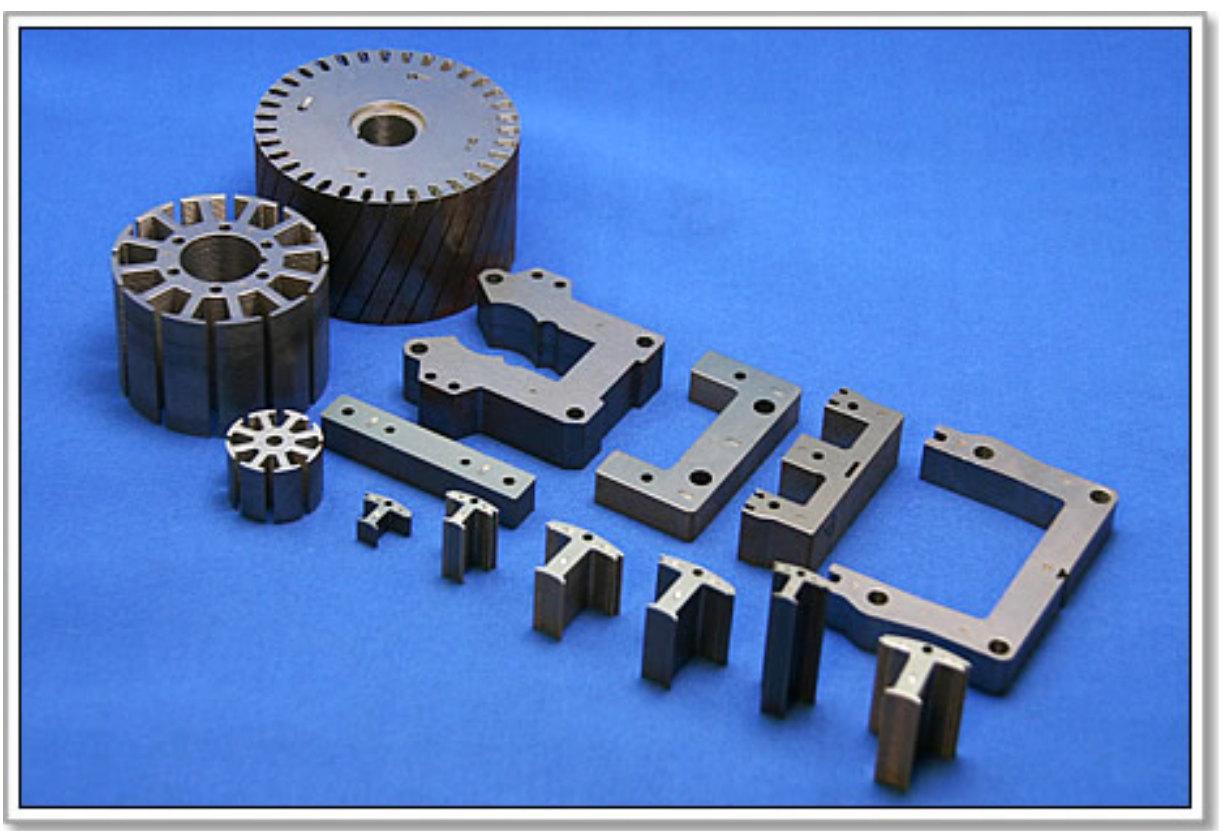

Figura 1: Exemplos de peças usadas na construção de núcleos de motores e transformadores elétricos [1].

Esse extenso campo de aplicações garante aos aços elétricos elevada importância. Seu volume de produção corresponde a 96\% do total de 12 milhões de toneladas de materiais magneticamente moles produzidas em 2006. A Figura 2 mostra as principais classes de materiais magneticamente moles e sua participação na produção mundial em toneladas para o ano de 2006 [2]. Nesta figura os materiais magneticamente moles estão divididos em três grandes grupos: aços elétricos de grão orientado (GO), aços elétricos de grão não orientado (GNO) e outros. Este último grupo é composto por ferritas, pós, ligas nanocristalinas, ligas amorfas, FeSi 6,5\% e liga FeNi. 


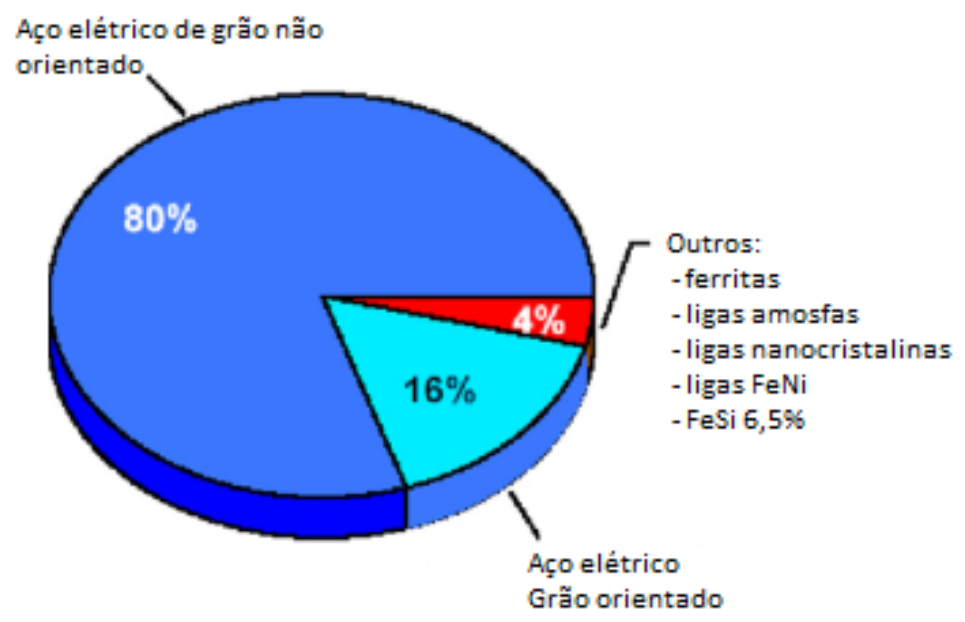

Figura 2: Distribuição da participação no volume de produção das diferentes classes de materiais magneticamente moles [2].

Conforme citado, os aços elétricos são divididos em duas classes. Os aços de grão orientado apresentam ótimo desempenho das propriedades magnéticas quando tomadas na direção de laminação da chapa. Isso se deve a sua microestrutura com forte textura cristalográfica do tipo (110) [001]. Os aços elétricos de grão não orientado devem ter boas propriedades magnéticas no plano da superfície da chapa independente da direção. Deseja-se dos aços GNO a textura (100) [uvw] [3].

O principal fator a explicar a disparidade de volume de produção entre essas duas classes de aços elétricos é a diversidade de aplicação de cada uma delas. A alta anisotropia das propriedades magnéticas dos aços GO restringe seu emprego à construção de transformadores, pois somente neste dispositivo o campo magnético é aplicado em uma única direção. No entanto, aços GNO estão presentes em diversos dispositivos tais como motores elétricos em aparelhos eletrodomésticos, pequenos transformadores e grandes geradores.

No Brasil, os aços elétricos de grão não orientado podem ser divididos em três grupos. Os aços totalmente processados, que são materiais de maior 
custo. Eles são entregues prontos para estampagem e uso, com baixo carbono e com recozimento final, e apresentam melhores propriedades magnéticas. Outra classe existente são os aços semi-processados, comprados por empresas que podem executar o tratamento térmico final para descarbonetação e recristalização após o corte. Por fim, existem os aços ABNT 1006. Eles não são produzidos especialmente para fins elétricos, porém são usados em larga escala mesmo sem recozimento em razão do seu baixo custo.

Novas tecnologias têm ampliado os horizontes para a aplicação do aço GNO. O mercado de energia eólica apresenta rápido desenvolvimento. O tamanho das turbinas e a potência nominal dos geradores de energia eólica estão em aumento significativo [4]. Outra novidade promissora é o desenvolvimento dos veículos híbridos. Essa tecnologia permite que motores elétricos possam ser usados em conjunto com motor à explosão. Nesses carros o motor elétrico atua de maneira complementar auxiliando ou substituindo o motor a combustão em situações de maior consumo de combustível.

\subsection{Dissipação de energia e os novos desafios}

Novas tecnologias e a crescente demanda por eletricidade tendem a elevar a importância dos aços elétricos no cenário mundial. Atender a essa crescente demanda não constitui o único desafio a ser superado. Os combustíveis fósseis, amplamente utilizados nos dias de hoje seja para as atividades industriais, residenciais ou comerciais, não são renováveis e caminham para a escassez. Diante da impossibilidade de uma rápida 
substituição dessa matriz energética por fontes limpas e renováveis tornam-se necessárias pesquisas que apontem para o desenvolvimento de dispositivos mais eficientes no que toca à dissipação de energia.

Dados relatam que a energia dissipada por dispositivos elétricos tem valores significativos. Um estudo sobre o consumo de energia elétrica em sistemas motorizados foi divulgado pela International Energy Agency em 2011. De acordo com essa publicação estima-se que motores elétricos consumam entre 43 e $46 \%$ da energia elétrica gerada em todo o mundo, sendo esse número duas vezes superior ao consumo correspondente à iluminação. Do ponto de vista ambiental esse consumo representa a emissão de 6040 Mt de $\mathrm{CO}_{2}$ por ano. Projeções apresentadas nesse mesmo estudo indicam que se nenhuma medida for tomada essa soma pode chegar a $8570 \mathrm{Mt}$ ao ano em 2030. Além de impactos ambientais o consumo elétrico dos motores representa um custo de 565 bilhões de dólares por ano, podendo chegar a 900 bilhões em $2030[5]$.

A potência útil de uma máquina elétrica pela perda de potência que ocorre nos motores elétricos e são principalmente atribuídas a esses três fatores [6].

Perdas magnéticas no aço.

Perdas no cobre.

Perdas mecânicas devidas ao atrito.

No que diz respeito às perdas magnéticas no aço, elas se devem ao fenômeno de histerese magnética, que é observado durante o processo cíclico de magnetização/desmagnetização. Ao longo do tempo observa-se uma 
melhora do desempenho energético dessa classe de aços, conforme indica a Figura 3. No entanto, estima-se que a perda magnética corresponda a um valor entre 5 e $10 \%$ da energia gerada em países desenvolvidos [7].

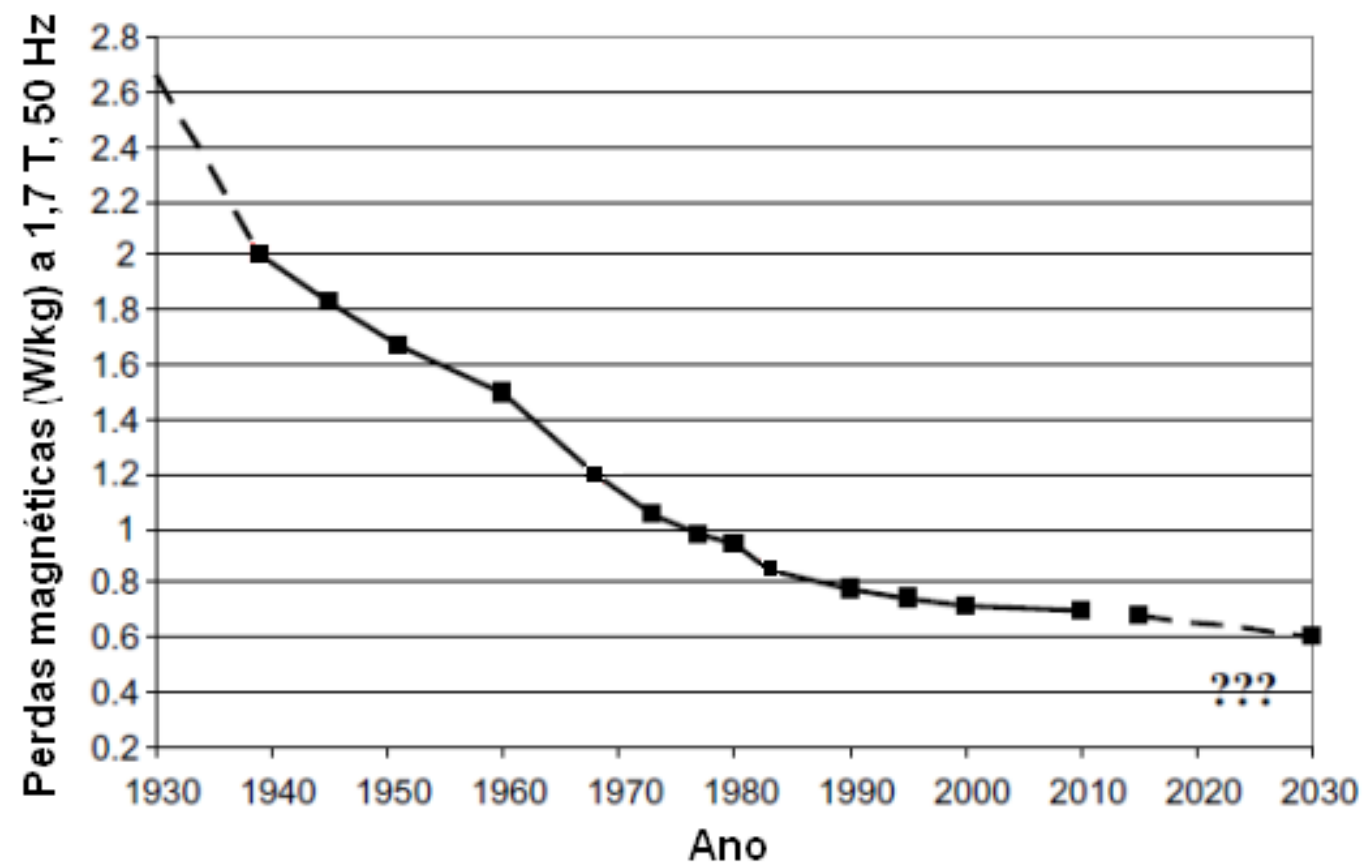

Figura 3: Gráfico indicando a redução da energia dissipada pelos melhores aços elétricos comerciais para transformadores ao longo do tempo (dados extraídos para indução máxima de 1,7 T a 50 Hz) [7].

Além da melhora de desempenho, outro grande desafio refere-se à redução do custo dos aços de melhor qualidade. Esse fator faz com que pequenos motores, frequentemente encontrados em eletrodomésticos, ainda usem material de baixa qualidade (com maior dissipação de energia).

A expansão do campo de aplicações dos aços elétricos traz consigo novos desafios. Inicialmente usados em dispositivos que operam em frequências constantes de 50 ou $60 \mathrm{~Hz}$, o uso em veículos híbridos ou geradores eólicos impõem condições mais severas de operação. Torna-se necessário maior entendimento sobre o comportamento desses materiais quando submetidos a frequências mais elevadas e sujeitas à variação. Essas condições mais severas impõem também a necessidade de melhores 
propriedades mecânicas visto que os aços elétricos são muito suscetíveis a deformação plástica.

Dessa forma, o desenvolvimento de aços de melhor qualidade é processo fundamental para atenuar a dissipação de energia e aprimorar o desempenho dos aços elétricos de grão não orientado frente às novas aplicações.

\subsubsection{O tratamento das perdas magnéticas: o procedimento de separação das perdas}

Esclarecida a importância que as perdas de potência têm para a indústria de dispositivos elétricos, torna-se necessário compreender quais os mecanismos que a ocasionam e sua relação com a microestrutura. A perda magnética costuma ser dividida em três parcelas cada uma delas ocasionada por um mecanismo de dissipação. São elas: perda histerética $\left(P_{h}\right)$, perda parasita $\left(P_{p}\right)$ e a perda de excesso $\left(P_{e}\right)$. Dessa maneira a perda magnética é frequentemente descrita pela soma dessas parcelas de acordo com a Equação 1.

$$
P_{t}=P_{h}+P_{p}+P_{e} \quad \text { Equação } 1
$$

As perdas de potência são dependentes da frequência de excitação, porém mesmo com a redução da frequência para valores extremamente baixos o material apresenta considerável perda energética. Essa dissipação de energia é a perda histerética. Ela pode ser medida diretamente através de ensaio de caracterização magnética conduzido em frequência baixa (neste trabalho será usado o valor de $0,5 \mathrm{mHz}$ ) caracterizando uma condição 
conhecida como quase estática. Nessa condição a energia dissipada está associada a mudanças bruscas de magnetização. É muito sensível a microestrutura dos aços, beneficiando-se do aumento do tamanho de grão, redução dos teores de elementos formadores de inclusões não metálicas tais como os sulfetos, nitretos e óxidos e da melhoria da orientação dos cristais dentro da chapa. Outras características microestruturais dos aços, tais como densidade de discordâncias, distribuição de tamanho de inclusões e precipitados também contribuem para a perda histerética [8].

Ao submetermos um material à ação de um campo magnético cuja intensidade varia com o tempo a variação de indução magnética irá induzir a circulação de corrente elétrica no corpo do material e este dissipa energia por efeito Joule. A essa corrente é dada o nome de correntes de Foucault, mostrada na Figura 4-a. Esse é o mecanismo responsável pela perda parasita. O cálculo da perda parasita é frequentemente realizado através da Equação 2. Este cálculo foi proposto por Thomson [9], e assume a simplificação de que a permeabilidade do material é constante. $B_{\max }$ é a indução máxima do ensaio, $\boldsymbol{e}$ é a espessura da lâmina, $\boldsymbol{f}$ a frequência, $\rho$ a resistividade elétrica e $d$ é a densidade. Esta equação descreve que essa parcela da perda cresce com o quadrado da espessura, por esta razão as partes de ferro das máquinas elétricas são sempre laminadas, e nunca são blocos maciços (Figura 4-b). 


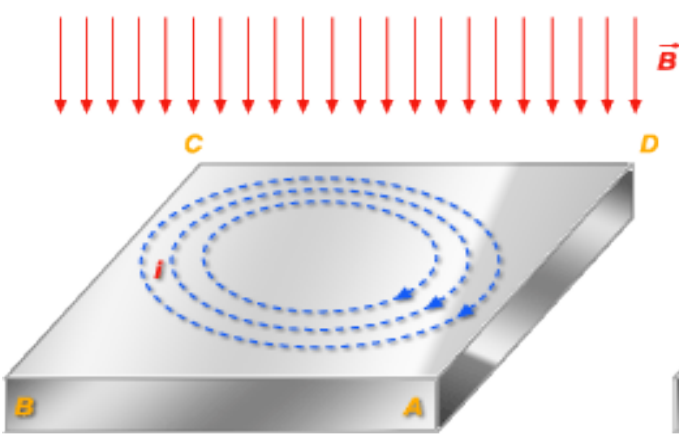

(a)

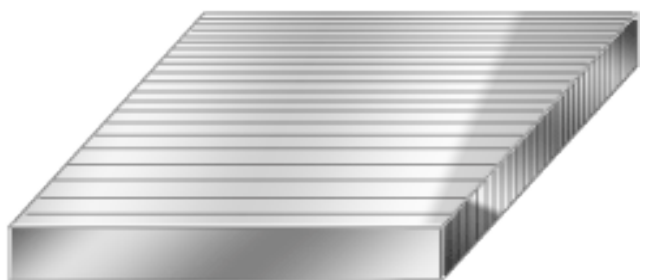

(b)

Figura 4: Ilustração mostrando as correntes de Foucault induzidas pela variação da indução magnética (a) e um empacotamento de chapas laminadas (b) [10].

$$
P_{p}=\frac{\left(B_{\max } \times \pi \times \mathrm{e} \times f\right)^{2}}{6 \times \rho \times d} \quad \text { Equação } 2
$$

O valor da perda parasita também é diminuído através do aumento da resistividade do material. Tal efeito pode ser alcançado por meio da adição de pequena quantidade de silício à liga em estado fundido. A soma das parcelas parasita e histerética das perdas magnéticas não atinge o valor da perda total. Esse complemento é atribuído à uma perda de excesso. Os mecanismos que as geram ainda são objetos de estudo. Um gráfico relatando a contribuição dessas três parcelas para a perda total pode ser observada na Figura 5. 


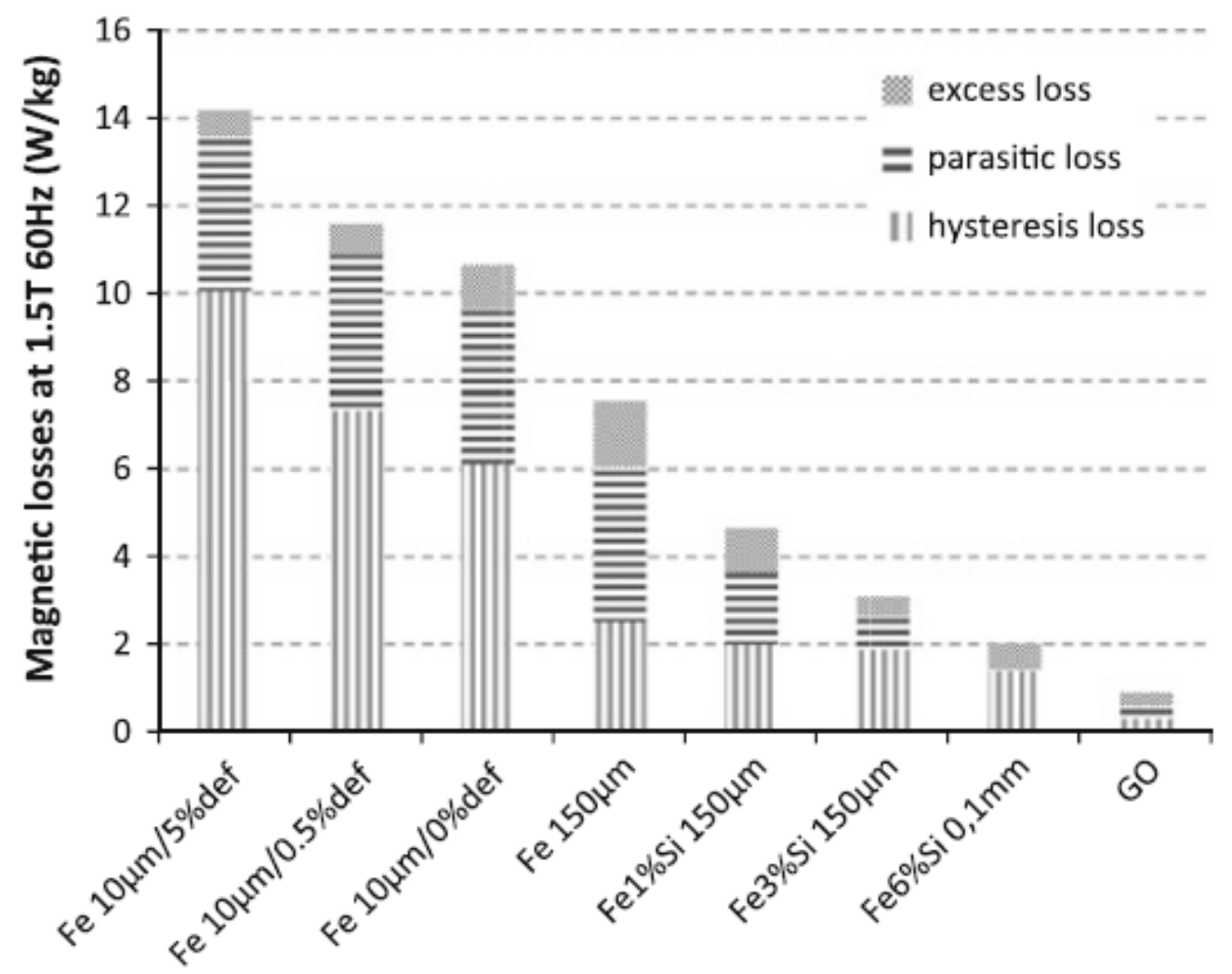

steels

Figura 5: Perdas totais e suas componentes para aços com teor de silício e processamento diferentes. Mantidas constantes a indução máxima de 1,0 T e a frequência 60 Hz [11].

Embora o procedimento de separação de perdas seja amplamente utilizado este modelo possui limitações. A Equação 2 é bastante criticada por Zirka [12 e 13] por esta ter origem na teoria desenvolvida para um meio ferromagnético com uma dependência $\mathrm{B} \times \mathrm{H}$ linear. Outra simplificação criticada nestes trabalhos é a restrição da aplicabilidade da equação para uma faixa de frequências onde o efeito de pele é irrelevante. A partir dessas condições, atribui-se incertezas à análise quantitativa das perdas de excesso através do procedimento de subtração. 


\subsection{Estrutura de domínios}

Um domínio magnético é determinado pelo volume do material onde a magnetização é igual ao seu valor de saturação e, em seu interior, os momentos magnéticos atômicos estão alinhados paralelos uns aos outros. Um material é composto por muitos domínios, cada um deles com sua própria direção e sentido de alinhamento momentos magnéticos. Dessa maneira, quando em estado desmagnetizado, a soma desses momentos é nula.

Os domínios magnéticos emergem no volume ferromagnético como resultado da competição entre as diferentes componentes da energia do sistema. Os momentos magnéticos atômicos em um domínio devem estar alinhados a uma direção específica do cristal. Este eixo é chamado de eixo de fácil magnetização e esta condição surge para atender a necessidade de redução da energia de anisotropia magnetocristalina. Momentos magnéticos vizinhos devem estar alinhados paralelamente uns aos outros determinando redução da energia de troca.

Outras energias relacionadas ao fenômeno magnético são energia magnetoelástica e energia do campo desmagnetizante. A primeira busca alinhar a magnetização espontânea em direções onde a magnetoestricção correspondente atua na redução de tensões internas provocadas por defeitos na rede cristalina. A segunda impede a presença de divergência na magnetização. A estrutura de domínios de um material ferromagnético desmagnetizado é fruto da minimização das energias mencionadas e alguns padrões para monocristal de ferro podem ser observados na Figura 6. Uma 
imagem de domínios magnéticos em material policristalino é mostrada na Figura 7.
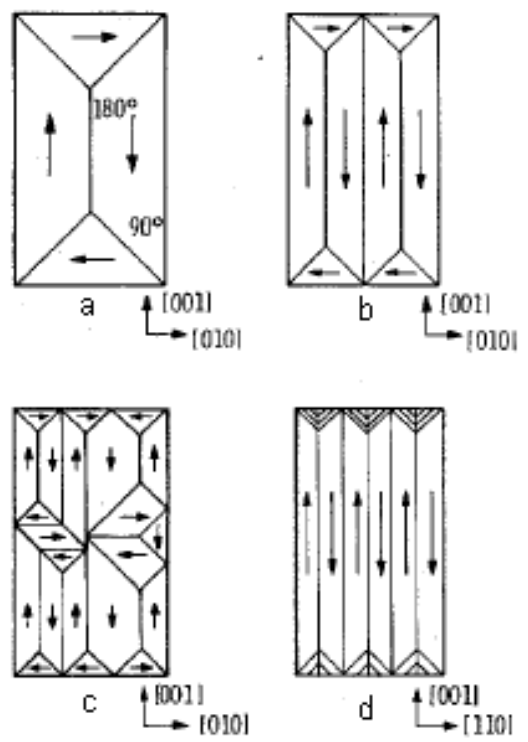

Figura 6: Monocristal de ferro desmagnetizado pela formação de estruturas de domínios [14].

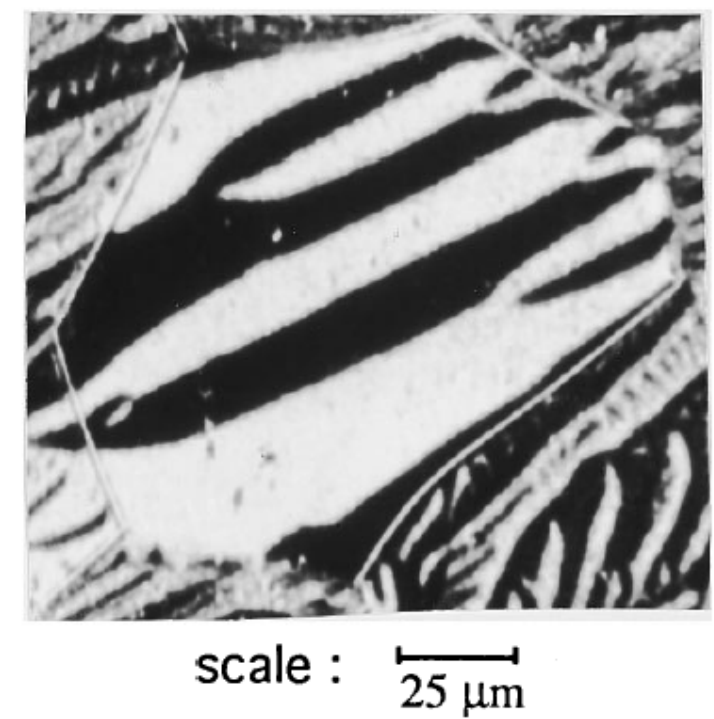

Figura 7: Estrutura de domínios observada em amostra de FeSi não orientado[15].

A fronteira entre os dois domínios vizinhos é chamada de parede de domínio. A parede consiste em uma região de transição da orientação dos dipolos magnéticos onde a direção dos momentos varia gradualmente. 
Portanto, a parede de domínio promove a transição de orientação dos dipolos atômicos entre os domínios vizinhos conforme ilustrado na Figura 8.

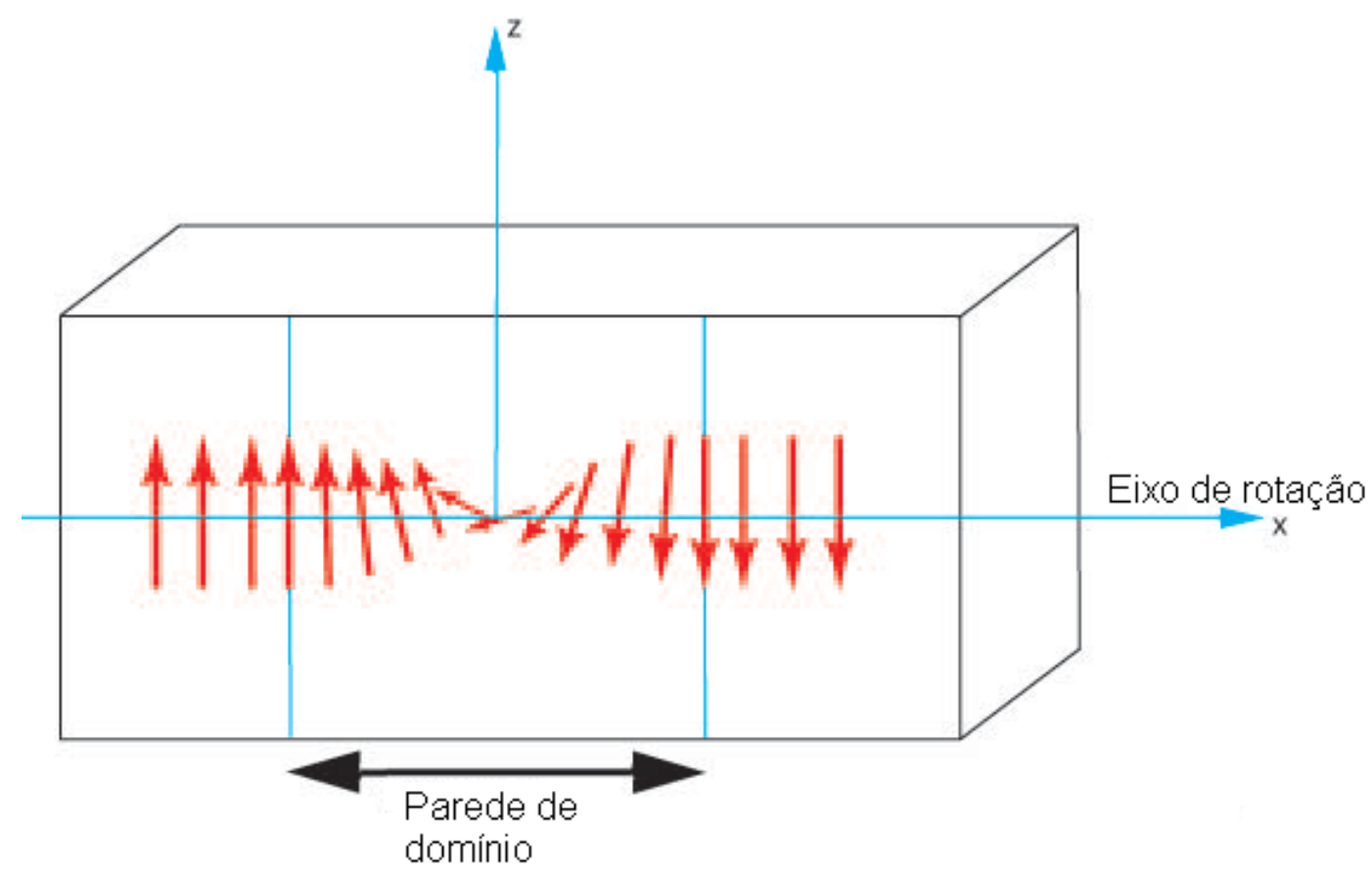

Figura 8: Mudança gradual na orientação dos dipolos através da parede de domínio [16].

\subsubsection{O processo de magnetização em termos da estrutura de domínios}

O processo de magnetização consiste na alteração da estrutura de domínios provocada pela aplicação de um campo magnético. As alterações se dão no sentido de conter o aumento de energia do sistema. Esse aumento é impulsionado pela energia magnetostática que é minimizada quando os momentos magnéticos atômicos estão alinhados paralelos ao campo externo. Dois mecanismos atuam no processo de magnetização.

Com aplicação de um campo de baixa intensidade a magnetização se dá majoritariamente com a movimentação das paredes de domínio. A movimentação se dá no sentido do aumento do volume dos domínios com melhor orientação em relação ao campo externamente aplicado. Dessa forma, 
uma determinada pressão é aplicada sobre a parede de domínio. Se a parede é ancorada em algum defeito da rede cristalina, ela pode se curvar até que (Figura 9), uma vez que se torne energeticamente favorável, a parede se liberta do defeito e prossegue em seu movimento.

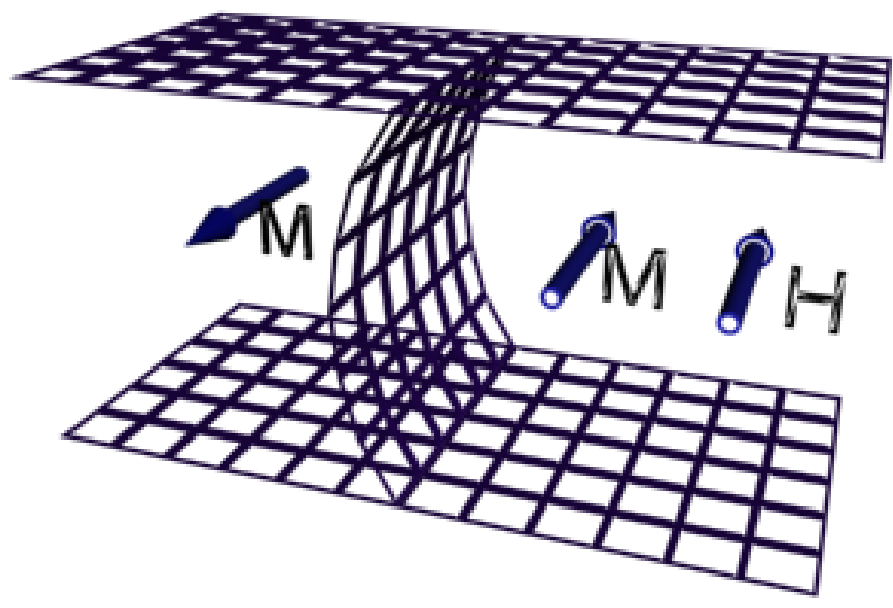

Figura 9: Parede de domínio encurvada sob a ação do campo magnético aplicado [17].

Sob a ação de campos moderados um segundo mecanismo se torna significante. A rotação de domínios ocorre quando momentos atômicos desfavoravelmente alinhados com o campo superam a energia de anisotropia e subitamente rotacionam a partir de sua direção original para outro eixo de fácil magnetização mais próximo da direção do campo. Por fim, quando o campo aplicado é intenso, ocorre a rotação coerente. Os momentos magnéticos abandonam as direções de fácil magnetização e se alinham paralelamente à direção do campo. Estas etapas do processo de magnetização estão descritas na Figura 10. 


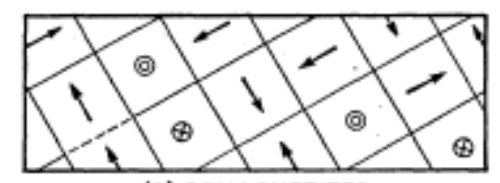

(a) DEMAGNETIZED

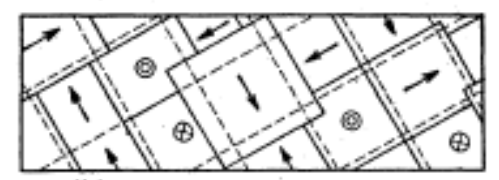

(b) PARTIAL MAGNETIZATION

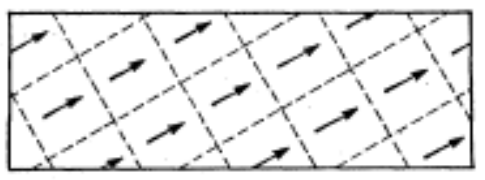

(c) SUDDEN REVERSALS COMPLETE

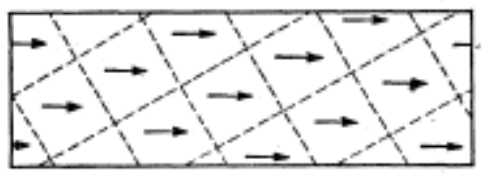

(d) SATURATED, DOMAINS ROTATED

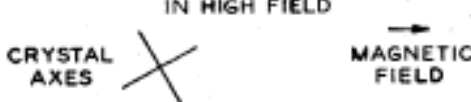

Figura 10: Esquema ilustrando a modificação da estrutura de domínios ao longo do processo de magnetização [18].

Embora exista uma variedade de técnicas disponível para a observação de domínios magnéticos, são poucos os dados encontrados referentes aos elétricos de grão não orientado. Defoug e Kaczmarek [15] afirmam em um de seus trabalhos que a análise de domínios em chapas de ferro silício não orientado virtualmente não existe. Baudouin [19] também constata uma carência de dados a esse respeito, porém cita que a situação é oposta quando se trata de materiais de grão orientado. Contudo, pesquisadores do Kyushu Institute of Technology apresentam resultados obtidos a partir observação de domínios magnéticos utilizando efeito Kerr em amostras GNO [20] e [21]. 


\subsection{Ferramentas de caracterização magnética}

\subsubsection{O ciclo de histerese}

O nome histerese é aplicado à tendência apresentada por materiais magnéticos para persistir em seu estado magnético. É em razão dessa propriedade que existem os imãs. Tal característica é observada expondo-se uma amostra a um campo magnetizante cuja intensidade inicialmente aumente gradualmente para posteriormente ser reduzida da mesma maneira. Nota-se que, tomando-se um valor arbitrário para o campo dentro do seu intervalo de variação, a indução magnética resultante apresenta valores diferentes para campo crescente e decrescente. Dessa forma, a indução magnética parece não acompanhar a variação do campo aplicado sendo "deixada para trás". Esse fenômeno recebe o nome de histerese magnética [22].

Todo material ferromagnético exibe histerese na indução magnética mediante a aplicação de um campo magnético que varia ciclicamente. Este ciclo consiste em um gráfico onde é mostrada a indução, ou polarização magnética $(\mathrm{J})$, em função de um campo $(\mathrm{H})$ para uma amostra submetida a um campo cuja intensidade e sentido de aplicação variam de maneira cíclica. A Figura 11 mostra um ciclo de histerese e seus principais pontos. 


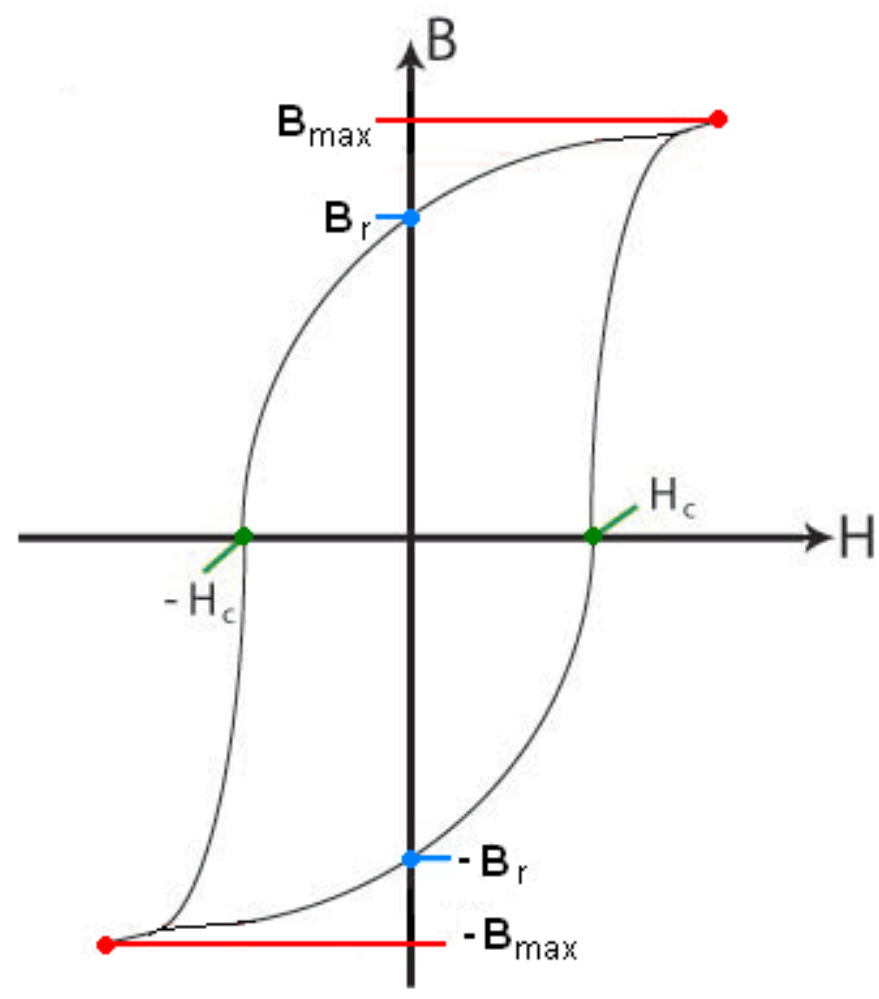

Figura 11: Ciclo de histerese magnética e seus principais pontos. Adaptado de [16]

Partindo-se de um material magnetizado, quando o campo é reduzido a zero a indução remanescente é chamada de indução remanente que aparece na Figura 11 indicada por $B_{r}$ e $-B_{r}$. Este ponto está ligado a propriedades do material tais como, densidade de sítios de ancoramento e anisotropia. Pode-se assumir que a indução remanente é maior na direção onde a energia de anisotropia tem seu menor valor [17]. Dessa forma, este parâmetro serve como um indicador indireto de textura.

O campo coercivo $\left(H_{c}\right.$ e $\left.-H_{c}\right)$ é o campo reverso necessário reduzir a indução magnética de um material à zero. Portanto, pode-se dizer que campo coercivo é o campo necessário para desmagnetizar o material. A indução máxima $B_{\max }$ é o valor de indução alcançado quando o campo aplicado tem intensidade arbitrária $H_{\max }$. Outra importante informação é descrita pela área 
interna do ciclo de histerese que corresponde à energia dissipada ao longo de um ciclo de magnetização.

Por ser sensível a características microestruturais (tais como tamanho de grão [23], presença de precipitados [24] e deformação [25]), o ciclo de histerese é uma ferramenta comum para a extração de dados sobre as propriedades magnéticas de um material. Com o objetivo de ampliar as possibilidades de utilização do ciclo de histerese para a avaliação de propriedades magnéticas, um grupo de pesquisadores propôs a subdivisão do ciclo de histerese [26]. Essa abordagem leva em conta que, mesmo em regime quase estático, mais de um mecanismo é responsável pela dissipação de energia.

O procedimento de subdivisão da histerese separa o efeito da microestrutura em duas diferentes faixas. Uma dessas faixas refere-se à área próxima ao campo coercivo, onde se acredita que movimentos irreversíveis de paredes de domínios sejam predominantes no processo de magnetização. A segunda faixa compreende as regiões que estão além do "joelho" da curva. A esta região atribui-se maior influencia de rotação irreversível, nucleação e aniquilação de domínios.

A subdivisão, segundo o procedimento proposto, é executada graficamente. A fronteira a determinar a mudança da predominância de mecanismo é determinada pela indução de máxima permeabilidade $\left(B_{\mu \max }\right)$ calculada através do ramo ascendente do ciclo de histerese no primeiro quadrante. Tendo em vista a simetria do ciclo com relação aos eixos do plano cartesiano, a subdivisão da histerese pode ser ilustrada pela Figura 12. 


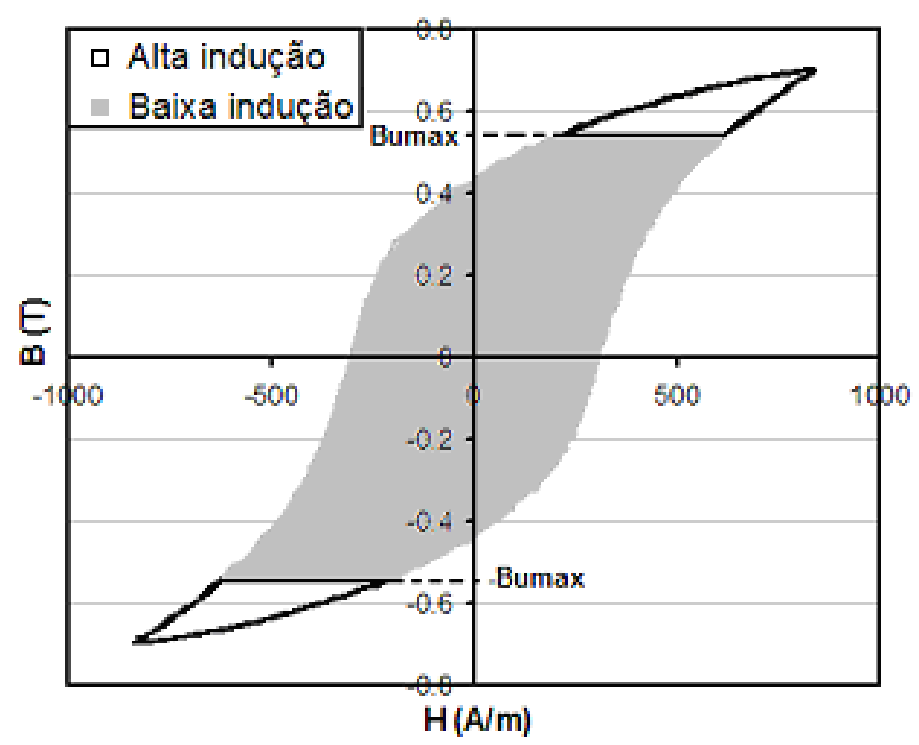

Figura 12: Subdivisão do ciclo de histerese em regiões de alta e baixa indução.

\subsubsection{O ruído de Barkhausen}

Uma análise menos criteriosa sobre uma curva de magnetização ou ciclo de histerese nos conduz à conclusão de que o processo de magnetização mediante a aplicação de um campo crescente se dá de maneira contínua. No entanto, a migração das paredes de domínios pode ser impedida pela presença de sítios de ancoramento. Esses sítios podem ser contornos de grão, discordâncias ou precipitados de uma segunda fase com propriedades magnéticas diferentes do material da matriz. A Figura 13 mostra uma parede de domínio presa a um precipitado em uma amostra de aço elétrico não orientado submetido a campo externo. Ao se livrar de um sítio de ancoramento, a parede se move de maneira abrupta, descontínua. 


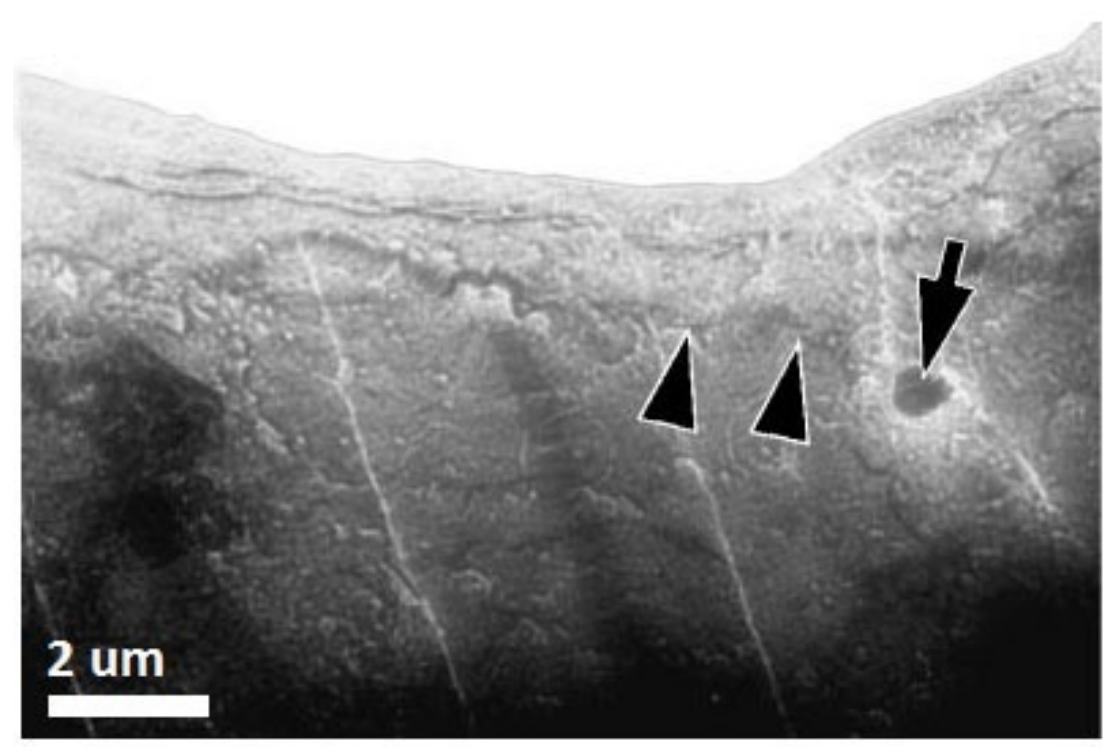

Figura 13: Imagem obtida por microscópio Lorentz onde a seta indica a presença de um precipitado atuando como empecilho à movimentação de uma parede de domínio em uma amostra de aço elétrico não orientado [27].

O ruído de Barkhausen, descoberto em 1919, é um efeito que ocorre quando um material ferromagnético é submetido a um campo magnético externo. Ele é detectado como uma série temporal de impulsos de tensão, numa bobina sensora. Em seu experimento, $\mathrm{H}$. Barkhausen conectou um altofalante à bobina sensora tal qual a representação da Figura 14. Os ruídos de Barkhausen foram detectados na forma de sons. O efeito Barkhausen consiste de mudanças descontínuas na indução magnética, conhecidas como saltos de Barkhausen. Estes são causados por movimento súbito de paredes de domínios quando elas se desprendem de seus sítios de ancoramento em razão de mudança no campo magnético externamente aplicado. Outra fonte de ruídos pode ser atribuída à nucleação de domínios. 

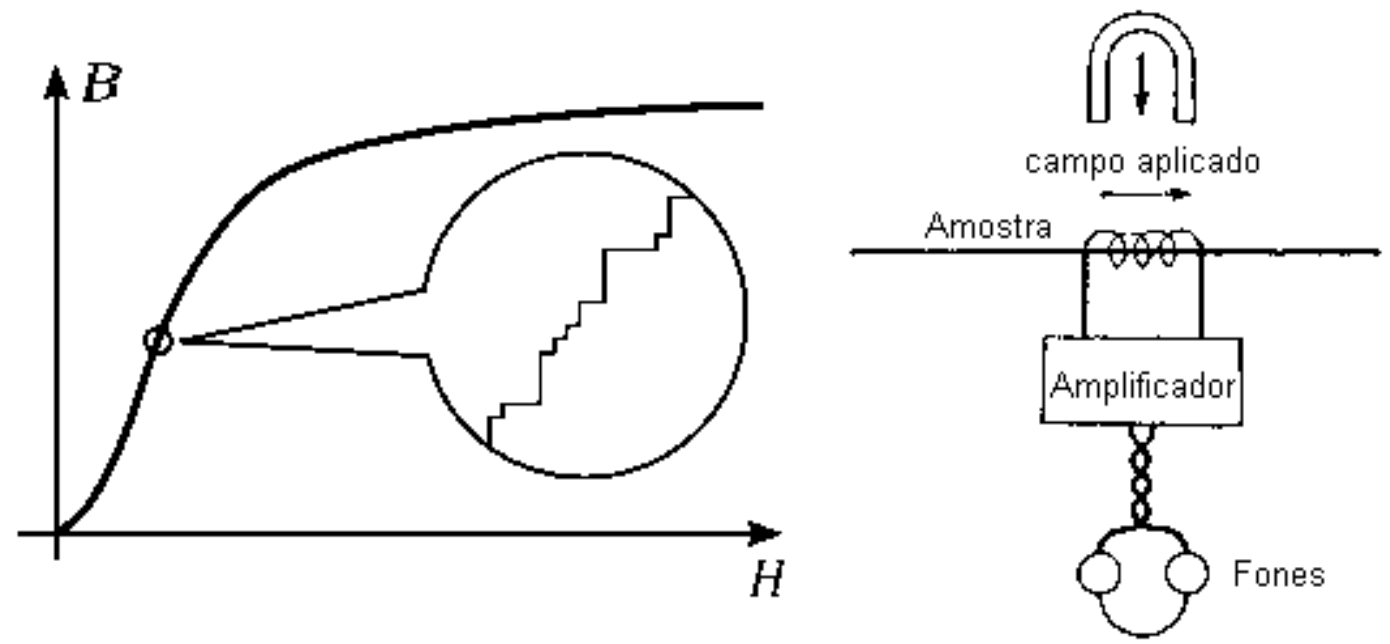

Figura 14: Curva de indução e o ruído Barkhausen detectado por uma bobina sensora.

No caso dos aços elétricos, o estudo de ruído Barkhausen é útil como uma ferramenta na investigação do mecanismo de perda ao longo da curva de histerese. É nos dias de hoje um dos mais populares métodos de caracterização para investigar indiretamente propriedades intrínsecas de materiais magnéticos tais como tamanho de grão, deformação e propriedades mecânicas. O espectro de Barkhausen consiste em um gráfico onde o número de eventos de Barkhausen é relacionado ao campo aplicado à amostra (ou à indução magnética). A intensidade dos eventos de Barkhausen é quantificada indiretamente através da tensão sobre a bobina sensora. A altura do pico é dependente da densidade e da natureza dos sítios de ancoramento no interior do material. A maior parte das atividades de Barkhausen ocorre perto do campo coercivo. Podem ocorrer dois picos, também a localização desses picos pode se deslocar como um resultado de mudanças na distribuição dos defeitos. 


\subsection{A lei da histerese de Steinmetz}

A relação entre a energia dissipada por histerese e a indução máxima foi primeiramente descrita por Steinmetz ainda em 1892. Esse equacionamento estabelece uma lei de dependência entre essas duas grandezas tal qual é descrito na Equação 3, onde $W_{h}$ é a energia dissipada por histerese, $c$ é um valor constante e $B_{\max }$ é a indução máxima.

$$
W_{h}=c \times B_{\max }^{1,6} \text { Equação } 3
$$

Por sua simplicidade e confiabilidade essa equação é utilizada pelos fabricantes de motores ainda nos dias de hoje para se efetuar estimativas acerca da perda histerética. No entanto, para valores de indução máxima superiores a 1,2 T o expoente da indução máxima não se mantém.

Buscando verificar o efeito da indução máxima em chapas submetidas à aplicação de campo magnético em três diferentes direções $\left(0,50\right.$ e $\left.90^{\circ}\right)$ em relação à direção de laminação, Landgraf [28] pode observar que há uma pequena anisotropia no coeficiente exponencial, mas é insuficiente para questionar a validade da lei para o intervalo de induções entre 0,3 e 1,2T. 


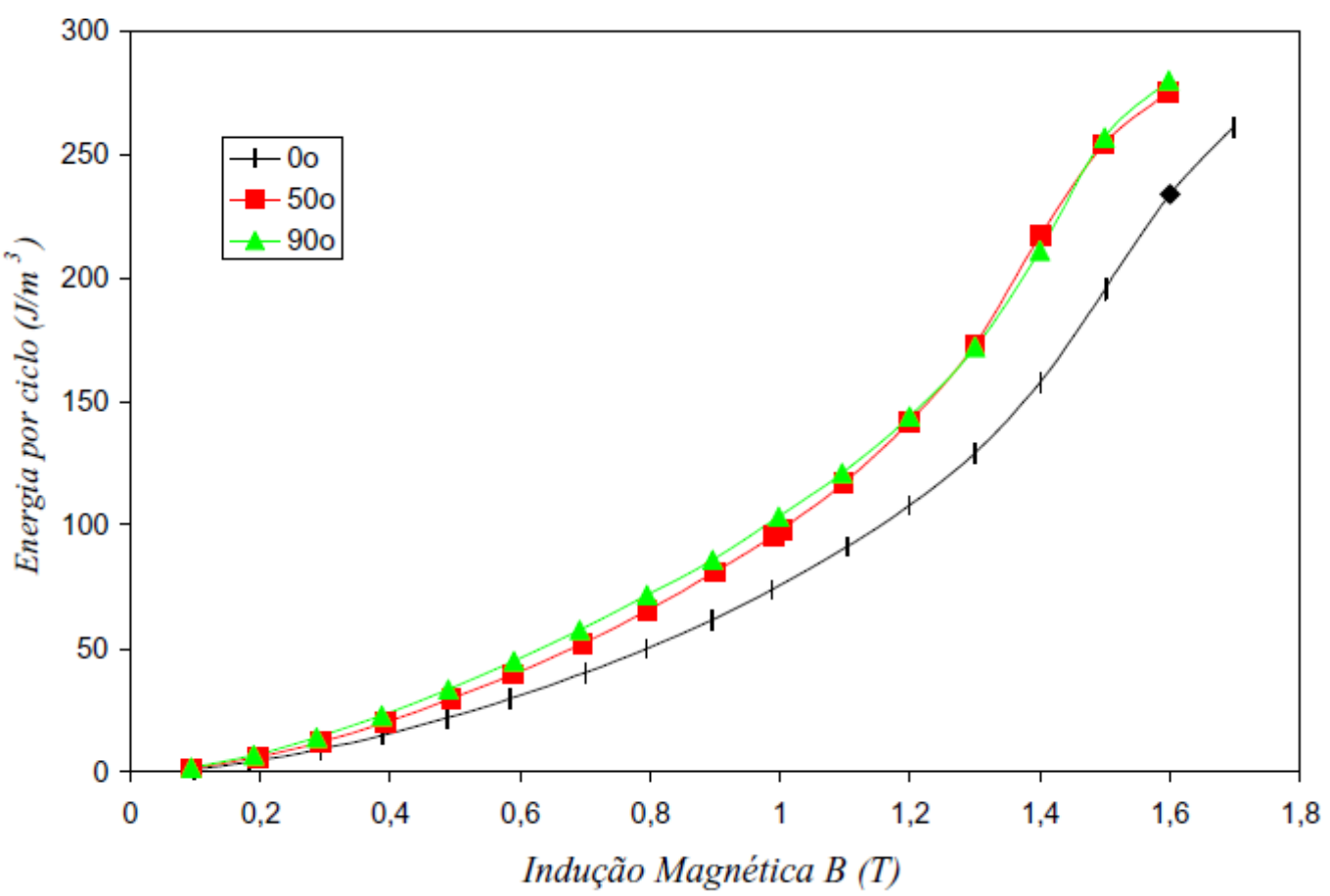

Figura 15: Energia dissipada por histerese em função da indução máxima para a aplicação do campo magnético em três orientações distintas [29].

A literatura acerca da lei de Steinmetz carece de dados sobre o comportamento da energia dissipada por histerese para induções superiores a 1,7 T. Uma possível causa para esse problema pode ser atribuída aos equipamentos frequentemente usados para a caracterização magnética de aços elétricos. A impossibilidade de fornecimento de elevados campos traz consigo a limitação do valor de indução máxima alcançada. Tal limitação impede uma maior precisão na previsão do comportamento de motores elétricos quando submetidos à indução máxima que exceda o valor usual de $1,5 \mathrm{~T}$.

Com o objetivo de fornecer campo elevado o bastante para que valores de indução superiores a 2,0 T fossem alcançados, um artigo [30] propõe o uso de um magnetômetro de amostra vibrante (MAV). Esse equipamento executa a caracterização magnética através da medição do momento magnético de uma 
amostra quando esta é vibrada perpendicularmente a um campo magnético uniforme [31].

A Figura 16 descreve a energia dissipada por histerese em função da indução máxima. Nesse experimento foi usada uma amostra de aço elétrico GNO, 0,8 \% Si, laminada a frio. Esta curva foi dividida em setores de acordo com a indução. Os dados com $\mathrm{B}_{\max }$ superiores a 1,7 $\mathrm{T}$ foram obtidos com uso do magnetômetro. Os valores inferiores foram obtidos por quadro de Epstein.

Nota-se que, para o intervalo de $B_{\max }$ entre 0,4 e 1,6 T, a relação apresenta exponencial de 1,57, próximo ao previsto pela equação de Steinmetz. No entanto, conforme indica a Figura 16, há intervalos onde o comportamento desvia do estabelecido pela Equação 3. Para $B_{\max }$ variando entre 1,2 e 1,6 T há uma notável queda no valor do expoente, indo para 1,18. Contudo, esse valor parece se recuperar indo para 1,51 quando a indução máxima supera 1,7 T.

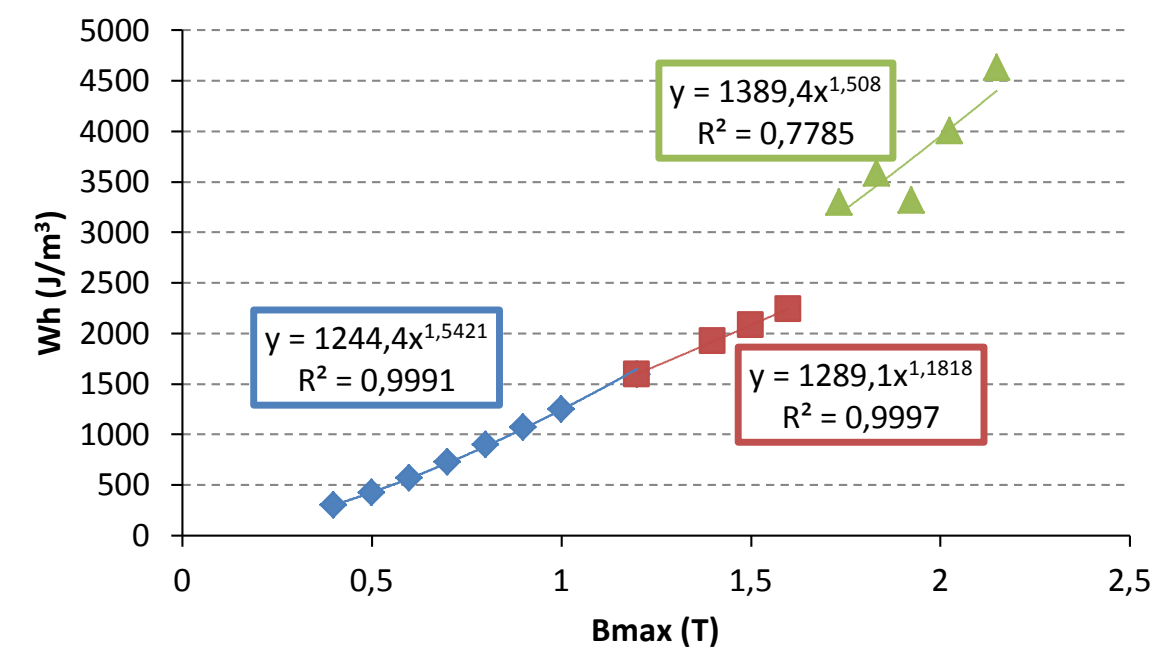

Figura 16: Energia dissipada por histerese em função da indução máxima apresentando os diferentes intervalos de variação de $B_{\max }$ e suas leis de potência [30]. 
No entanto, as medidas com uso de MAV ainda requerem maior refino do procedimento experimental a ser seguido. As medidas apresentadas na Figura 16 foram todas tomadas em regime quase estático $(f=0,5 \mathrm{mHz}$ ). Em razão da elevada magnitude do campo fornecido, este apresentou uma elevada taxa de variação do campo ao longo do tempo. Consequência desse fenômeno pode ser observada pelo incremento no valor do campo coercivo para induções superiores a 1,7 T (Figura 17).

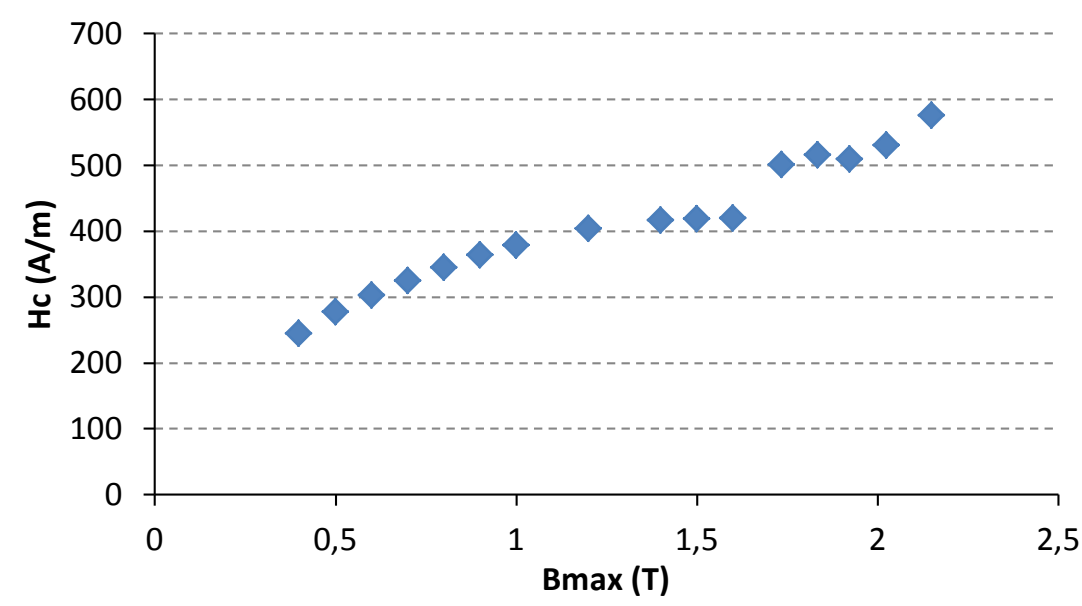

Figura 17: Evolução do campo coercivo em função do aumento da indução máxima [30]. 


\section{Objetivos}

Foram apresentados até aqui alguns dados sobre o uso de aços elétricos para a confecção de motores e importância econômica e ambiental. Também foram mostrados alguns conceitos sobre a estrutura de domínios e o processo de magnetização. Essas informações serviram para a introdução acerca da relação entre microestrutura e propriedades desses materiais.

O presente trabalho analisa a correlação entre microestrutura de deformação e as propriedades magnéticas desses aços. Deseja-se observar a degradação das propriedades magnéticas frente às diferentes quantidades de deformação bem como usar as mudanças do comportamento magnético para inferir sobre as transformações microestruturais provenientes da deformação e sua ação sobre a configuração da estrutura de domínios magnéticos das chapas laminadas. 


\section{Revisão bibliográfica}

\section{1 estado deformado}

O termo estado deformado será usado aqui para descrever a microestrutura de um metal policristalino, CCC ou CFC com alta energia de empilhamento, submetido a processo de deformação plástica executada por laminação a frio. Esse conjunto de características que compõem o estado deformado é resultado das transformações macro e microscópicas ocorridas durante o processo de acomodação da deformação.

Dentre essas transformações algumas merecem maior destaque. A primeira delas é a mudança do formato dos grãos juntamente com aumento da área de contornos. Outra característica é o surgimento de estruturas de defeitos no interior dos grãos. Essas duas alterações estão relacionadas com a geração de discordâncias em decorrência da deformação. Por fim, os grãos de um agregado policristalino podem sofrer rotação em sua orientação espacial em razão da direção da tensão aplicada.

\subsubsection{Arranjos de discordâncias: subdivisão dos grãos}

A deformação plástica de materiais policristalinos exige processos de acomodação para que seja observada a continuidade da deformação através dos contornos de grão. Sendo assim, os processos de deformação são marcados pela heterogeneidade. Tal característica foi observada por Barret [32]. Segundo o autor, os grãos durante o processo de deformação se dividem 
em regiões dentro da quais a orientação cristalina é constante, porém significativamente diferente da orientação nas regiões vizinhas.

A origem dessas estruturas está na necessidade de ativação de diferentes sistemas de deslizamentos. Esses diferentes sistemas operam em um grão durante a deformação. Kestenbach [33] descreve alguns modelos teóricos que explicam as alterações microestruturais provocadas pela deformação. Fenômeno decorrente das heterogeneidades de deformação, a fragmentação de grãos consiste na subdivisão de um grão em regiões onde um número reduzido de sistemas (diferentes) opera. Isso causa diferença de rotação para cada região e formação de paredes de discordâncias entre elas. As diferentes linhas de deslizamentos são representadas esquematicamente na Figura 18.

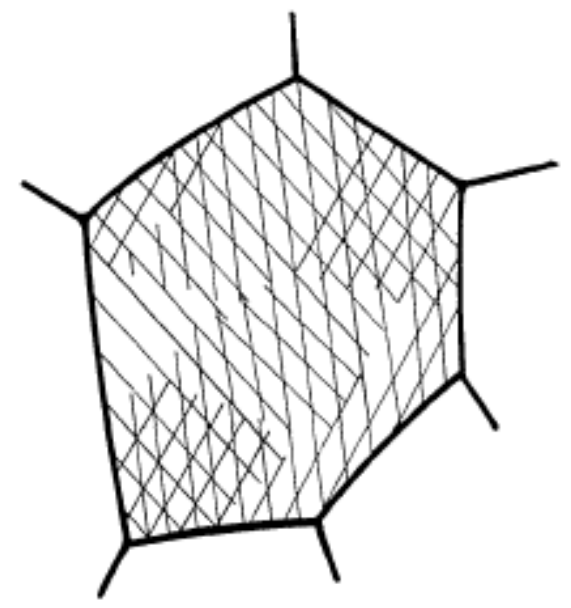

Figura 18: Representação esquemática das diferentes linhas deslizamento no interior de um grão, apresentada por Niels Hansen [34].

Durante a deformação uma pequena fração da energia mecânica é armazenada no metal. Essa energia é armazenada na forma de defeitos sendo o principal deles as discordâncias [34]. A diferença essencial entre o estado 
deformado e o estado recozido recai sobre a densidade e o arranjo das discordâncias. Estas discordâncias não são aleatoriamente distribuídas, elas se acumulam em paredes separando regiões com densidade de discordâncias

relativamente baixas e submetidas a diferentes rotações. Este fenômeno ocasiona a divisão dos grãos em estruturas menores. As estruturas formadas por esses arranjos de discordâncias serão aqui apresentadas conforme uma escala, visando relatar o contínuo processo de subdivisão dos grãos no decorrer da deformação [35].

\subsubsection{A menor escala de subdivisão: células de discordâncias}

A menor característica microestrutural que surge durante a deformação plástica é o acúmulo de discordâncias em arranjos celulares tridimensionais. Os volumes micrométricos que são formados no interior das células têm densidade de discordâncias muito menor que os contornos que os rodeiam. Isto possibilita sua observação em microscópio eletrônico de transmissão. Os contornos de células não têm direcionalidade, isto indica que são constituídos de discordâncias que foram incidentalmente armadilhadas nesta configuração como resultado de suas interações. Por esta razão estes contornos são chamados de contornos incidentais.

A misorientação (ângulo entre as diferentes orientações) entre células adjacentes varia entre aproximadamente 0,3 a $15^{\circ}$ e o diâmetro da célula é por volta de $1 \mu \mathrm{m}$. O tamanho das células parece diminuir com a deformação enquanto a misorientação tende a aumentar. No entanto, para este tipo de 
subdivisão os efeitos sobre a evolução da textura podem ser desprezados uma vez que a misorientação permanece baixa [35].

\subsubsection{Subdivisão por microbandas e blocos de células}

Quando a espessura sofre redução entre 10 e 15 \% [35], um segundo tipo de subdivisão ocorre em uma escala maior do que o tamanho das células de discordâncias. Regiões do grão rotacionam dando origem a estruturas celulares denominadas blocos de célula (cell blocks). Estes blocos são consequência da heterogeneidade de sistemas de deslizamento no interior do grão. Cada bloco de células é constituído por células de mesmo sistema de deslizamento.

Densas paredes de discordância e microbandas separam volumes com diferentes sistemas de deslizamento operando, entre os quais a misorientação se desenvolve. Essas estruturas são formadas pelo acúmulo de discordâncias de mesmo sinal que devem compensar as diferentes rotações de blocos vizinhos e que por essa razão recebem o nome de contornos geometricamente necessários (Geometrically Necessary Boundaries - GNBs) [35].

As estruturas formadas durante a fragmentação do grão são ilustradas na Figura 19. As mesmas estruturas podem ser observadas na Figura 20. 


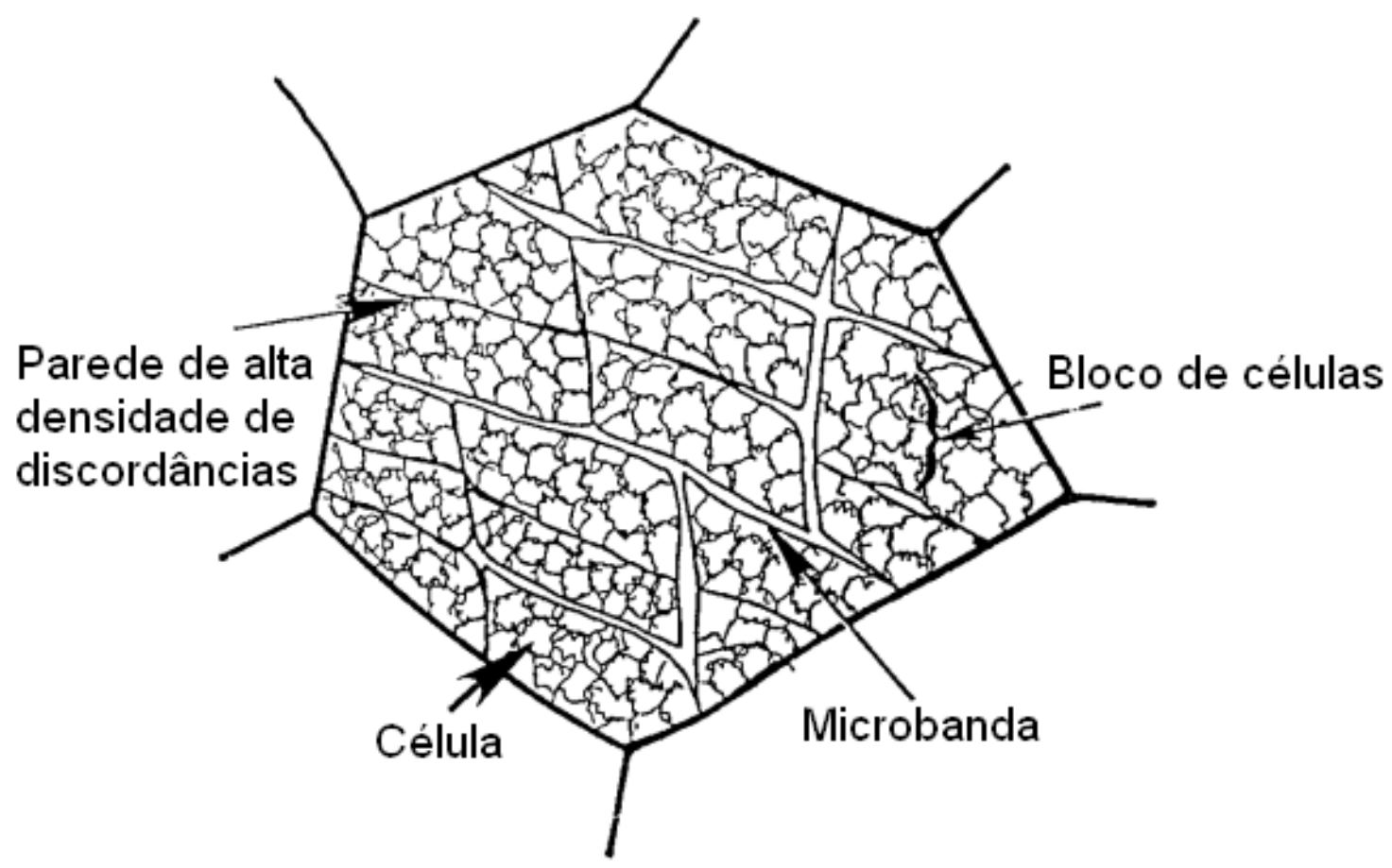

Figura 19: Ilustração das estruturas formadas durante o processo de fragmentação dos grãos em razão da deformação plástica. Estão destacadas as microbandas, paredes de alta densidade de discordâncias, blocos de células e células [36].

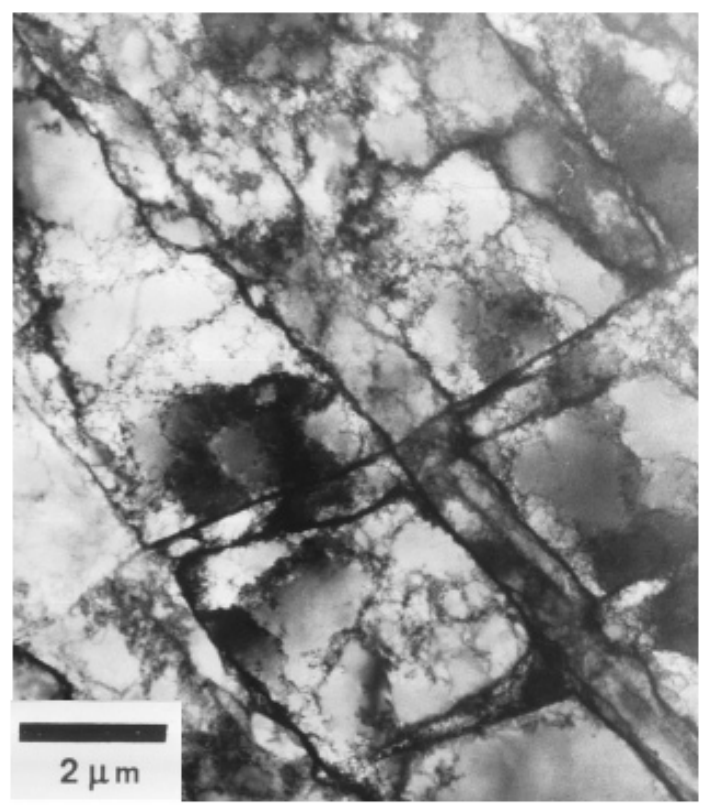

Figura 20: Estrutura deformada observada por microscopia eletrônica de transmissão em amostra de níquel com deformação $\varepsilon=3.5$, produzida por torção [36]. 


\subsubsection{Microestruturas de grandes deformações}

Em deformações elevadas, observa-se a presença de uma subestrutura lamelar. Essas lamelas são chamadas de bandas de deformação e são regiões do grão que têm orientações distintas como resultado da deformação plástica. São separadas por bandas de transição que tem espessura finita através das quais a orientação muda gradualmente [35].

Assim como os blocos de células, as bandas de deformação exercem grande influência sobre a textura. Elas dão origem a alta misorientação dentro dos grãos e sua extensão é dependente da orientação do grão original.

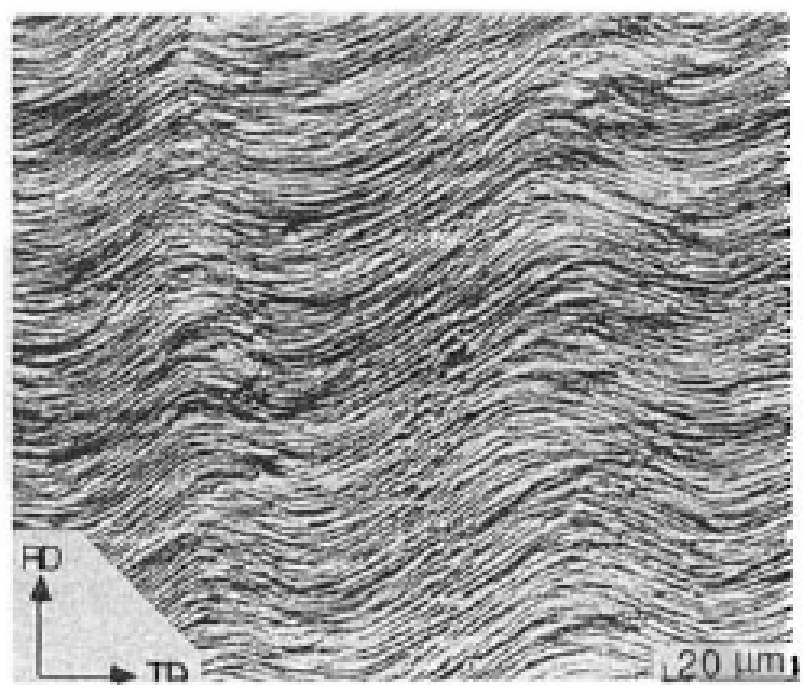

Figura 21: Micrografia de uma amostra de cobre com grãos grosseiros subdivididos em bandas de deformação [37].

\subsubsection{A difícil nomenclatura das estruturas de deformação}

Embora um bom conhecimento sobre o processo de fragmentação dos grãos e sobre heterogeneidade da deformação já esteja disponível, ainda não há consenso sobre a nomenclatura das estruturas de deformação. Hansen [34] 
identifica estruturas como microbandas, blocos de células e DDWs (nomenclatura também adotada neste trabalho). No entanto é possível encontrar diferentes nomes com mostra a Tabela 1 que lista alguns nomes dados às estruturas presentes na Figura 22.

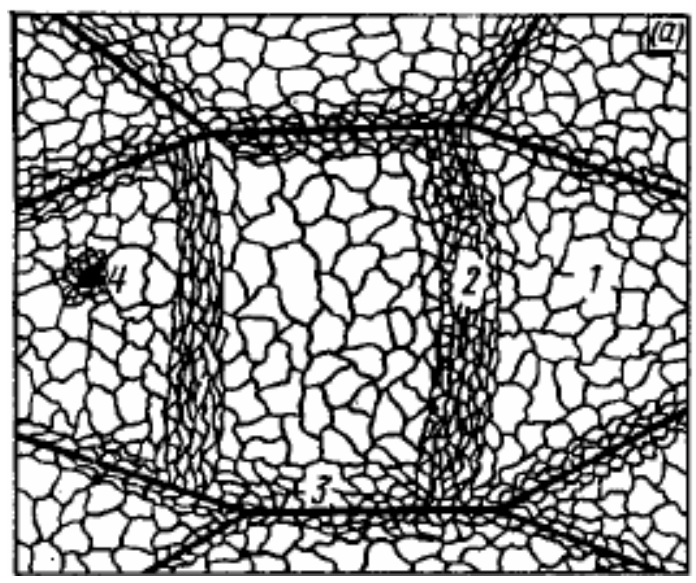

Figura 22: Subestruturas formadas durante deformação plástica de aço [3]. (1 - banda de deformação, 2 - microbandas, 3 - regiões de contorno de grão, 4 - regiões de inclusão).

Tabela 1: Diferentes nomenclaturas para as estruturas 1 e 2 apresentadas na Figura 22 [3].

\begin{tabular}{l|c|c}
\hline \multicolumn{1}{c|}{ Autores } & Região 1 & Região 2 \\
\hline \hline Gorelik & Banda de deformação & Microbanda \\
\hline $\begin{array}{l}\text { Walter e Koch } \\
\text { Hutlamore, Morris, Smith, }\end{array}$ & Banda de deformação & Banda de transição \\
\hline Doherty & Banda matriz & Banda de transição \\
\hline Hu & Banda matriz & Microbanda \\
\hline Hansen e Bay & Bloco de células & $\begin{array}{c}\text { Microbandas de primeira e } \\
\text { segunda geração }\end{array}$ \\
\hline Barnett e Jonas & & $\begin{array}{c}\text { Banda de cisalhamento } \\
\text { intragranulares }\end{array}$ \\
\hline \hline
\end{tabular}




\subsection{O efeito do trabalho a frio sobre as propriedades mecânicas}

As transformações microestruturais provocadas pela deformação a frio trazem consigo alterações nas propriedades mecânicas. O endurecimento por deformação plástica é um conhecido procedimento para a elevação do limite de escoamento de uma amostra metálica. Esse fenômeno, onde um metal dúctil se torna mais duro e resistente quando é deformado plasticamente, recebe o nome de encruamento. Uma demonstração da ação da deformação sobre as propriedades mecânicas pode ser vista a partir da Figura 23 [38] onde 0 encruamento é caracterizado por uma elevação do limite de escoamento do material laminado a frio.

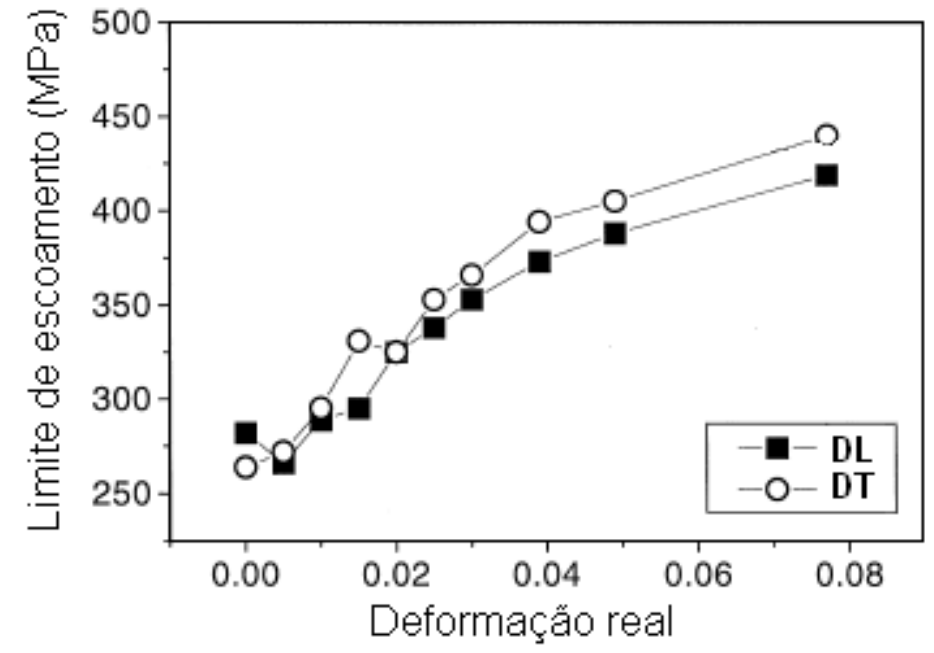

Figura 23: Efeito da deformação plástica, fornecida por laminação a frio, sobre o limite de escoamento de um aço elétrico GNO com 2 \% de silício. Adaptado de [38].

Pode-se explicar o encruamento com base nas interações entre campos de tensões ocasionados pela presença de discordâncias. A densidade de discordâncias aumenta com a execução de trabalho a frio. Esse fato ocorre por 
meio da formação ou multiplicação desses defeitos em decorrência da ativação de fontes de discordâncias. A variação da densidade de discordâncias em função da deformação real pode ser observada através do gráfico da Figura 24 publicada por Keh e Weismann [39] para amostras de aço de diferentes tamanhos de grão. Isso implica em redução da distância média entre discordâncias favorecendo as interações que, geralmente, tem caráter repulsivo. Esse impedimento ao movimento de discordâncias torna o material menos susceptível à deformação plástica.

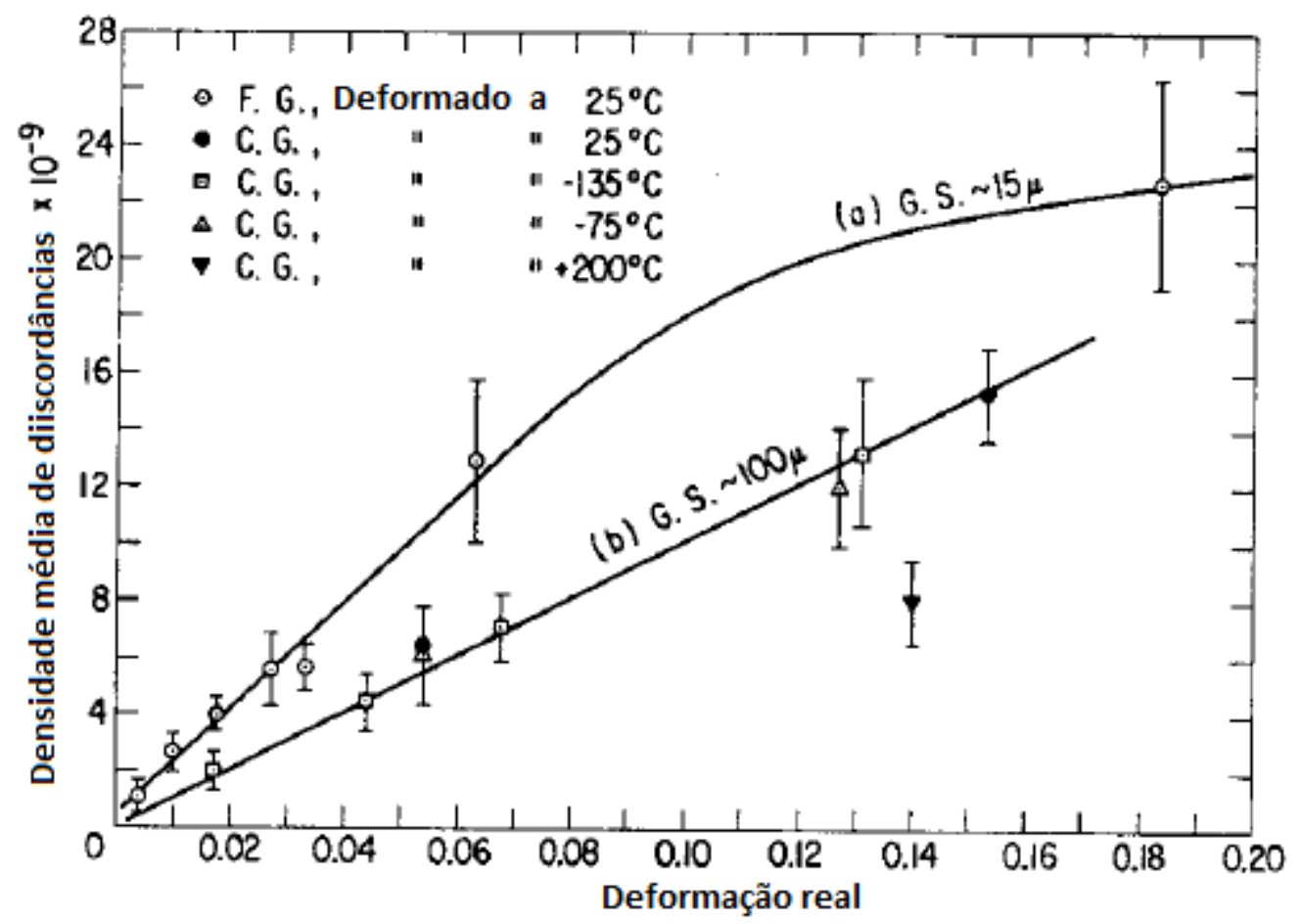

Figura 24: Gráfico relatando o aumento da densidade de discordâncias com o aumento da deformação real para amostras de ferro com diferentes tamanhos de grão [39].

Não há consenso na literatura sobre uma lei de crescimento para quantificar a densidade de discordâncias com relação à deformação plástica. A própria Figura 24 indica que fatores microestruturais (neste caso, o tamanho de grão) podem influenciar o modo de crescimento. A partir de dados 
experimentais (Figura 25), Tomota e colaboradores [40] apresentam uma lei de potência para descrever a variação da densidade de discordâncias com relação à quantidade de deformação. Essa lei está representada na Equação 4, onde A e B são constantes e $\rho_{0}$ é $2 \times 10^{13} \mathrm{~m}^{-2}$. No entanto este artigo cita o trabalho de Johnson e Gilman [41] que assume uma relação linear. Vale ressaltar que tal relação é resultado de uma análise apenas qualitativa sem que dados experimentais nesse sentido fossem tomados.

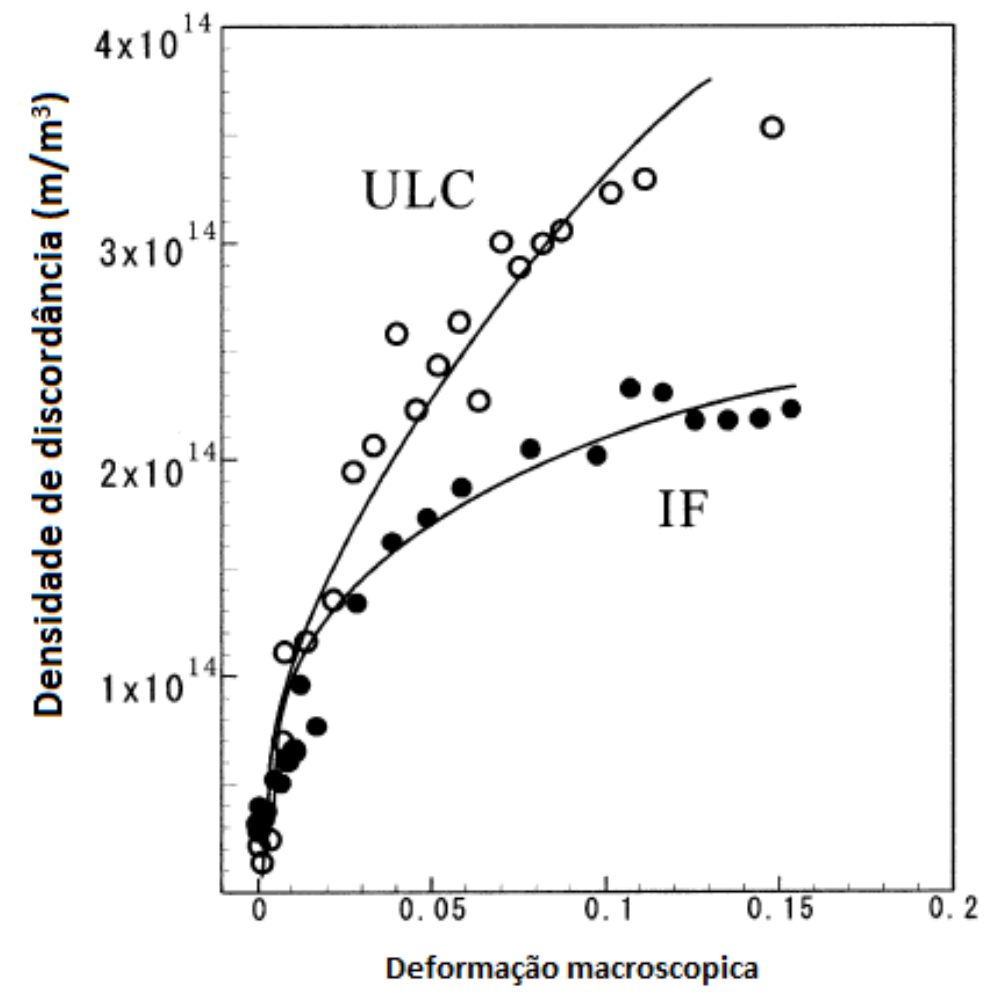

Figura 25: Gráfico relatando o aumento da densidade de discordância com a deformação para amostras de aço livre de intersticial (IF) e de carbono ultra baixo (ULC) publicado por [40].

$$
\rho=\rho_{0}+A \times \varepsilon^{B} \quad \text { Equação } 4
$$

Uma estimativa da densidade de discordância em material deformado a frio por laminação foi obtida por Campos [42]. Nesse artigo, amostras de aço foram submetidas a ensaio de difração de raios $X$. Sendo a espessura a meia 
altura dos picos de difração relacionada a tensões residuais oriundas da deformação, esse dado pode ser utilizado para um cálculo estimado da densidade de discordância das chapas laminadas. O mesmo procedimento foi utilizado no presente trabalho e será descrito em maiores detalhes mais adiante.

\subsection{Deformação plástica e propriedades magnéticas: a concepção de Kronmüller}

Publicado em 1972, o artigo de Kronmüller [43] onde são revisados os fundamentos da interação entre densidade de discordâncias e domínios magnéticos permanece até os dias de hoje como importante referência. Neste artigo foram discutidos alguns conceitos sobre técnicas de caracterização magnéticas para o estudo de discordâncias em materiais ferromagnéticos. Em sua introdução é abordada pelo autor a necessidade de se ter uma técnica que nos permita obter simultaneamente informações sobre os arranjos de discordâncias e as tensões internas que as discordâncias produzem. De acordo com o texto, técnicas magnéticas para o estudo de discordâncias desenvolvidas na década que antecedeu a publicação podem atender essa necessidade. Kronmüller comenta ainda que estudos anteriores mostraram que propriedades como, curva de magnetização, campo coercivo e susceptibilidade inicial podem ser usadas para a determinação da densidade de discordâncias em função da deformação plástica. Essas técnicas, entretanto, não foram adotadas. 
Ao longo do texto é feita a ressalva de que o uso de técnicas magnéticas para esse tipo de caracterização é adequado apenas aos estudos de metais e ligas ferromagnéticas. No entanto essa aparente desvantagem é compensada pelo número de propriedades que podem ser usadas para a determinação da relação entre tensão e densidade de discordâncias.

\subsubsection{Parâmetros característicos da estrutura de discordâncias}

As propriedades microscópicas da densidade de discordâncias são determinadas principalmente por flutuações não estatísticas da densidade de discordâncias, segundo o artigo [43]. Tais flutuações se devem a formação de grupos no plano primário de deslizamento ou formação de paredes ou dipolos com o objetivo de reduzir a energia armazenada. Essas flutuações são, por um lado, regra predominante no sistema primário de deslizamento. Por outro lado, elas são geradas pela interação de longo alcance entre campos de tensão das discordâncias. Há forte interação entre discordâncias de sinais opostos.

Na rede cristalina, prevalece a tendência de que qualquer discordância ou grupo de discordância de sinal positivo seja rodeado por grupos de discordância de sinal negativo. Essa tendência de "blindagem" pode ser realizada por diferentes arranjos de discordâncias. A Figura 26 a seguir relata alguns exemplos de arranjos de discordâncias. Em razão da tendência de autoblindagem a tensão interna oscila ao longo de distâncias da ordem de um arranjo de discordâncias. Parâmetros característicos microscópicos das discordâncias são, portanto: amplitude e comprimento de onda das tensões 
internas. $\mathrm{O}$ autor cita que em um estudo com amostras de Ni notou-se que o arranjo por camadas predominou.

a)

Dipolos de discordâncias

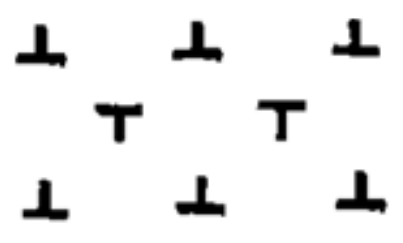

c)

Grupos de discordâncias

(correlacionadas)

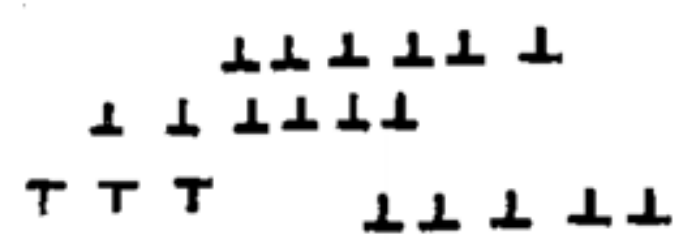

b)

Parede de discordâncias

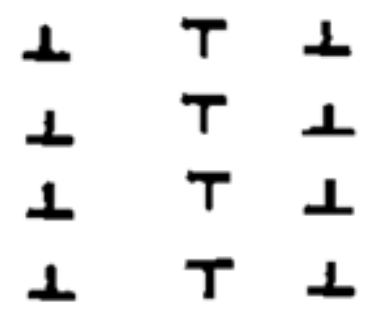

d)

Grupos de discordâncias (em camadas)

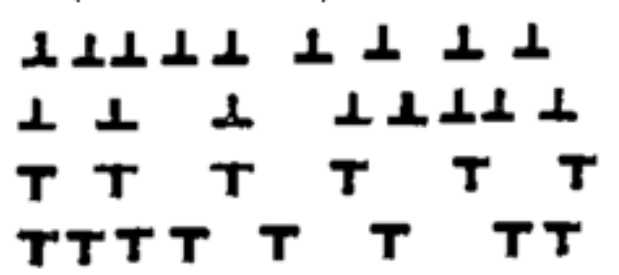

Figura 26: Exemplos de arranjos de discordâncias mostrados no trabalho de Kronmüller [43].

\subsubsection{Interações fundamentais entre discordância e magnetização}

A principal interação entre tensão interna e magnetização espontânea deve ser atribuída a efeitos magnetoestrictivos. Em correspondência a esse efeito, a direção de magnetização espontânea é notoriamente influenciada por campos de tensão elástica. Assim, podemos ter em mente que a magnetização espontânea se alinha na direção em que as tensões internas estão relaxadas por uma apropriada magnetoestricção. Por consequência, na região vizinha a uma discordância, onde há tensões de tração e compressão, a orientação da magnetização espontânea se torna heterogênea (Figura 27). 


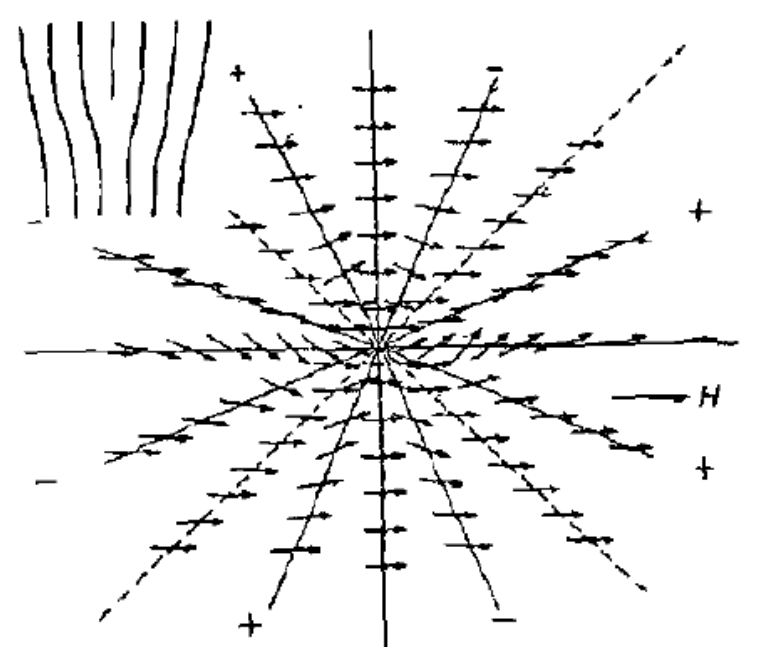

Figura 27: Arranjo da magnetização espontânea no campo de tensão de uma discordância em cunha [43].

O efeito da tensão interna sobre a magnetização espontânea resulta na chamada energia de acoplamento magnetoelástico. São abordados no artigo dois tipos de situação para a interação entre a discordância e a magnetização espontânea: interação com as paredes de Block e interação próxima da saturação.

O autor descreve que a presença de uma discordância cuja linha seja paralela à parede de domínio dará origem a uma força paralela à direção normal ao plano da parede. Para que uma parede de domínio possa se mover e ultrapassar uma discordância a parede deve superar um valor máximo de interação. Sobre esse ponto o autor afirma ainda que a intensidade dessa força de interação depende do tipo de discordância e do tipo de parede de Block.

\subsubsection{Determinação da relação entre densidade de discordâncias e tensão aplicada}

Partindo da relação entre volume médio dos domínios em materiais ferrmomagnéticos (ferro e níquel são usados como exemplo) e a densidade de 
discordâncias nesses materiais o autor afirma que a movimentação de paredes de domínio enfrentará a interação com grande número de discordâncias tratando-se, portanto, de um fenômeno estatístico. Dessa forma, tomando-se por $z$ a posição da parede de domínio e $z_{n}$ a posição da enésima discordância a soma das forças de interação $(V)$ podem ser descritas pela Equação 5.

$$
V(z)=\sum_{i} v\left(z-z_{i}\right) \quad \text { Equação } 5
$$

O campo de força estatístico foi caracterizado pelos parâmetros indicados na Figura 28.

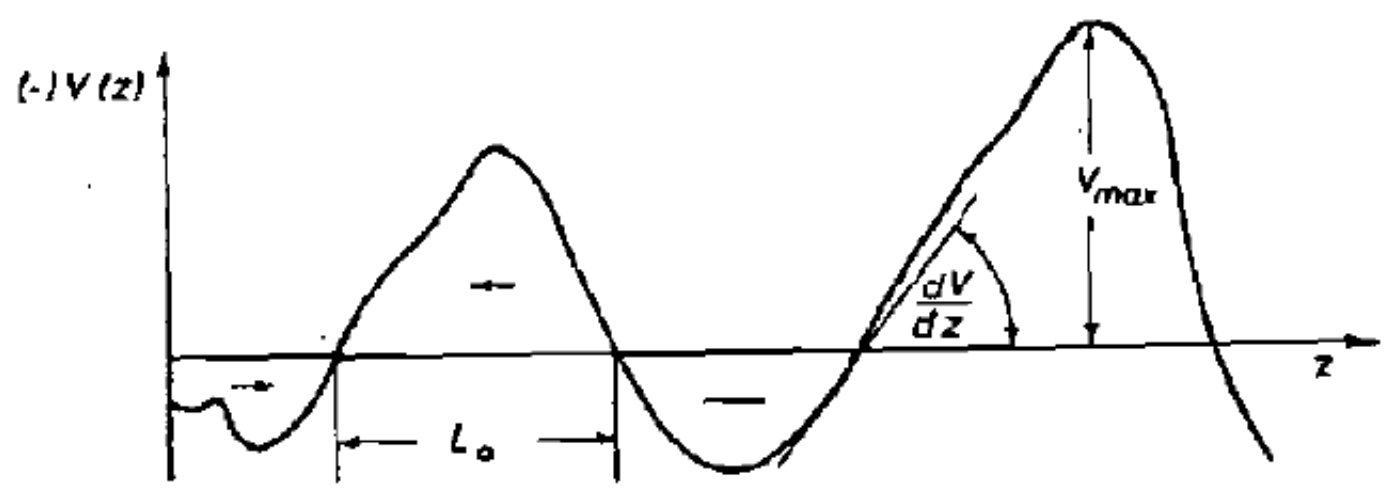

Figura 28: Definição dos parâmetros característicos de um campo de forças atuando sobre uma parede de domínio [43].

A partir dessa concepção, tomando-se valores de campo onde a magnetização ocorre por movimentação de paredes de domínios, o autor apresenta relações entre a densidade de discordâncias $(\mathrm{N})$ e o campo coercivo $\left(H_{c}\right)$.

$$
X_{0} \propto \frac{1}{\sqrt{N}} \text { Equação } 6
$$




$$
\begin{array}{rr}
H_{C} \propto \sqrt{N} & \text { Equação 7 } \\
\alpha \propto \frac{1}{N} & \text { Equação 8 }
\end{array}
$$

\subsubsection{A questão da ação da deformação plástica sobre a dissipação de energia}

Pelos dados já citados compreende-se a necessidade de desenvolvimento de motores elétricos de alta eficiência. Compreender as relações entre microestrutura e as propriedades magnéticas é uma necessidade que tem motivado as pesquisas e impulsionado o aumento do valor agregado dos aços elétricos.

A despeito da melhora da qualidade dos aços elétricos vários aspectos do seu comportamento continuam incompreendidos. Um deles é o efeito da deformação plástica nas propriedades magnéticas. O efeito da deformação plástica pode ser quantificado pela observação das perdas magnéticas que sofrem aumento, ainda que para pequenas deformações, deixando claro o efeito de degradação das propriedades magnéticas do material [44].

O problema da deformação apresenta-se de maneira inerente ao processo de produção dos dispositivos elétricos. O corte das chapas laminadas, executado por meio de puncionamento, introduz defeitos microestruturais na região próxima à borda oriundos da deformação local (conforme indica a Figura 29). O empilhamento das peças para a construção dos rotores e estatores também provoca pequena deformação [45]. 


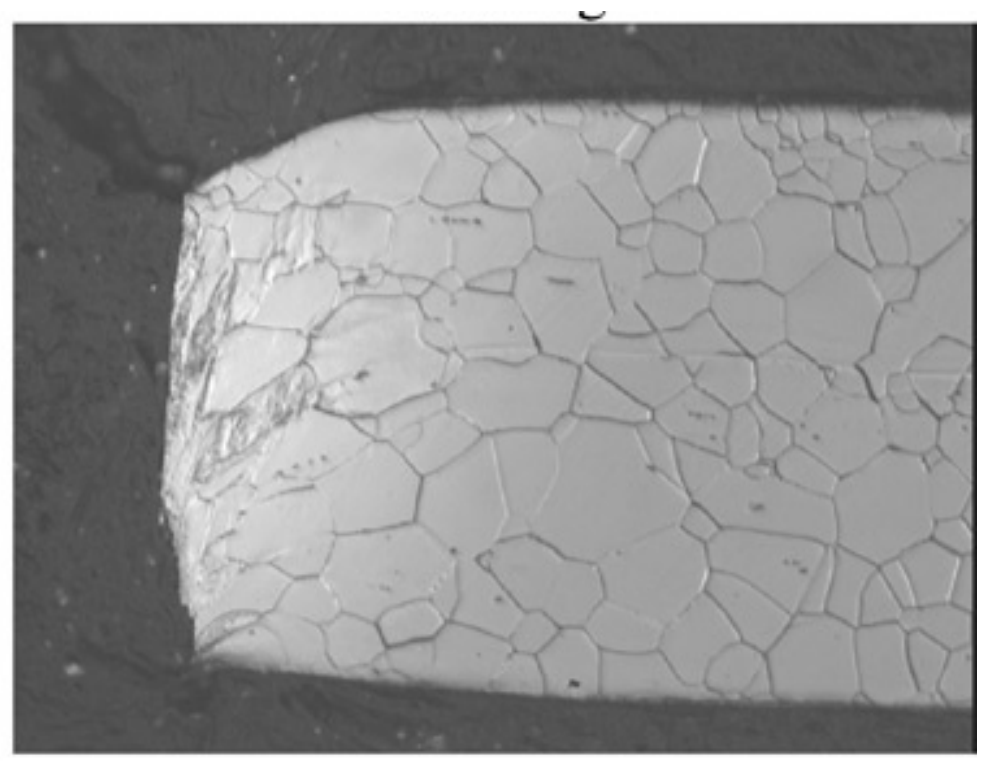

Figura 29: Perfil da extremidade de corte por puncionamento de uma amostra de aço elétrico 2 \% Si completamente processado [46].

É sabido que as transformações microestruturais decorrentes do processo de deformação a frio não se distribuem de maneira homogênea ao longo de todo o material. Em aços elétricos de grão não orientado, as discordâncias geradas pela deformação tendem a se agrupar dando origem a estruturas complexas, caracterizadas por heterogeneidades de deformação. No entanto, é possível verificar na literatura um tratamento simplificado, onde as relações entre a deformação a frio e as propriedades magnéticas são explicadas partindo-se de uma estrutura onde as discordâncias geradas na deformação são distribuídas homogeneamente [43] desprezando-se os seus complexos arranjos frequentemente observados em material deformado. 


\subsubsection{Combinação entre propriedades magnéticas e mecânicas em aços elétricos}

Embora as propriedades magnéticas sejam as características de maior importância nos aços elétricos, as propriedades mecânicas desses produtos laminados merecem destaque. $\mathrm{O}$ termo magneticamente mole, usado para designar uma das principais características dos materiais ferromagnéticos, coincidentemente nos diz um pouco sobre as propriedades mecânicas dos aços elétricos de grão não orientado. O caráter dúctil desses aços os torna suscetíveis a deformação plástica ao longo do processo de construção e uso dos dispositivos elétricos.

Outra característica afetada pelas propriedades mecânicas é a puncionabilidade. A superfície lateral da lâmina cortada por puncionamento é composta de quatro regiões conforme mostra Figura 30: raio de puncionamento, área de corte, área de fratura e rebarba. Chapas com elevada razão elástica (razão entre limite de escoamento e de resistência) apresentam menor formação de rebarbas após a operação de corte. Estas rebarbas dificultam o empilhamento das peças e também podem cortar o isolamento elétrico entre as chapas deteriorando as propriedades magnéticas dos dispositivos elétricos.

A vida útil da ferramenta de corte também é fator importante. $O$ esforço executado pela ferramenta de corte é crescente conforme ela avança sobre o material até que ocorre um súbito alívio provocado pela fratura. Assim, aços mais dúcteis ocasionam maior desgaste às ferramentas de corte por puncionamento. 


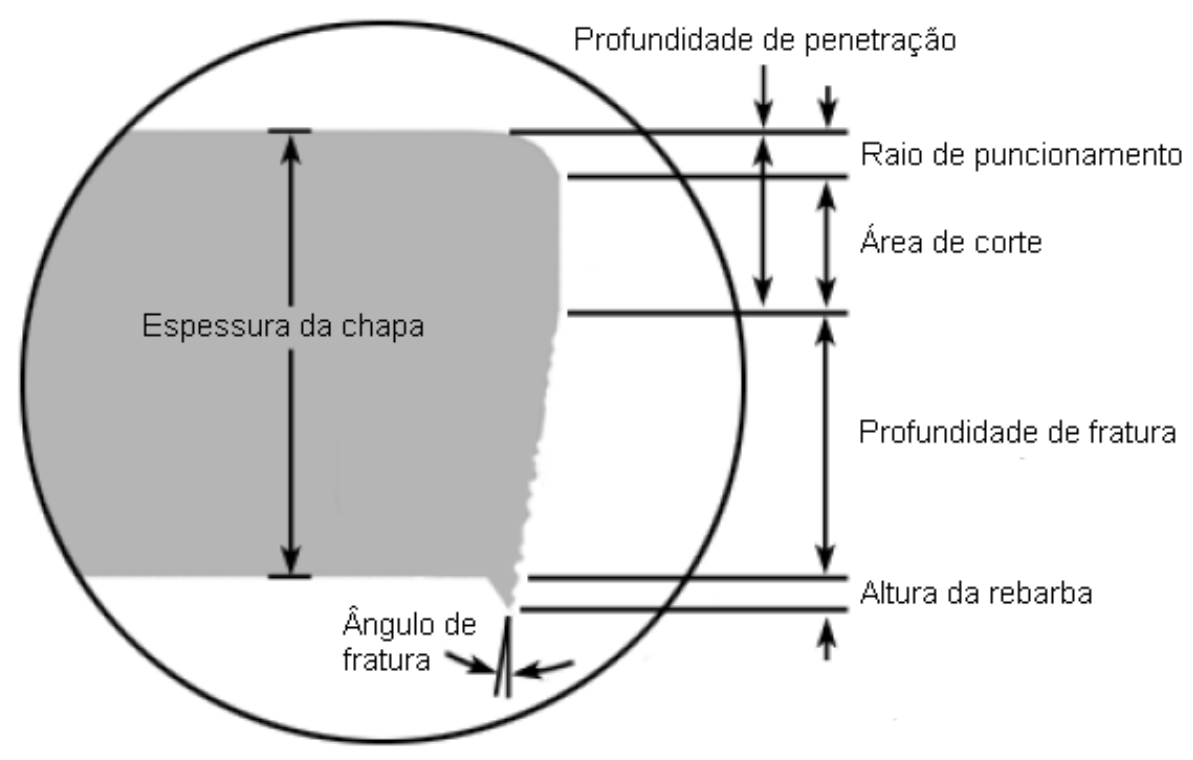

Figura 30: Ilustração mostrando as regiões que compõem a superfície lateral de uma lâmina cortada por puncionamento. Adaptado de [47].

Procedimentos que promovam o aumento do limite de escoamento, tal como laminação de encruamento, garantem melhor estampabilidade. Contudo, sacrificam-se as propriedades magnéticas tornando-se o resultado indesejável, sobretudo para chapas que não passarão por tratamento térmico posterior [48].

\subsubsection{O tratamento térmico de recuperação das propriedades magnéticas}

A tentativa de se alcançar melhora das propriedades mecânicas com prejuízo mínimo ou nulo das propriedades magnéticas deve ter reflexo sobre o processo de produção de aços para fins elétricos. Patente expedida em 2006 [49] propõe a introdução de um tratamento térmico de recuperação das propriedades magnéticas. Nesta sessão são apresentados alguns dados presentes nessa patente que mostram como essa etapa complementar do processo de produção pode melhorar as propriedades magnéticas de chapas de aço que por suas propriedades mecânicas já possuem boa estampabilidade. 
Essa nova etapa consiste em um recozimento conduzido em temperaturas entre 300 e $700{ }^{\circ} \mathrm{C}$ por períodos entre 15 minutos a 50 horas. Esse tratamento térmico não visa promover crescimento de grãos ou recristalização do material e é aplicado aços 1006 e aços de grão não orientado semi-processado. Dessa forma, o tratamento térmico de recuperação das propriedades magnéticas deve promover o aumento da permeabilidade e a redução das perdas magnéticas desses aços sem causar amolecimento.

A carta patente apresenta alguns dados acerca de algumas famílias de aços presentes no mercado nacional. Estes dados são parcialmente reproduzidos na Tabela 2. Por vezes, esses aços são utilizados na condição como fornecido para a construção de pequenos motores elétricos, tipicamente usados em eletrodomésticos. Dessa forma, buscando-se obter redução de custos, trabalha-se com material de baixa qualidade e desempenho magnético pobre.

Tabela 2: Propriedades típicas de aços disponíveis no mercado brasileiro para chapas em estado como fornecido e espessura 0,6 $\mathrm{mm}$ [49].

\begin{tabular}{|c|c|c|c|c|c|c|}
\hline Aço & $\sigma_{\mathrm{e}}(\mathrm{MPa})$ & $\sigma_{\mathrm{r}}(\mathrm{MPa})$ & $\begin{array}{l}\text { Razão } \\
\text { elástica }\end{array}$ & Dureza (HV) & $\begin{array}{c}\text { Perdas 1,0T } \\
60 \mathrm{~Hz}\end{array}$ & $\begin{array}{c}\text { Permeabilidade } \\
1,0 \mathrm{~T} 60 \mathrm{~Hz}\end{array}$ \\
\hline 1006 & 190 & 310 & 0,61 & 100 & 8,5 & 1270 \\
\hline $\begin{array}{l}1006 \text { semi- } \\
\text { processado }\end{array}$ & 300 & 350 & 0,86 & 120 & 10 & 960 \\
\hline $\begin{array}{l}\text { Aço } 2 \% \mathrm{Si} \\
\text { totalmente } \\
\text { processado }\end{array}$ & 314 & 450 & 0,7 & 147 & 2,4 & 7000 \\
\hline
\end{tabular}

Prática utilizada na indústria para a obtenção de melhores propriedades magnéticas é o recozimento acima de $750{ }^{\circ} \mathrm{C}$ por mais de uma hora. Por meio 
da Tabela 3 nota-se melhora das propriedades magnéticas (com redução da perda e aumento da permeabilidade) em detrimento das propriedades mecânicas (redução da razão elástica, sobretudo para o aço 1006 semiprocessado).

Tabela 3: Propriedades típicas dos aços disponíveis no mercado brasileiro após recozimento executado pelos fabricantes de máquinas e com espessura 0,6 mm [49].

\begin{tabular}{|c|c|c|c|c|c|c|}
\hline Aço & $\sigma_{\mathrm{e}}(\mathrm{MPa})$ & $\sigma_{r}(\mathrm{MPa})$ & $\begin{array}{l}\text { Razão } \\
\text { elástica }\end{array}$ & Dureza & $\begin{array}{c}\text { Perdas 1,0T } \\
60 \mathrm{~Hz} \\
\end{array}$ & $\begin{array}{l}\text { Permeabilida } \\
\text { de } 1,0 \text { T } 60 \mathrm{~Hz}\end{array}$ \\
\hline 1006 & 150 & 260 & 0,58 & 70 & 5,6 & 2900 \\
\hline $\begin{array}{l}1006 \text { semi- } \\
\text { processado }\end{array}$ & 110 & 260 & 0,43 & 60 & 4,7 & 3300 \\
\hline
\end{tabular}

Os dados da Tabela 4 informam as propriedades de duas famílias de aço após tratamento térmico de recuperação magnética. Uma comparação com os dados da Tabela 2 mostra que as propriedades mecânicas sofreram poucas alterações em razão do recozimento. Observa-se também melhora do desempenho magnético com redução das perdas e a permeabilidade dos materiais praticamente dobrou.

Tabela 4: Propriedades típicas de aços disponíveis no mercado brasileiro após o tratamento térmico de recuperação das propriedades magnéticas proposto na carta patente [49].

\begin{tabular}{|c|c|c|c|c|c|c|}
\hline Aço & $\sigma_{\mathrm{e}}(\mathrm{MPa})$ & $\sigma_{r}(\mathrm{MPa})$ & $\begin{array}{l}\text { Razão } \\
\text { elástica }\end{array}$ & Dureza & $\begin{array}{c}\text { Perdas 1,0T } \\
60 \mathrm{~Hz}\end{array}$ & $\begin{array}{l}\text { Permeabilida } \\
\text { de } 1,0 \text { T } 60 \mathrm{~Hz}\end{array}$ \\
\hline 1006 & 210 & 0,68 & 0,68 & 90 & 7 & 2150 \\
\hline $\begin{array}{l}1006 \text { semi- } \\
\text { processado }\end{array}$ & 320 & 0,89 & 0,89 & 115 & 7,8 & 2220 \\
\hline
\end{tabular}

A ação do tratamento térmico de recuperação sobre a microestrutura de amostras submetidas à deformação a frio e seus reflexos sobre as 
propriedades mecânicas e magnéticas dessas amostras será avaliada neste trabalho.

\subsection{O fenômeno de recuperação}

O termo recuperação refere-se ao processo pelo qual grãos com elevada quantidade de defeitos cristalinos podem reduzir sua energia. Esse processo pode ocorrer por rearranjo ou aniquilação desses defeitos e não se dá exclusivamente em materiais deformados. Também não ocorre em um único estágio e sim de acordo com uma série de mecanismos.

Inicialmente, ocorre a eliminação de defeitos pontuais. Discordâncias se movem e se reagrupam podendo sofrer aniquilação através da interação com outra discordância de sinal oposto. O rearranjo de discordâncias ocorre no sentido de se formarem configurações de menor energia. Por fim, ocorre poligonização (formação e crescimento de subgrãos). Essas mudanças estruturais não envolvem migração de contornos de alto ângulo, portanto, durante o estagio de recozimento, a textura do metal deformado essencialmente não muda. Se uma ou todas essas fases irão ocorrer, isso depende de uma série de parâmetros com o tipo de material, sua pureza, deformação, temperatura de deformação e de recozimento.

Tratando-se de metais submetidos à deformação, temos como força motriz para o processo de recuperação a energia armazenada em função da deformação. Dessa maneira, os fenômenos de recuperação e recristalização são concorrentes. A extensão da recuperação deverá ser determinada pela facilidade com a qual ocorre a recristalização. 
Essas mudanças estruturais não envolvem migração de contornos de alto ângulo, portanto, durante o estagio de recozimento, a textura do metal deformado essencialmente não muda. Estas transformações não podem ser observadas opticamente, porém, são prontamente observadas por meio de microscopia de transmissão quando densidade de discordâncias é consideravelmente reduzida e as remanescentes são reorganizadas.

\subsubsection{Migração e aniquilação das discordâncias durante a recuperação}

Durante a recuperação ocorre diminuição de energia através de rearranjo ou aniquilação de discordâncias. Algumas das estruturas formadas por esses rearranjos são aqui apresentadas.

\subsubsection{Poligonização}

Com o recozimento, as discordâncias se reorganizam em configurações de menor energia na forma de arranjos regulares ou contornos de baixo ângulo. O caso mais simples ocorre quando discordâncias de apenas um vetor de Burgers estão envolvidas. Uma forma especialmente simples de recuperação estrutural é observada quando um cristal é flexionado de modo que apenas um sistema de deslizamento opere e posteriormente recozido. $\mathrm{O}$ cristal se divide em um número de subgrãos livres de deformação cada um preservando a orientação original do cristal que foi flexionado. Os subgrãos são separados por planos de subcontornos.

Esse processo simples de reorganização de discordâncias foi observado por Cahn [50] e recebeu desse autor o nome de poligonização. O mecanismo 
da poligonização pode ser descrito pela Figura 31. Este é um contorno de baixo ângulo particularmente simples e são conhecidos como tilt boundaries.

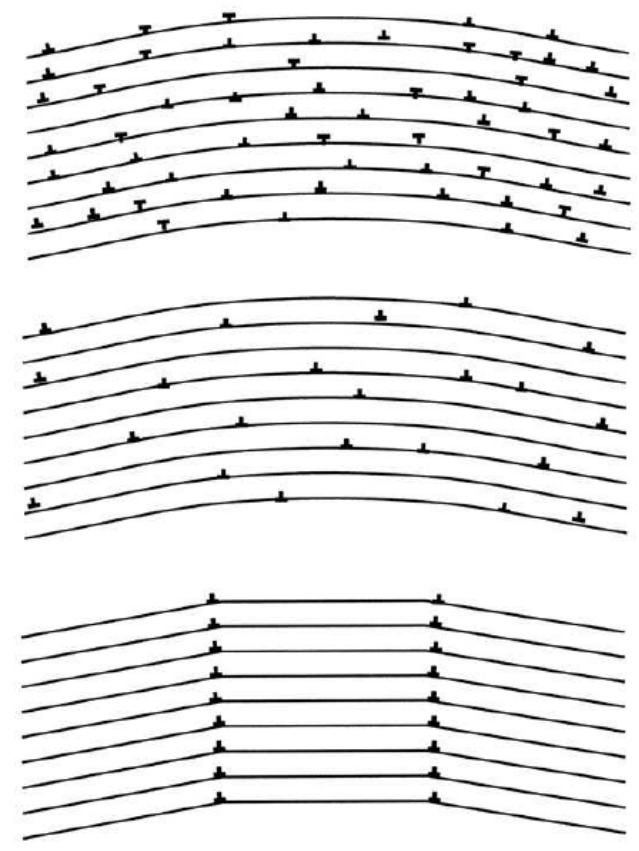

Figura 31: Contornos de baixo ângulo formados por arranjos de discordâncias decorrentes de poligonização [51].

\subsubsection{Formação de subgrãos}

Em materiais policristalinos sujeitos a grandes deformações, a estrutura de discordâncias produzidas pela deformação e subseqüente recozimento é mais complexa. Sendo a temperatura de recozimento insuficiente para a ocorrência de recristalização, a microestrutura do material deformado sofrerá alterações provenientes do rearranjo de discordâncias.

Em ligas de alta energia de defeito de empilhamento as discordâncias estão tipicamente arranjadas (após deformação) formando uma estrutura tridimensional de células. As paredes de células são compostas por emaranhados de discordâncias. Após recozimento, a densidade de 
discordâncias no interior de cada célula é diminuída. O emaranhado das paredes de célula se torna um arranjo mais regular de discordância dando origem a contornos de baixo ângulo. As células passam a ser subgrãos.

\subsubsection{Propriedades afetadas pela recuperação}

Durante a recuperação as mudanças microestruturais são súbitas e ocorrem em pequena escala. A observação através de microscopia óptica freqüentemente falha quando se deseja estudar esse tipo de transformação. Por essa razão, recuperação é usualmente medida indiretamente, seguindo-se a variação de alguma propriedade ligada à microestrutura [51]. Esse tipo de análise foi usado em [52] no estudo de corpos de prova de alumínio. Tomandose a variação do limite de escoamento, foi observado o efeito da temperatura e do tempo de recozimento. Os resultados estão descritos na Figura 32 para amostras com tamanho de grão 4 e $22 \mu \mathrm{m}$ e $2 \%$ de deformação executada por tração.
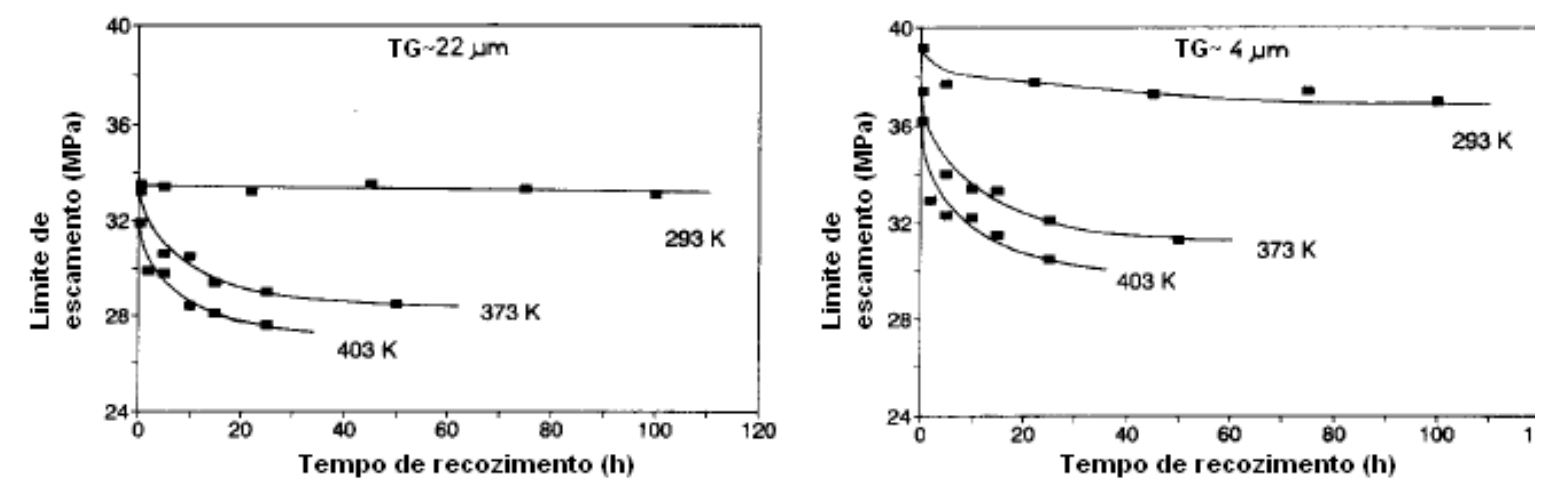

Figura 32: Efeito do tratamento térmico de recuperação sobre o limite de escoamento em amostras de alumínio de diferentes tamanhos de grão [52]. 
Martinez-de-Guerenu et. al relata que não apenas propriedades mecânicas são afetadas por recuperação. Em seu trabalho fica evidente que este tratamento térmico proporciona melhora das propriedades magnéticas através da redução do campo coercivo e aumento da indução remanente. Os autores atribuem esse efeito à aniquilação e rearranjo de discordâncias. O artigo também propõe o monitoramento das propriedades magnéticas para a verificação da recuperação visto que estas são mais sensíveis a pequenas variações microestruturais que as propriedades mecânicas [53].

Trabalho recente produzido na Escola Politécnica da USP também discute este tema [54]. A partir de uma bobina de aço GNO 0,8 \% Si foram extraídos dois conjuntos de amostras, laminados a frio, com deformação real 0,03 e 0,06. O tratamento térmico de recuperação se deu em meio à atmosfera inerte, com tempo variando entre 30 e 90 minutos. A temperatura variou entre 300 e $500^{\circ} \mathrm{C}$.

Os resultados foram analisados frente a uma comparação entre as variações obsevadas para a perda total, medida a $50 \mathrm{~Hz}$ e indução máxima 1,0 T, e o limite de escoamento das amostras (Figura 33). Tal qual foi concluído em [53], as propriedades magnéticas mostraram-se mais sensíveis à ação do recozimento. Segundo os autores, ambas as propriedades são afetadas pela aniquilação de discordâncias. Além disso, propriedades magnéticas sofrem o efeito da diminuição das tensões residuais. Portanto, propriedades magnéticas são mais sensíveis ao recozimento de recuperação que as propriedades mecânicas. 

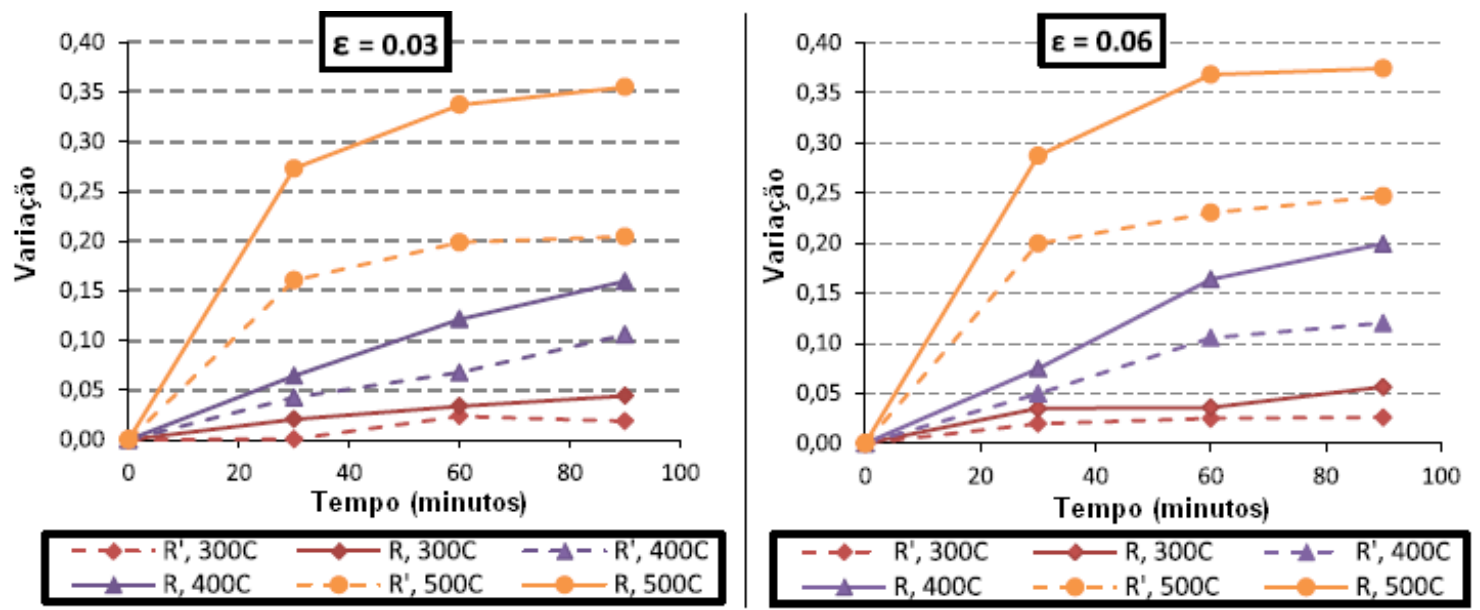

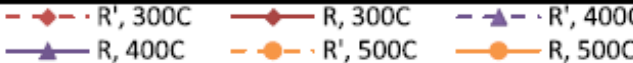

Figura 33: Variação do limite de escoamento (R') e da perda total (R) para amostras com diferentes valores de deformação real ao longo do recozimento de recuperação [54]. 


\section{Materiais e métodos}

O procedimento experimental aqui seguido visa a extração de dados que permitam avaliar o efeito da deformação plástica sobre as propriedades magnéticas em amostras de aço elétrico de grão não orientado. A sequência de procedimentos está dividida nas seguintes etapas: material utilizado, produção das amostras, caracterização microestrutural e caracterização magnética.

\subsection{Material utilizado}

O material de partida escolhido para a execução desse trabalho foi uma bobina de aço elétrico de grão não-orientado completamente processado e sem laminação de encruamento. A composição química desse material é descrita na Tabela 5. A espessura do material como recebido era de 0,681 mm.

Tabela 5: Composição química do material sob estudo.

\begin{tabular}{ccccccccccc}
\hline $\mathbf{C}$ & $\mathbf{M n}$ & $\mathbf{P}$ & $\mathbf{S}$ & $\mathbf{S i}$ & $\mathbf{A l}$ & $\mathbf{C u}$ & $\mathbf{C r}$ & $\mathbf{N i}$ & $\mathbf{M o}$ & $\mathbf{T i}$ \\
\hline 0,001 & 0,524 & 0,0374 & 0,0075 & 0,8185 & 0,2154 & 0,008 & 0,016 & 0,005 & 0,0011 & 0,0025 \\
\hline
\end{tabular}

\subsection{Produção das amostras}

O método escolhido para prover deformação plástica ao material foi a laminação a frio. O procedimento foi conduzido em um laminador dotado de tração avante e à ré na empresa Brasmetal Waelzholz. 
A quantidade de deformação foi avaliada comparando-se a espessura das chapas laminadas com a espessura do material como recebido. A laminação foi executada de modo contínuo, ou seja, todo o material foi passado no laminador de uma só vez e a distância entre os cilindros do laminador foi diminuída a cada 1,5 $\mathrm{m}$ de chapa laminada. Dessa forma, obteve-se ao término da laminação uma grande chapa de material laminado onde o grau de deformação varia a cada 1,5 m material laminado (no sentido do comprimento da chapa) formando degraus.

O corte das amostras foi realizado inicialmente na região do degrau dividindo a chapa laminada em chapas menores de acordo com sua espessura. Visto que essa região pode apresentar gradiente de deformação, todo o material compreendido em uma faixa que se estendia a até $10 \mathrm{~cm}$ de extremidade do degrau foi descartada.

Essas chapas foram levadas a uma guilhotina, onde foram cortadas em lâminas de dimensões adequadas para a etapa de caracterização magnética $(300 \times 30 \mathrm{~mm})$. O corte foi realizado de maneira que o comprimento dessas amostras fosse mantido paralelo à direção de laminação. Para cada grau de deformação (critério segundo o qual essas amostras foram agrupadas) foram produzidas doze lâminas. Dessa forma, foram produzidos nove conjuntos de amostras compostos por doze lâminas cada um. A quantidade de deformação e a espessura após a laminação desses conjuntos estão listadas na Tabela 6, onde "S/lam" corresponde ao material como recebido (sem laminação) e as demais amostras estão identificadas em ordem alfabética de acordo com a quantidade de deformação calculada segundo a Equação 9, onde $e_{f}$ e $e_{i}$ são as espessuras do material após a laminação e como recebido, respectivamente. 


$$
\text { Deformação }=\ln \left(\frac{e_{i}}{e_{f}}\right) \quad \text { Equação } 9
$$

Tabela 6: Espessura final e quantidade de deformação real das amostras laminadas a frio.

\begin{tabular}{l|cccccccc}
\hline \hline Nome & S/Lam & A & B & C & D & E & F & G \\
\hline Espessuras (mm) & 0,681 & 0,663 & 0,635 & 0,617 & 0,601 & 0,561 & 0,536 & 0,510 \\
\hline Deformação real (\%) & 0 & 3 & 7 & 10 & 12 & 19 & 24 & 29 \\
\hline \hline
\end{tabular}

\subsection{Caracterização microestrutural}

A avaliação da microestrutura foi realizada através da avaliação superficial por microscopia óptica, ensaio de difração de raios $X$ e para a amostra G (com 29\% de deformação real) também foi realizada análise por meio de electron backscatter diffraction. Esses procedimentos têm como objetivo proporcionar dados que auxiliem a avaliação do estado de deformação dos corpos de prova.

\subsubsection{Observação microestrutural}

A observação superficial se deu após a preparação metalográfica. Tal preparação consiste no procedimento para a obtenção de uma superfície plana e polida, para a observação em microscópio óptico. De cada conjunto de amostras foi extraída uma lâmina que foi destruída para o corte dos corpos de prova. A superfície analisada foi a secção longitudinal. Para facilitar o manuseio 
das amostras, os corpos de prova foram embutidos individualmente em baquelite. A superfície de cada um dos corpos de prova foi lixada e depois polida. O lixamento foi executado em politriz giratória em presença de água. Foram usadas lixas de carbeto de silício nas granulometrias 220, 400, 600, 1200 MESH, nessa ordem. O polimento se deu com uso de politriz giratória. Foi usada pasta de diamante como material abrasivo nas granulometria 6,3 e 1 $\mu \mathrm{m}$, nessa ordem. Por fim, para o acabamento da superfície polida utlizou-se sílica coloidal como material abrasivo. Álcool etílico foi usado como lubrificante (exceto para a operação de acabamento, onde água destilada foi usada) nessa etapa da preparação.

Para que a microestrutura fosse revelada, a superfície das amostras foi atacada quimicamente com uso do reagente Nital 3\%. Após o ataque foram extraídas fotografias da microestrutura dos corpos de prova através de uma câmera integrada a um microscópio óptico. A captura das imagens foi realizada através do Software Micrometrics.

A fim de se observar mais detalhadamente a formação de estruturas de deformação na amostra submetida a maior quantidade de laminação, a frio executou-se após preparação metalográfica e ataque com Nital a análise da superfície polida por meio de microscopia eletrônica de varredura.

A verificação de desvios de orientação ocorreu por meio de análise por EBSD (electron backscatter diffraction) usando-se a ferramenta Grain Reference Orientation Deviation, Tal ferramenta permite estabelecer para um determinado grão sua orientação média e assim determinar localmente regiões no interior do cristal que apresentem desvios com relação a essa orientação. 


\subsubsection{Ensaio de difração de raios $X$}

Os ensaios de difração de raios-X foram executados em um difratômetro Shimadzu 6000. Assumiu-se que os picos observados seguiam uma distribuição Lorentziana e através de um software foi adotado um procedimento para a eliminação das contribuições vindas de $\mathrm{CuKa}_{2}$.

\subsection{Caracterização magnética}

As propriedades magnéticas são o principal parâmetro de seleção dos aços elétricos. O procedimento de caracterização aqui adotado busca extrair dados sobre essas propriedades para relacioná-los com características microestruturais. Dois equipamentos foram utilizados nessa etapa do trabalho, um quadro de Epstein e um detector de ruídos de Barkhausen.

\subsubsection{Medição da perda histerética}

Esta etapa do procedimento experimental contou com o uso de um quadro de Epstein. A perda histerética foi medida em ensaio quase-estático a $5 \mathrm{mHz}$ para indução máxima variando entre 0,4 e 1,6T. Desses ensaios foram extraídos os ciclos de histerese magnética e a perda histerética (Ph). A partir do ciclo de histerese foram calculados, para cada valor de indução máxima, o campo coercivo e indução remanente.

A energia dissipada na histerese (Wh) foi calculada através do valor da perda histerética medida no ensaio quase estático através da Equação 10, 
onde $f$ corresponde á frequência $(60 \mathrm{~Hz})$ e d é a densidade do material. Essa energia corresponde à área da histerese.

$$
W h=\frac{P h \times d}{f} \quad \text { Equação } 10
$$

\subsubsection{Medição das perdas totais e separação das perdas}

A medição das perdas totais foi tomada em frequências que variaram entre 25 e 175 Hz, para indução máxima de 1,0 T.

Um conhecido procedimento de separação de perdas foi usado para analisar os resultados obtidos no quadro de Epstein. O valor da chamada perda parasita "clássica" foi determinado a partir da Equação 2 e a perda de excesso foi calculada através do método da subtração descrito na Equação 1.

\subsubsection{Ruídos de Barkhausen}

As medidas de ruído Barkhausen foram realizadas com um equipamento experimental desenvolvido na Universidade de Caxias do Sul. Este aparelho consiste em uma bobina primária com 1290 espiras, $350 \mathrm{~mm}$ de comprimento e $50 \mathrm{~mm}$ de diâmetro interno. Associado a este solenóide, encontra-se uma sonda envolvente constituída por um par de bobinas, com 300 espiras cada, em contra-fase, enroladas sobre uma estrutura polimérica.

Para produzir e coletar o ruído de Barkhausen o enrolamento primário é alimentado com corrente senoidal, magnetizando a amostra alternadamente. 
Então, uma das bobinas sensoras, a que está envolvendo a amostra, capta o sinal produzido por esta e a outra bobina o filtra, reduzindo o sinal de excitação e parte dos ruídos indesejados. Em seguida, o sinal é filtrado, amplificado e coletado por uma placa de aquisição de dados DaqBoard/3005. 


\section{Resultados e discussão}

Nesta seção busca-se apresentar os resultados de modo a fundamentar a discussão sobre as relações entre a microestrutura e as propriedades magnéticas.

\section{1 ensaio de raios $X$ para estimativa da densidade de discordâncias}

A Figura 34 mostra o efeito da deformação plástica sobre a largura à meia altura dos picos de difração (aqui designada pela sigla FWHM - Full Width at Half Maximum).

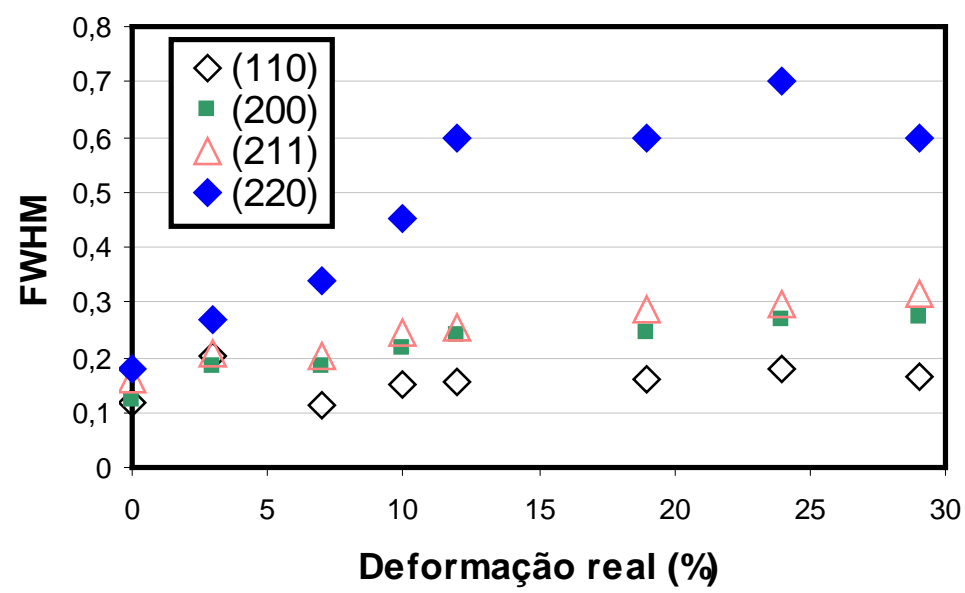

Figura 34: Largura à meia altura dos picos de difração em função da deformação real.

Esses resultados foram usados para estimar a densidade de discordância das amostras usando o modelo descrito por Campos et al, [42] que é baseado na equação de Stibitz [55]. A densidade de discordâncias está associada à macro-tensões residuais (W) que é relacionada ao módulo de Young [56] para 
a direção perpendicular ao plano $h k /$ a partir da Equação 11. Aqui y é a constante de Poisson tomada com 0,28 para ferro isotrópico

$$
W=\frac{3}{2} \times E_{h k l}\left\langle\varepsilon^{2}\right\rangle=\frac{3}{2} E_{h k l} \frac{\left(\frac{\Delta d}{d}\right)^{2}}{1+2 \gamma^{2}} \quad \text { Equação 11 }
$$

Usando-se a largura a meia altura dos picos de difração mostrados na Figura 34 foi calculada a deformação média quadrada $(\Delta d / d)^{2}$ por meio da Equação 12 onde d é a distância interplanar e $\theta$ é o ângulo de Bragg para o pico de difração hkl e B a largura a meia altura do pico de difração.

$$
\left(\frac{\Delta d}{d}\right)^{2}=\frac{B^{2}}{4 \times \tan ^{2} \theta} \quad \text { Equação } 12
$$

A estimativa da densidade de discordância deu-se então pela Equação 13 onde $\rho$ é a densidade de discordâncias, b é o vetor de Burgers, G o módulo de cisalhamento, a uma constante de valor 0,1 e Re também é constante com valor 0,1 $\mu \mathrm{m}[57]$.

$$
\rho=\frac{W}{\alpha \times \ln \left(\frac{R_{e}}{|b|}\right) \times G \times|b|^{2}} \quad \text { Equação } 13
$$

Os resultados da estimativa estão dados na Tabela 7. 
Tabela 7: Espessura final, densidade de discordâncias (estimada por difração de raio-X) e deformação real das amostras laminadas a frio.

\begin{tabular}{l|cccccccc}
\hline \hline $\begin{array}{l}\text { Espessura após } \\
\text { laminação a frio } \\
(\mathbf{m m})\end{array}$ & 0,681 & 0,663 & 0,635 & 0,617 & 0,601 & 0,561 & 0,536 & 0,510 \\
\hline Deformação real & 0 & 0,03 & 0,07 & 0,10 & 0,12 & 0,19 & 0,24 & 0,29 \\
\hline $\begin{array}{l}\text { Densidade de } \\
\text { discordâncias } \\
\left(\mathbf{1} / \mathbf{m}^{\mathbf{2}}\right)\end{array}$ & $6,7 \mathrm{E}+13$ & $1,2 \mathrm{E}+14$ & $2,1 \mathrm{E}+14$ & $2,3 \mathrm{E}+14$ & $3,2 \mathrm{E}+14$ & $3,8 \mathrm{E}+14$ & $3,7 \mathrm{E}+14$ & $4,1 \mathrm{E}+14$ \\
\hline
\end{tabular}

Nota-se que a densidade de discordâncias aumenta com a deformação indicando a geração desses defeitos. No entanto, para pequenas deformações, entre 0 e 0,03 o aumento dessa densidade é mais intenso e a partir de 0,12 o incremento é mínimo. A literatura [42] diz que após aproximadamente 0,10 de deformação ocorre a formação de células de discordâncias. A equação de Stibitz falha ao detectar a formação dessas estruturas. Em outras palavras, essa equação reflete as discordâncias distribuídas aleatoriamente ao longo da rede cristalina cuja densidade pouco aumenta a partir de $10 \%$ de deformação. Os dados também indicam a diferença entre a densidade de discordâncias observada para a mostra com deformação real $0 \%$ e o valor descrito na literatura $\left(10^{12} \mathrm{~m} / \mathrm{m}^{3}\right.$, aproximadamente) para amostra de ferro recozido [39]. Tal fato pode ser atribuído à hipótese da existência de alguma deformação plástica inerente ao processo de corte das amostras [58], ou bobinamento das chapas.

\subsubsection{Estrutura de grãos do material laminado}

Outro aspecto microestrutural a ser observado é o reflexo da deformação sobre a estrutura de grãos. Os resultados obtidos por microscopia óptica para a amostra mais deformada mostram algumas estruturas típicas de deformação 
plástica. É possível observar bandas de deformação em alguns grãos. Essas bandas se manifestam deixando na superfície do grão um aspecto semelhante a ranhuras. O fato de nem todos os grãos apresentarem tal aspecto é um indicativo da natureza heterogênea da deformação. A literatura [59] descreve este tipo de estrutura com sendo típica de aços baixo carbono submetidos a deformação. Uma micrografia obtida por microscopia óptica para amostra com deformação real 0,29 é apresentadas na Figura 35. Uma imagem mais detalhadas produzida através de microscópio eletrônico de varredura é apresentada na Figura 36.

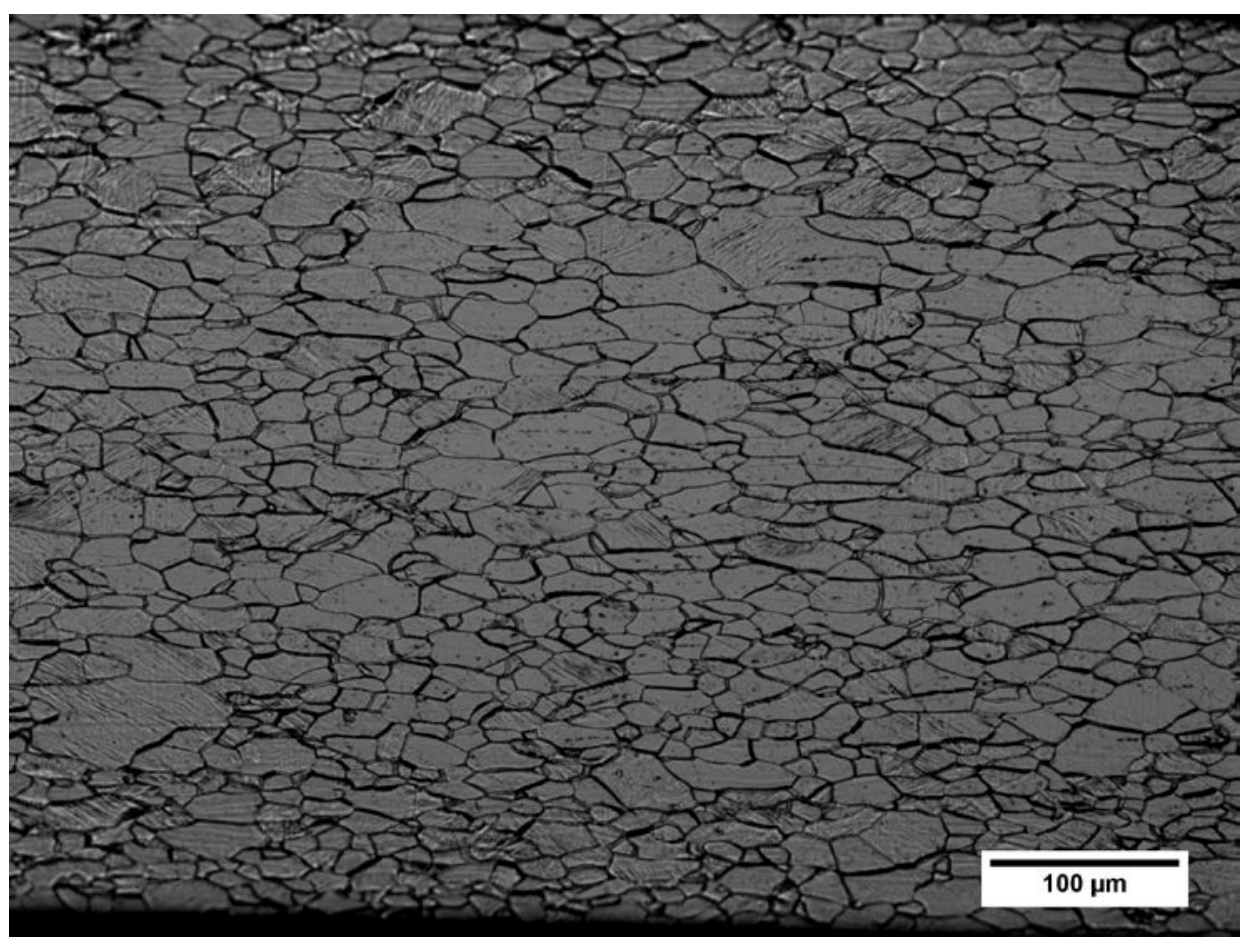

Figura 35: Micrografia da seç̧ão longitudinal de uma amostra com deformação real de 0,29, extraída por meio de microscopia óptica. 


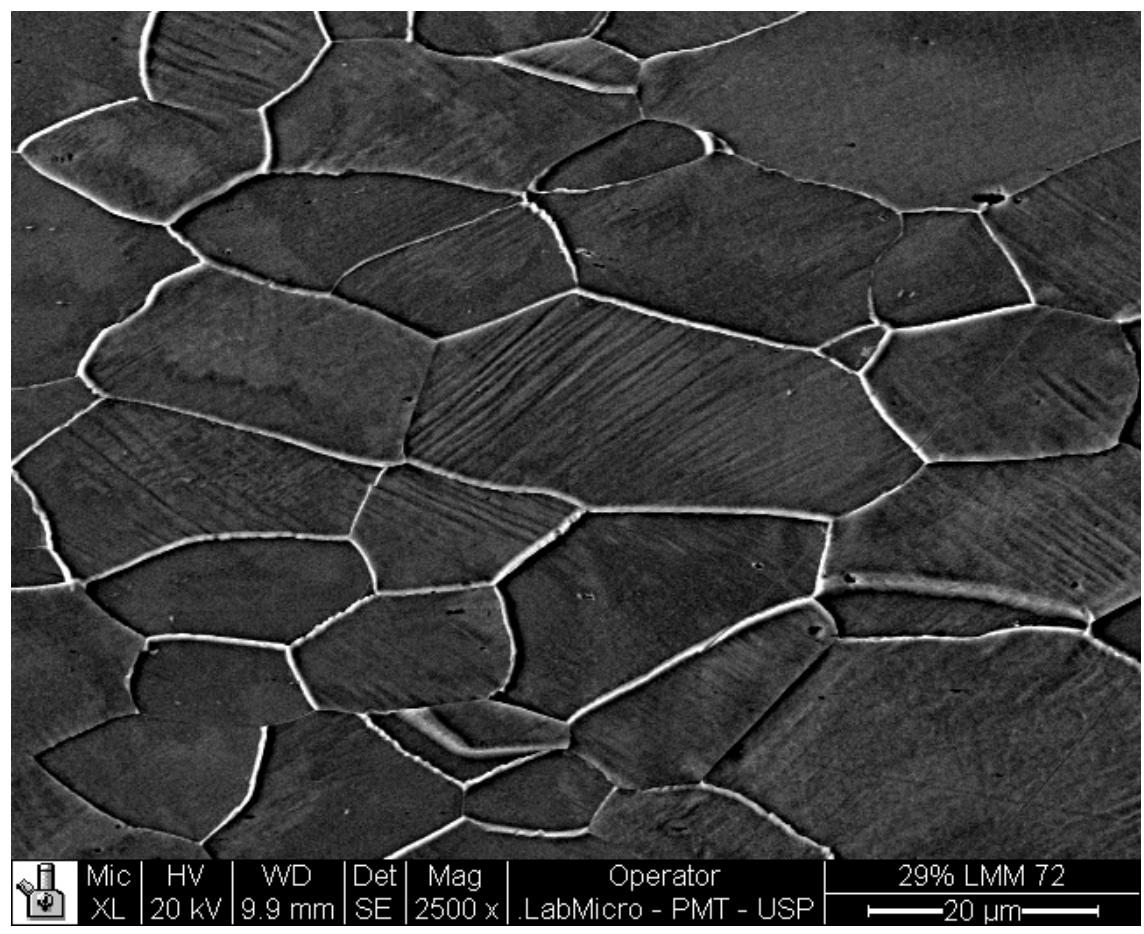

Figura 36: Detalhe mostrando grãos deformados em amostra com deformação real 0,29. Imagem extraída na secção longitudinal por microscopia eletrônica de varredura.

Estes resultados vão ao encontro do que foi observado por Silva [3] quando esta analisou a microestrutura de amostras de aço elétrico GNO 1,25\% Si (Figura 37).

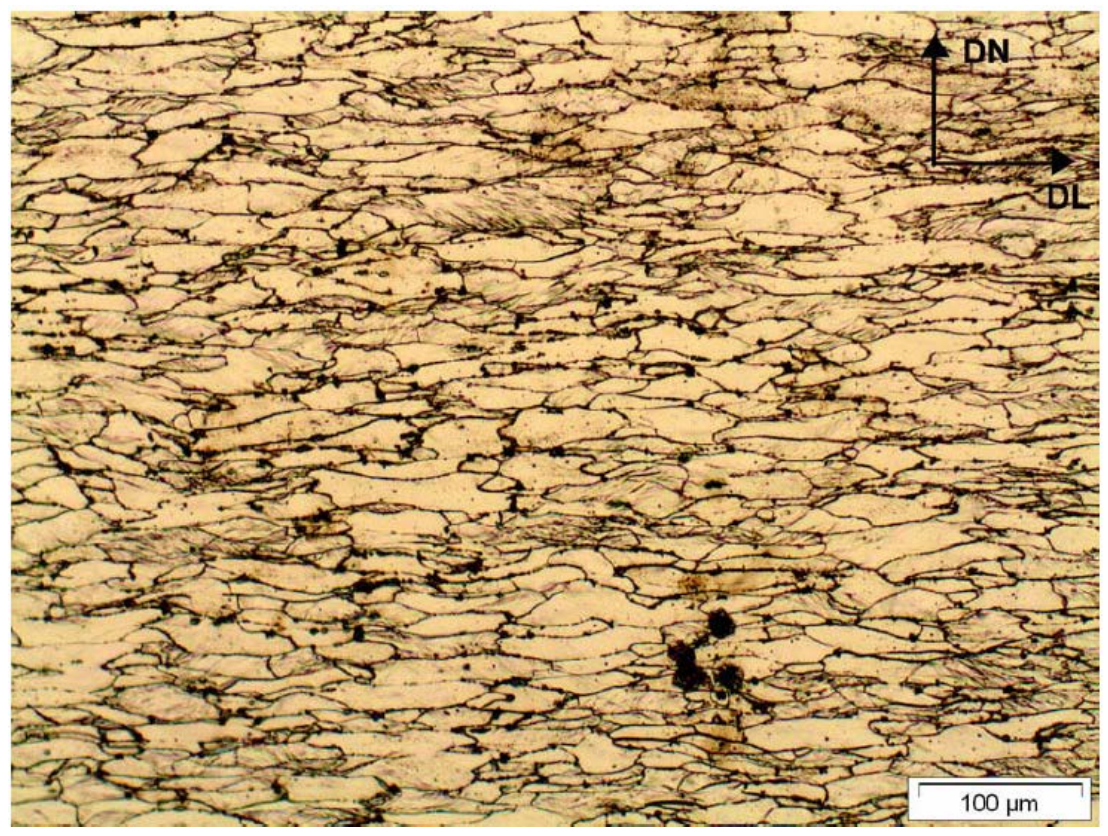

Figura 37: Microestrutura de um aço GNO 1,25 \% Si com 50 \% de redução por laminação a frio observado por [3] 


\subsection{A ação da deformação sobre a curva de magnetização}

A Figura 38 traz as curvas de magnetização das amostras submetidas a laminação a frio. Nota-se que ocorre degradação da permeabilidade magnética (também observada por [60] conforme mostra a Figura 39), porém o efeito da deformação é mais intenso no início da curva (campo inferior a 2000 A/m). A curva de magnetização torna-se menos dependente da deformação para campos mais altos. A partir de $3000 \mathrm{~A} / \mathrm{m}$ as curva das duas amostras de maior deformação se sobrepõem e por fim, se cruzam.

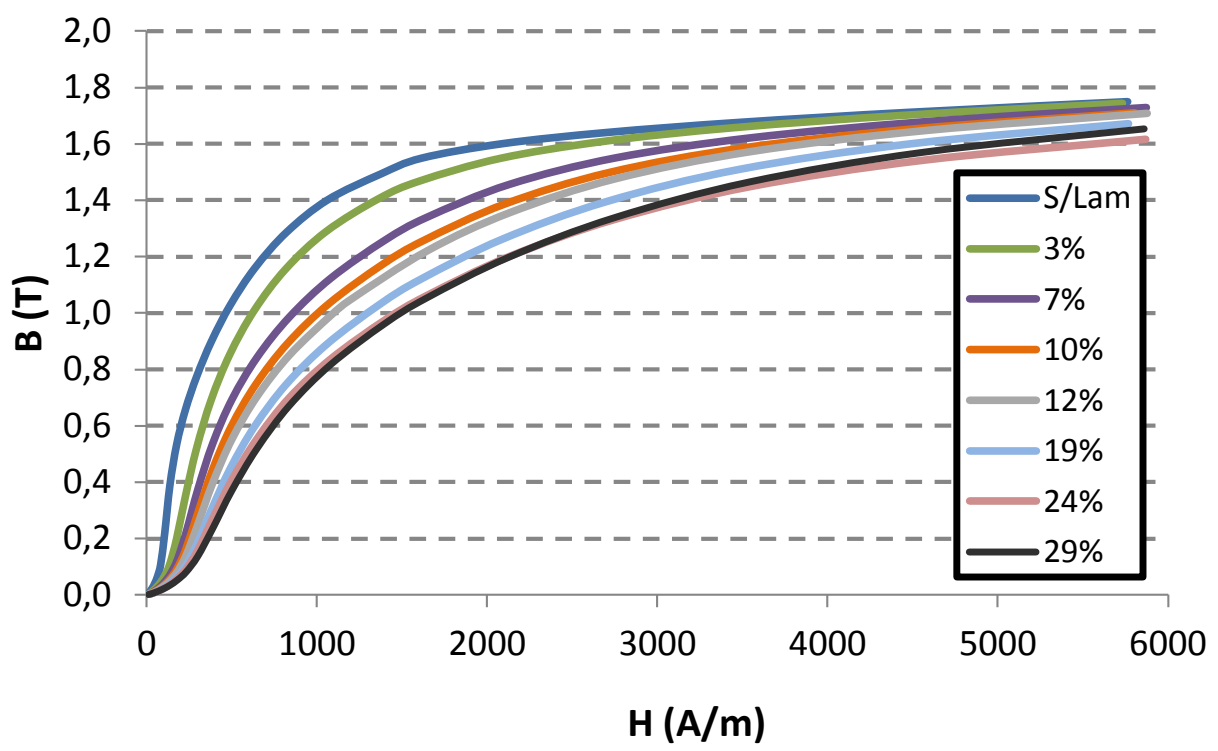

Figura 38: Gráfico das curvas de magnetização das amostras deformadas por laminação a frio. 


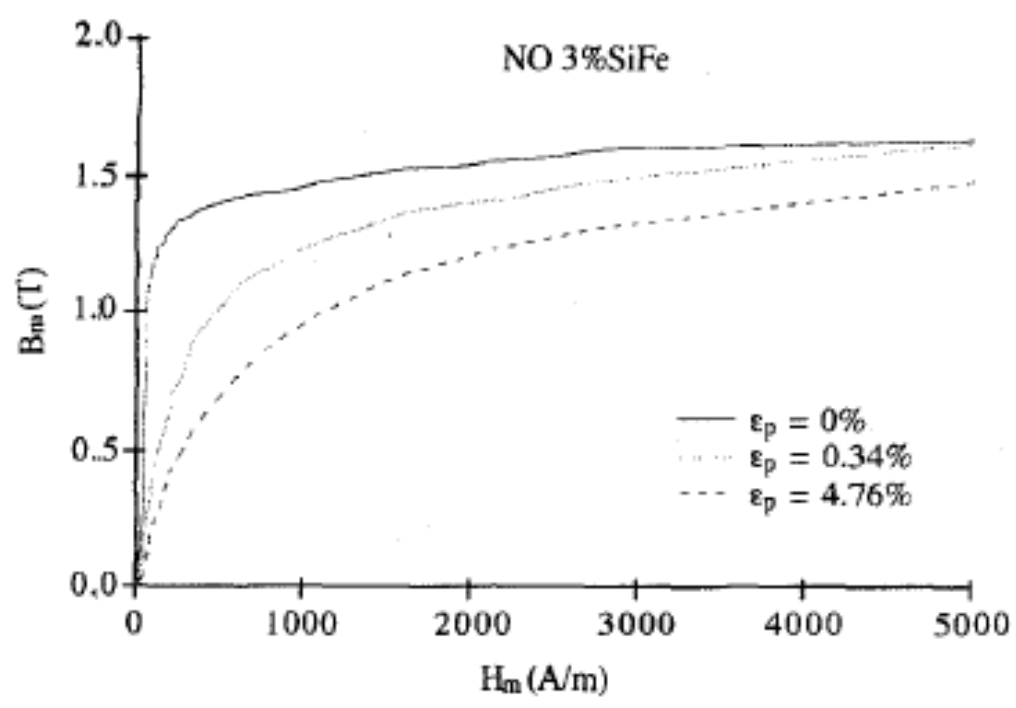

Figura 39: Gráfico das curvas de magnetização das amostras de aço não orientado 3 \% Si deformado a frio [60].

O comportamento adverso observado para alto valor de campo aplicado nas duas amostras de maior deformação se repete na Figura 40 onde são apresentados os valores da indução B50 em função da deformação real. A indução B50 refere-se ao valor de indução magnética para um campo aplicado de $5000 \mathrm{~A} / \mathrm{m}$ (ou $50 \mathrm{~A} / \mathrm{cm}$ ). Esse parâmetro é importante no estudo de materiais magneticamente moles onde a aplicação de um campo dessa intensidade já se encontra na região na qual a magnetização por rotação de domínios predomina. Tendo em vista a anisotropia das propriedades magnéticas em aços elétricos, espera-se que o B50 seja um indicador indireto de textura. Essa foi descrita por Fukuhara [61]. Ele observa aumento da fibra gama ocasionado por deformação plástica e atribui a este fator a diminuição do B50 em função do aumento da deformação. Uma comparação entre os resultados do presente trabalho $(0,8 \% \mathrm{Si})$ e os observados por Fukuhara pode ser vista na Figura 41. 


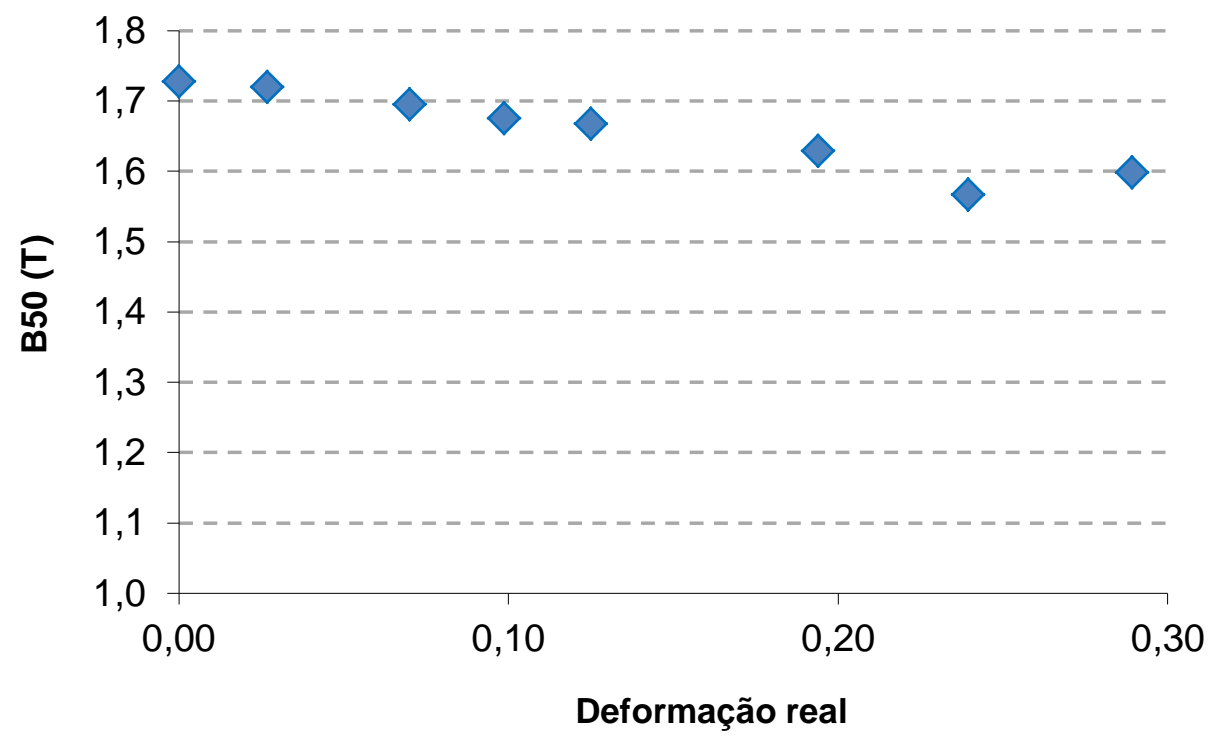

Figura 40: Gráfico da indução B50 em função da deformação.

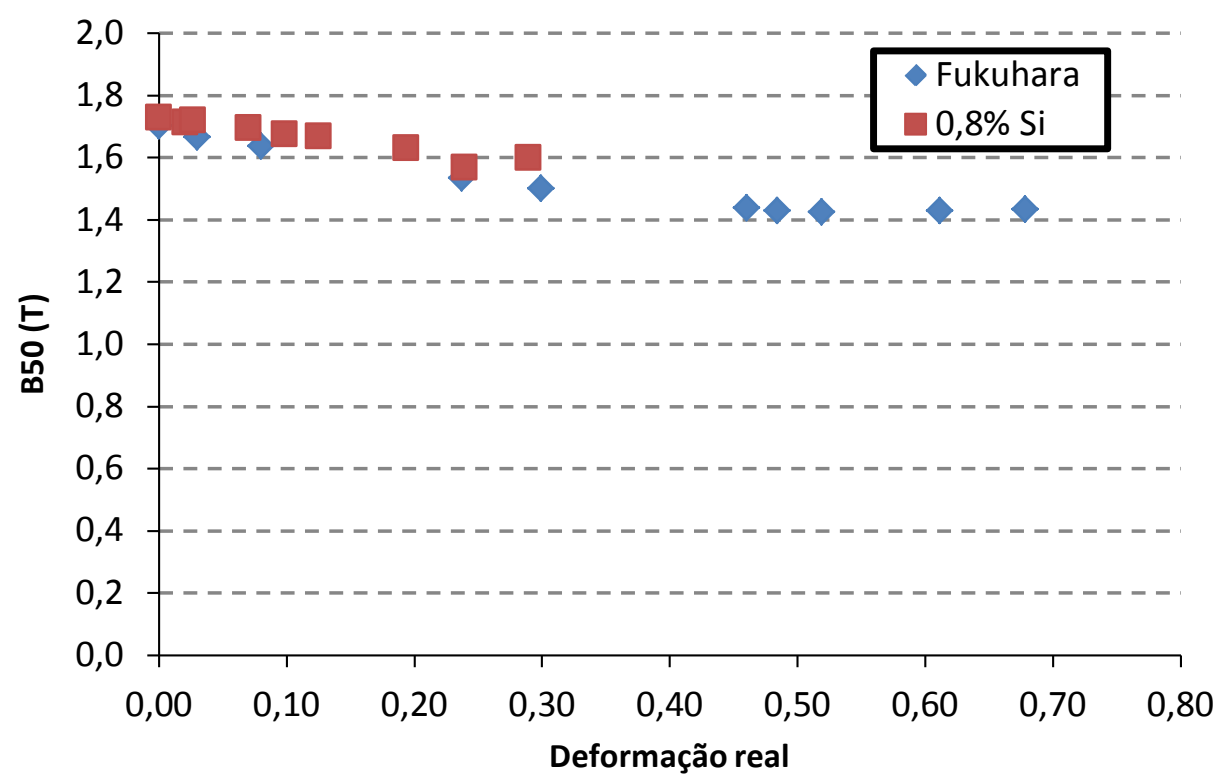

Figura 41: Curvas B50 em função da deformação real observadas por Fukuhara [61] e para as amostras $0,8 \%$ Si do presente trabalho.

Sobre os dados expostos na Figura 38 pode ser aplicada a Equação 14 para o cálculo da permeabilidade relativa descrita por $\mu_{\mathrm{r}}$, onde $\mu_{0}$ é a permeabilidade magnética do vácuo. A ação da deformação sobre a permeabilidade relativa pode ser vista através da Figura 42. A deterioração das 
propriedades fica evidente através da diminuição dos picos de $\mu_{\mathrm{r}}$ com 0 aumento da deformação.

$$
\mu_{r}=\frac{B}{\mu_{0} \times H} \quad \text { Equação } 14
$$

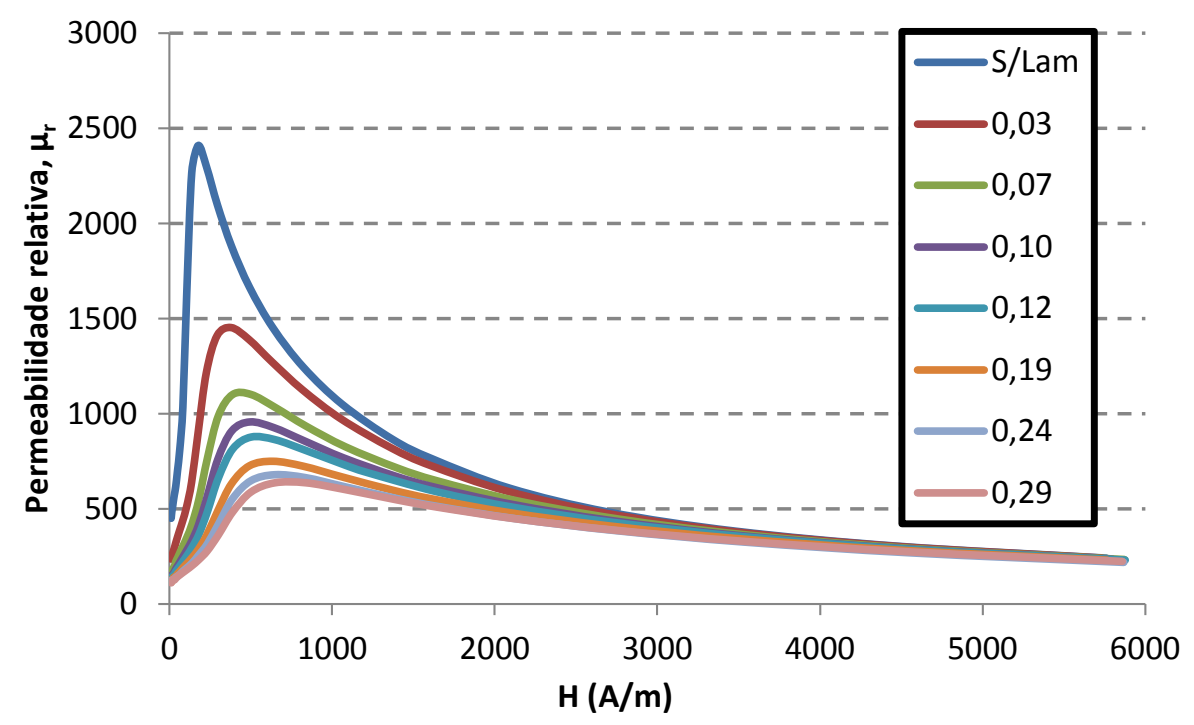

Figura 42: Gráfico indicando a permeabilidade relativa e função do campo magnético para as amostra deformadas.

\subsection{Energia dissipada por histerese}

A diminuição da permeabilidade em decorrência da deformação plástica afeta também o formato da curva de histerese. Observa-se um cisalhamento da curva com o aumento da deformação conforme indica a Figura 43. Nota-se que há aumento do campo máximo aplicado e do campo coercivo. Isso resulta em aumento da área do ciclo de histerese, ou seja, da energia dissipada. Os mesmos comportamentos são observados na Figura 44. 


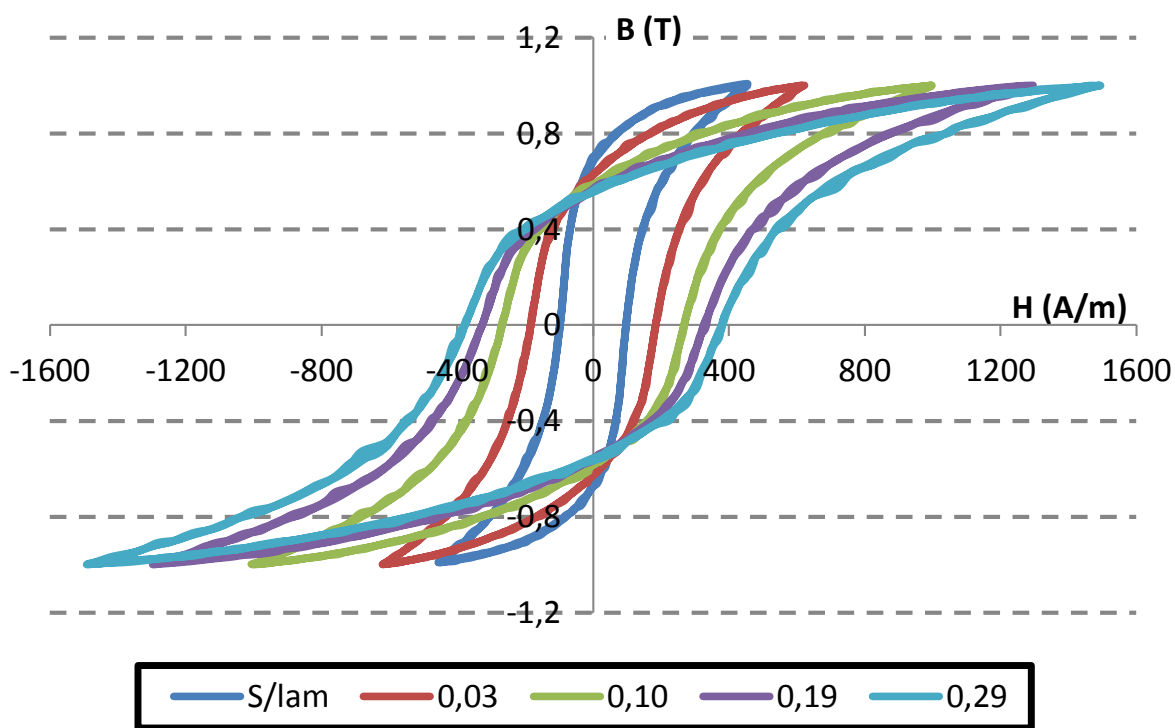

Figura 43: Ciclos de histereses quase estáticos? de algumas das amostras deformadas para indução máxima de 1,0 T.

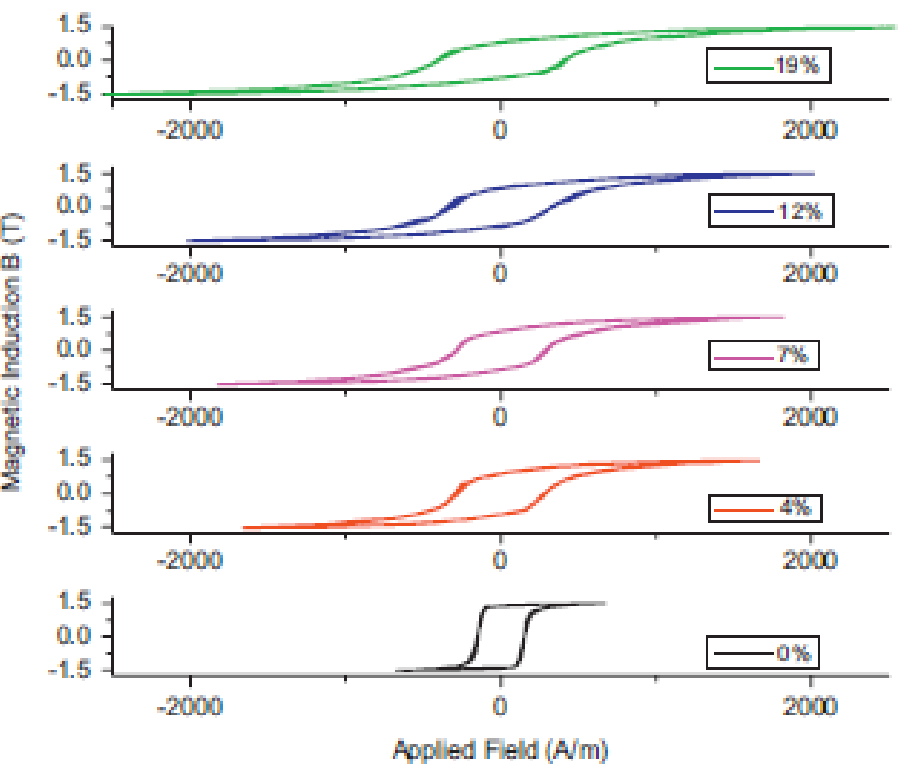

Figura 44: Ciclos de histerese (quase estáticos) obtidos para amostras deformadas por laminação[42].

Analisando-se a Figura 45, nota-se que a deformação plástica provoca aumento da área do ciclo de histerese, ou seja, ocorre a diminuição do rendimento energético do material com consequente aumento da energia dissipada por histerese para diferentes níveis de indução máxima aplicada no ciclo. 


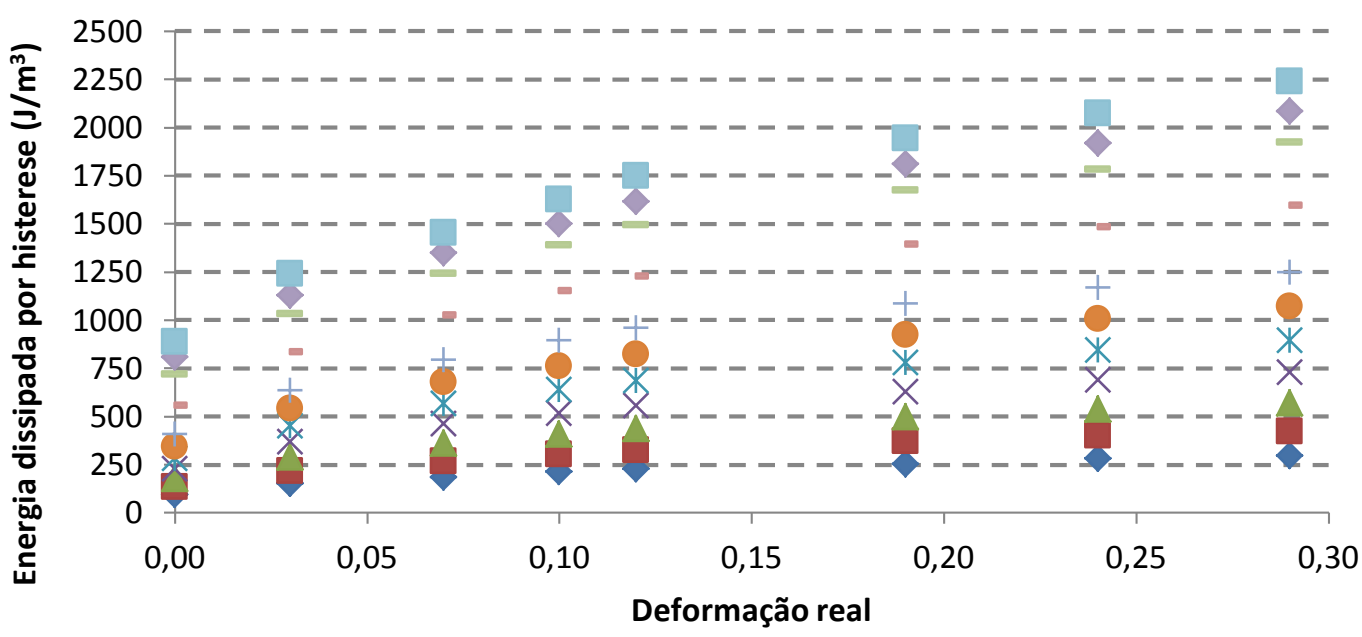

$\diamond \mathrm{Bmax}=0,4 \mathrm{~T} \square \mathrm{Bmax}=0,5 \mathrm{~T} \triangle \mathrm{Bmax}=0,6 \mathrm{~T} \times \mathrm{Bmax}=0,7 \mathrm{~T} * \mathrm{Bmax}=0,8 \mathrm{~T} \bigcirc \mathrm{Bmax}=0,9 \mathrm{~T}$

$+\mathrm{Bmax}=1,0 \mathrm{~T}-\mathrm{Bmax}=1,2 \mathrm{~T}-\mathrm{Bmax}=1,4 \mathrm{~T} \diamond \mathrm{Bmax}=1,5 \mathrm{~T} \square \mathrm{Bmax}=1,6 \mathrm{~T}$

Figura 45: Gráfico da energia dissipada por histerese quase estática em função da deformação real para diferentes valores de indução máxima.

Os resultados expostos na Figura 46 podem ser descritos como um crescimento linear da energia dissipada por histerese em função da raiz quadrada da deformação. 


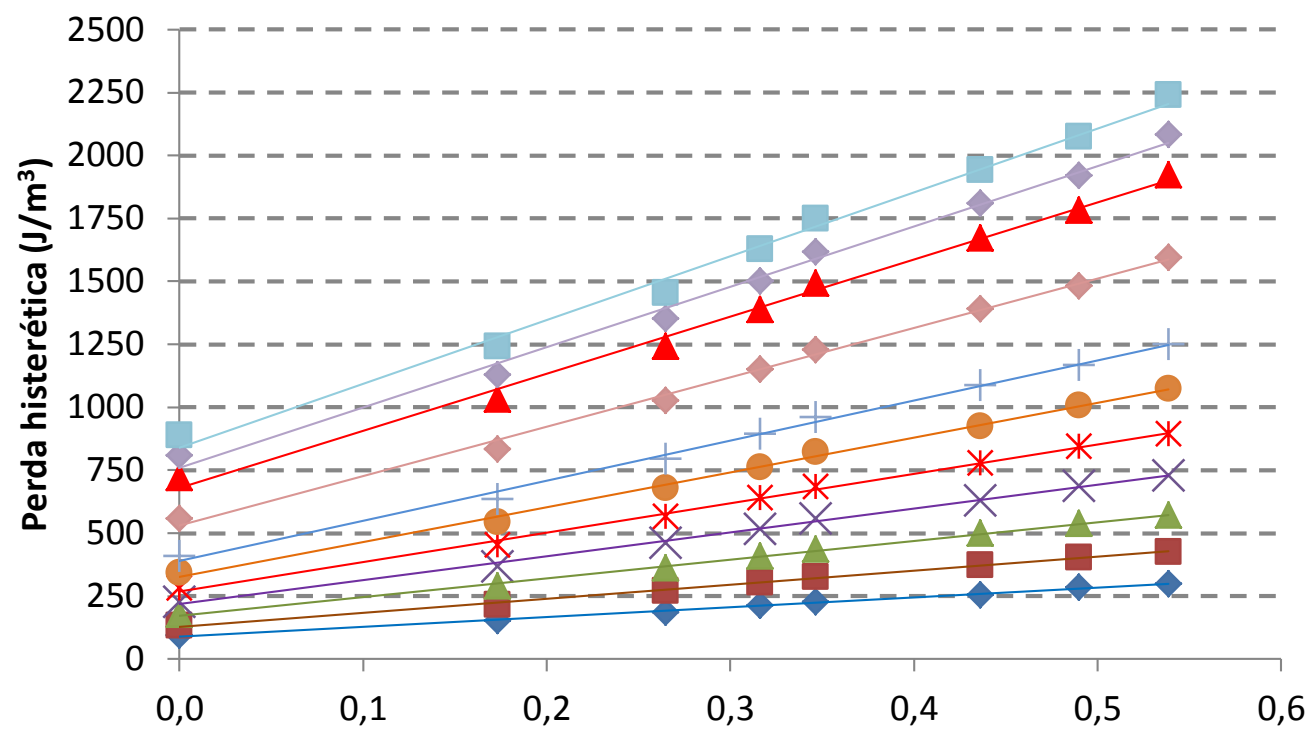

(Deformação) $)^{1 / 2}$

$\triangle \mathrm{Bmax}=0,4 \mathrm{~T} \square \mathrm{Bmax}=0,5 \mathrm{~T} \triangle \mathrm{Bmax}=0,6 \mathrm{~T} \times \mathrm{Bmax}=0,7 \mathrm{~T} * \mathrm{Bmax}=0,8 \mathrm{~T} \bigcirc \mathrm{Bmax}=0,9$

$+\mathrm{Bmax}=1,0 \mathrm{~T} \diamond \mathrm{Bmax}=1,2 \mathrm{~T} \Delta \mathrm{Bmax}=1,4 \mathrm{~T} \diamond \mathrm{Bmax}=1,5 \mathrm{~T} \square \mathrm{Bmax}=1,6 \mathrm{~T}$

Figura 46: Gráfico indicando aumento linear da energia dissipada por histerese (em regime quase estático) com a raiz quadrada da deformação.

A mesma lei de dependência foi verificada por Hou e Lee [62] conforme relata a Figura 47 obtida a partir de amostra de aço de grão não orientado, 0,27 \% Si e laminado a frio. A diferença é que a extrapolação de Hou e Lee para deformação zero resultou acima do valor experimental, enquanto os resultados da Figura 46 mostram o contrário. 


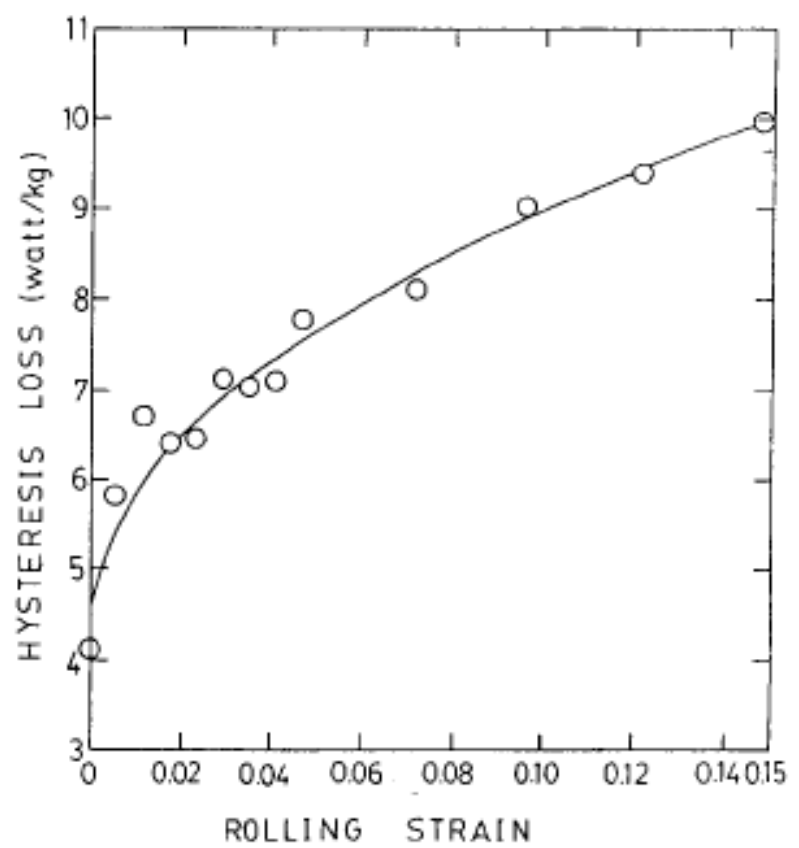

Figura 47: Gráfico publicado por Hou e Lee indicando aumento da perda histerética com a raiz quadrada da deformação [62].

Trabalhos anteriores analisaram aços submetidos a deformação plástica e sugerem que a mudança no comportamento magnético desses aços pode ser atribuída a geração de discordâncias e agrupamentos de discordância durante a deformação a frio [63]. Discordâncias dão origem a sítios de ancoramento que restringem os movimentos das paredes de domínio durante o processo de magnetização. Esse movimento é impedido até que o campo magnético atinge um valor crítico. O campo coercitivo $(\mathrm{Hc})$ aumenta com a deformação uma vez que os deslocamentos de paredes de domínios se tornam mais difíceis [64].

A Figura 48 traz uma comparação com os resultados observados por Fukuhara [65] (amostras 2 e 3,1 \% Si) para a relação entre deformação plástica e perda histerética. Os resultados experimentais ali descritos foram tomados para indução máxima de 1,5 T. O autor relata deterioração das propriedades magnéticas caracterizada por aumento das perdas e aumento do campo coercivo. Tais fatos foram descritos como resultado de aumento da densidade 
de discordâncias. Tal fator proporcionaria maior impedimento à movimentação das paredes de domínio. Outro ponto abordado por Fukuhara foi o aumento da intensidade de orientações desfavoráveis à magnetização no sentido da direção de laminação da chapa. No entanto, os resultados comparados divergem com relação à lei de dependência entre perda histerética e deformação plástica. Nota-se que, para uma lei de crescimento linear com a raiz da deformação, a qualidade do ajuste é sensivelmente menor.

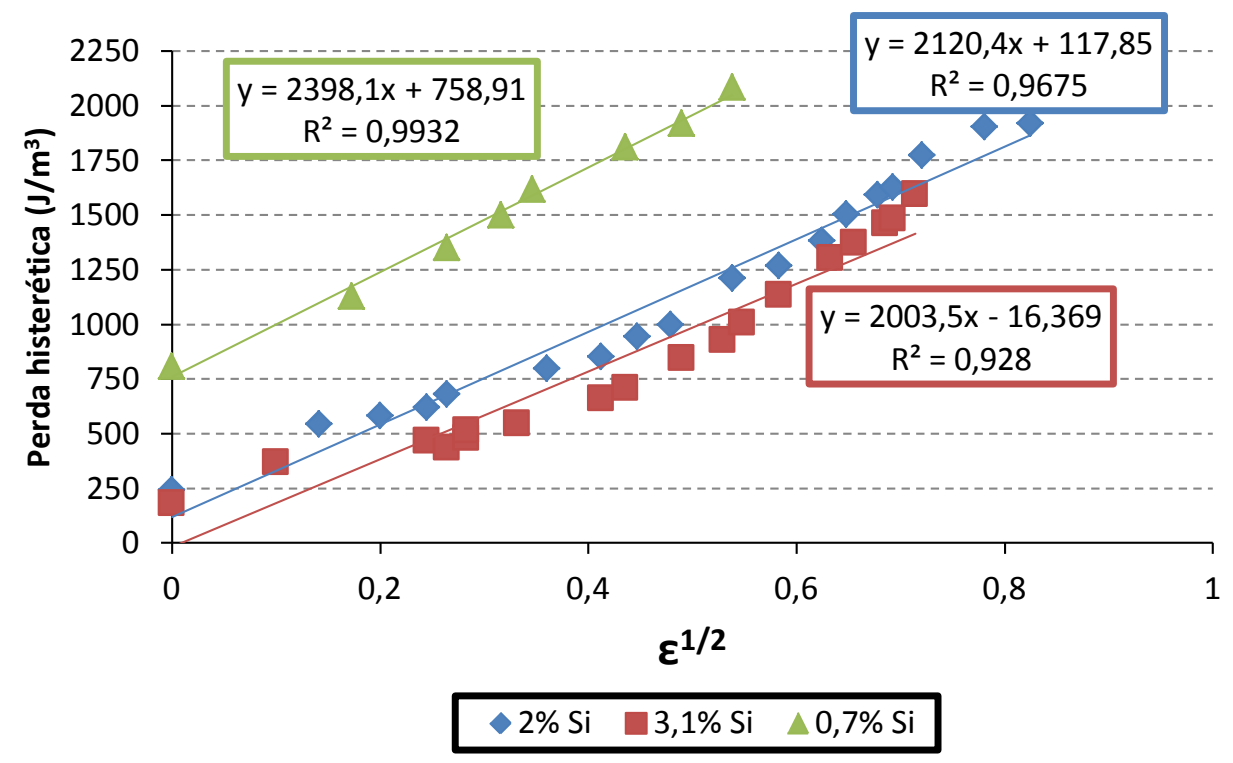

Figura 48: Comparação entre os resultados desse trabalho $(0,7 \% \mathrm{Si})$ e os dados apresentados por Fukuhara (2 e 3,1\% Si) [65].

A Figura 49 descreve crescimento da perda histerética com o aumento da densidade de discordâncias em razão da deformação plástica. Os resultados experimentais podem ser ajustados para uma lei de crescimento linear. No entanto, a imprecisão do ajuste ( $R^{2}$ entre 0,950 e 0,963) indicam, conforme aponta Fukuhara que aumento da densidade de discordâncias não é o único fator a causar diminuição da eficiência energética do material. 


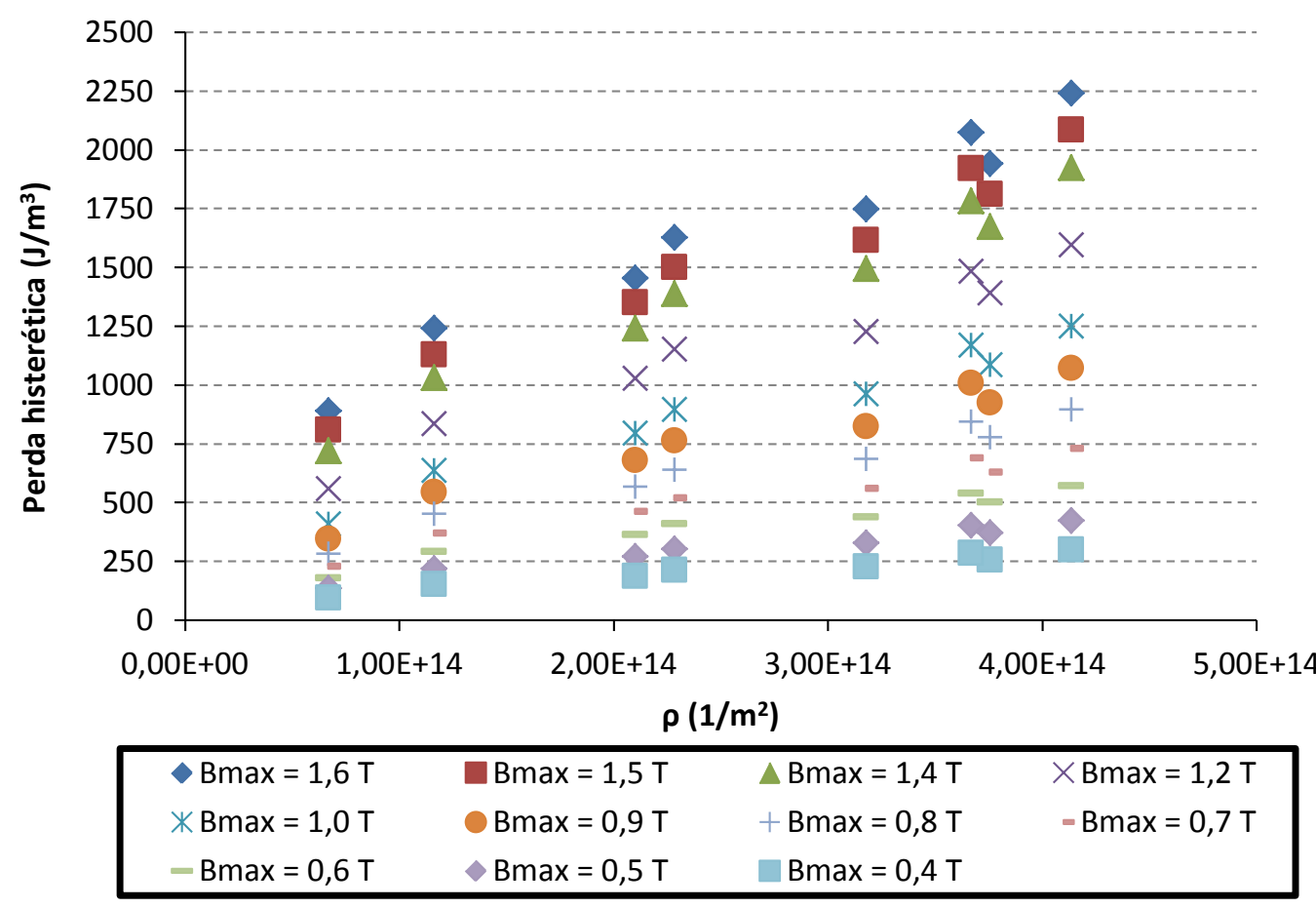

Figura 49: Evolução da perda histerética com o crescimento da densidade de discordâncias estimada por meio de difração de raios X.

A Figura 50 traz um gráfico que relata o comportamento dos coeficientes angular (inclinação) e linear (intercepção) das retas que compõem a Figura 46, que descreve a relação entre energia dissipada e a raiz da deformação. 0 coeficiente linear reflete o aumento da energia dissipada por histerese em função do $B_{\max }$ das amostras não laminadas. A equação que melhor se ajusta aos dados experimentais é uma lei de potência com exponencial igual a 1,62. Esse é próximo do previsto pela lei de Steinmetz e usada até hoje pelos fabricantes de motores para relacionar energia dissipada por histerese e indução máxima. Com relação à inclinação da curva, ou seja, o efeito da deformação, nota-se que o expoente é bem menor, 1,3, com uma diminuição da taxa de incremento a partir de indução máxima de 1,2 T. 


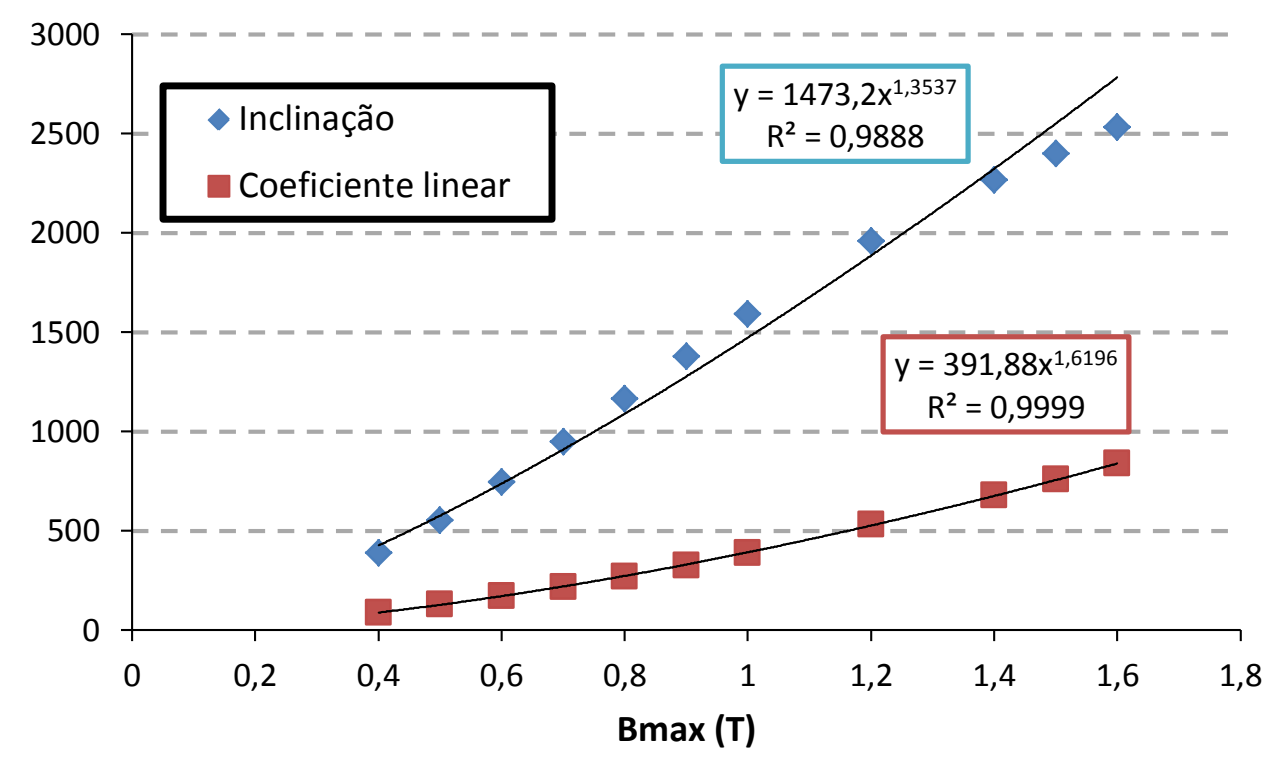

Figura 50: Variação da inclinação e do coeficiente linear das retas obtidas no gráfico da Figura 46.

Aplicando-se o procedimento de subdivisão da energia dissipada por histerese percebe-se que a amostra não laminada apresenta menor indução de máxima permeabilidade (Figura 51). Este comportamento revela que nesta amostra a mudança de predominância de mecanismo de magnetização é antecipada. Por outro lado, as curvas revelam que o pico se dá na amostra de deformação 0,03. A partir de deformação igual a 0,10 os valores de $B_{\mu m a x}$ pouco se alteram com a deformação. 


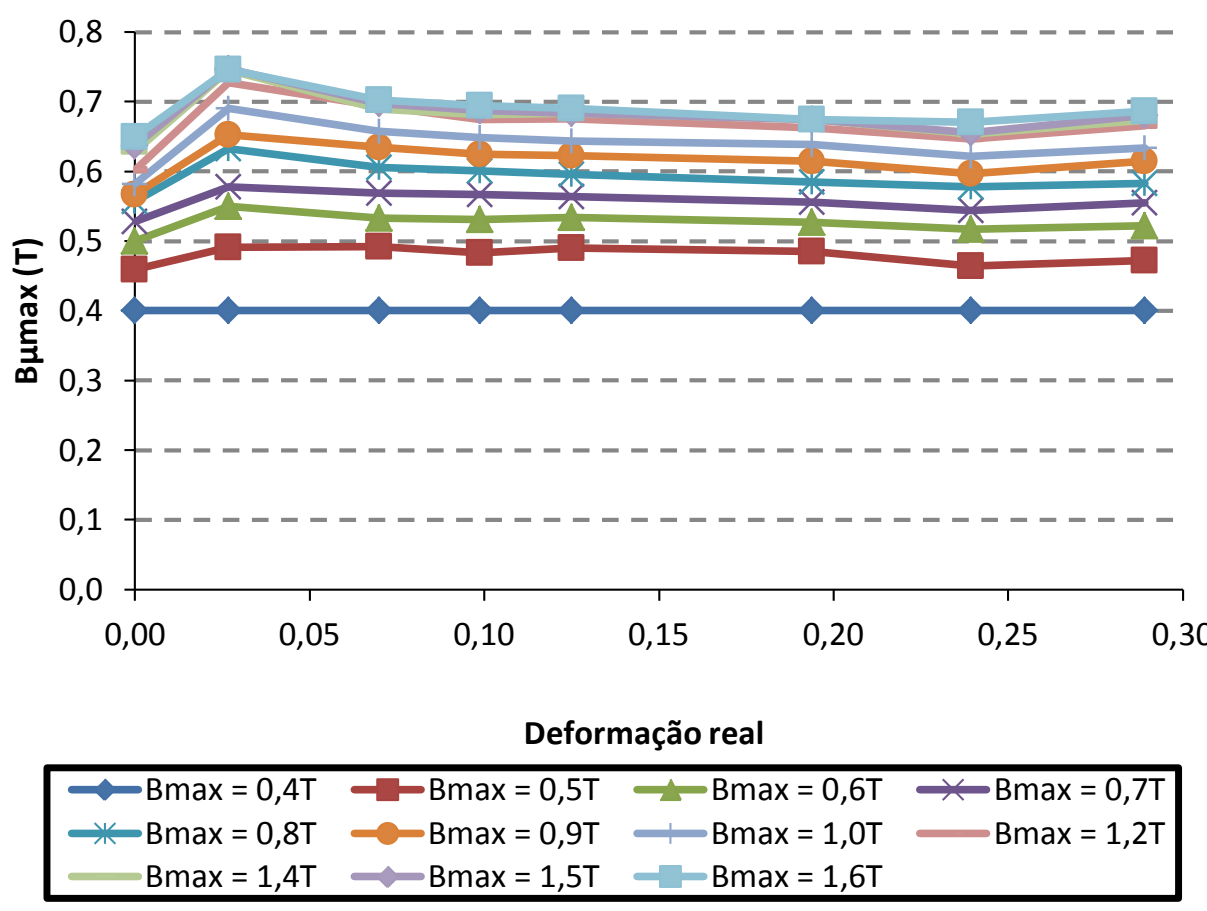

Figura 51: Indução de máxima permeabilidade em função da deformação real.

A Figura 52 traz a evolução das perdas em região de baixa indução com o aumento da deformação. Nota-se que há aumento da energia dissipada nessa região. Tendo em vista que em baixa indução a magnetização se dá majoritariamente por movimentação de paredes de domínios, é plausível creditar à ação de discordâncias o aumento da dissipação de energia. O gráfico da Figura 53 estabelece essa relação onde a energia dissipada na região de baixa indução apresenta um ajuste razoável com a raiz de densidade de discordância. Hou [62] atribui a esse mecanismo a piora das propriedades magnéticas de aços elétricos submetidos à deformação. 


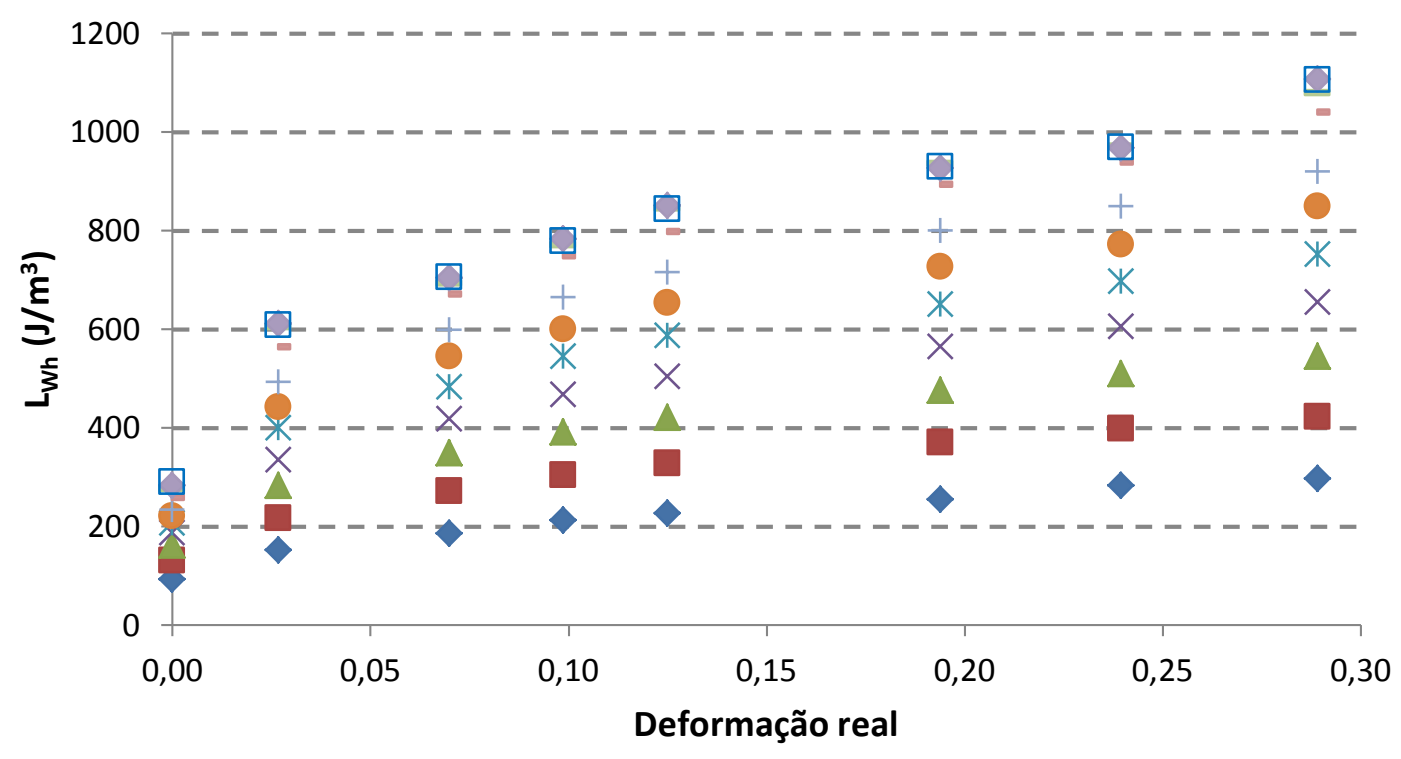

\begin{tabular}{rlll|}
\hline $\mathrm{Bmax}=0,4 \mathrm{~T}$ & $\square \mathrm{Bmax}=0,5 \mathrm{~T}$ & $\triangle \mathrm{Bmax}=0,6 \mathrm{~T}$ & $\times \mathrm{Bmax}=0,7 \mathrm{~T}$ \\
$* \mathrm{Bmax}=0,8 \mathrm{~T}$ & $\mathrm{Bmax}=0,9 \mathrm{~T}$ & $+\mathrm{Bmax}=1,0 \mathrm{~T}$ & $-\mathrm{Bmax}=1,2 \mathrm{~T}$ \\
$-\mathrm{Bmax}=1,4 \mathrm{~T}$ & $\triangleright \mathrm{Bmax}=1,5 \mathrm{~T}$ & $\square \mathrm{Bmax}=1,6 \mathrm{~T}$ & \\
\hline
\end{tabular}

Figura 52: Energia dissipada por histerese na região de baixa indução, $L_{W h}$, em função da deformação real.

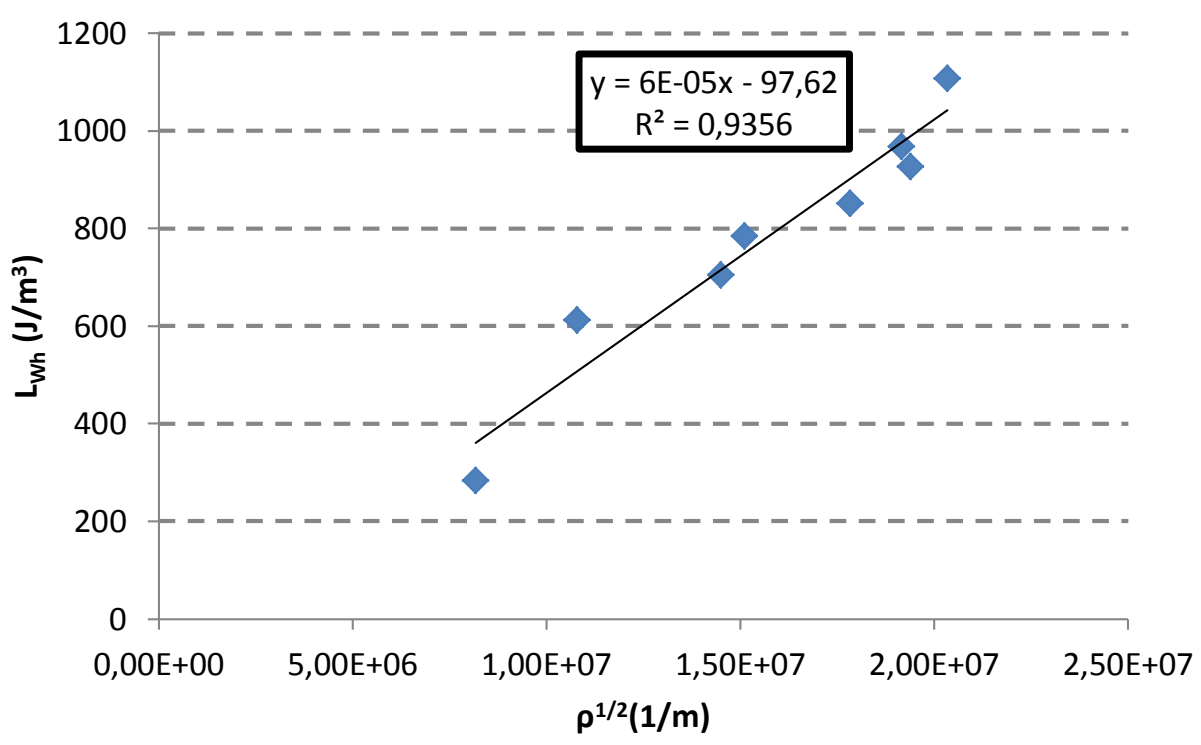

Figura 53: Gráfico da energia dissipada na região de baixa indução, $L_{W h}$, (indução máxima de 1,5 T) em função da raiz da densidade de discordâncias estimadas por raios X.

Com relação à região de alta indução (Figura 54), nota-se que a dissipação de energia torna-se relevante apenas para indução máxima superior a 0,8 T. Isso ocorre por que a indução de máxima permeabilidade para as 
amostras analisadas tem valor inferior a esse limite. A deformação plástica provoca aumento da dissipação de energia também nessa região. Isso indica que a interação entre paredes de domínio e discordâncias talvez não seja o único mecanismo operante. De acordo com Landgraf [26], é possível que tensões residuais afetem o mecanismo de nucleação e aniquilação de domínios, principal responsável pela dissipação de energia na região de alta indução do ciclo de histerese. Tensões residuais surgem porque a tensão externamente aplicada durante o processo de deformação plástica não é uniformemente distribuída ao longo do material. Grãos são submetidos a diferentes quantidades de deformação uma vez que seu limite de escoamento depende de sua orientação cristalográfica.

Observa-se que nas duas regiões a energia dissipada parece se comportar da mesma forma com relação ao aumento da deformação. Isso contribui para um bom ajuste onde a energia dissipada cresce linearmente com a raiz quadrada da deformação. Além disso, os resultados vão ao encontro do que é mostrado na Figura 55 onde os dados apresentados foram extraídos em indução máxima 1,5 T. 


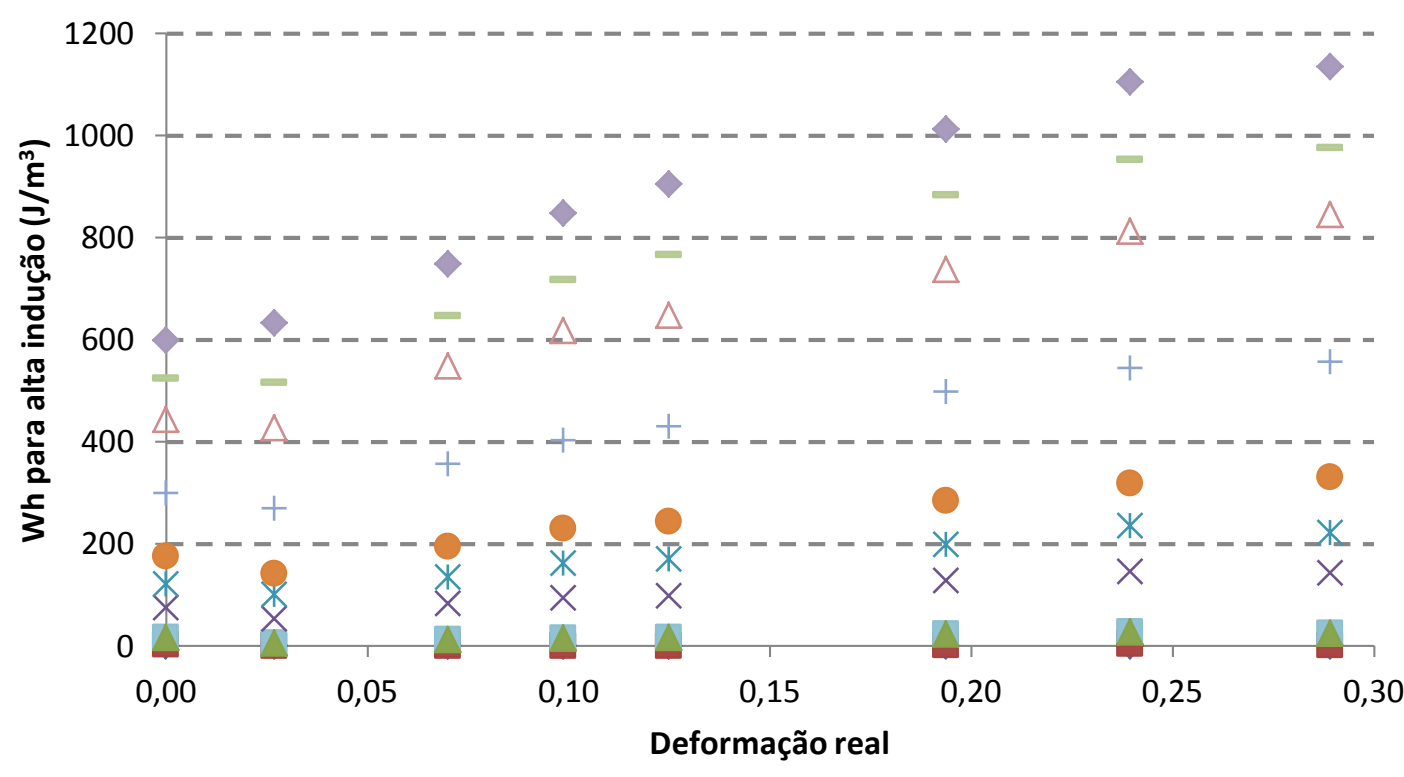

$\triangle \mathrm{Bmax}=0,4 \mathrm{~T} \square \mathrm{Bmax}=0,5 \mathrm{~T} \square \mathrm{Bmax}=0,6 \mathrm{~T} \triangle \mathrm{Bmax}=0,7 \mathrm{~T} \times \mathrm{Bmax}=0,8 \mathrm{~T} \quad * \mathrm{Bmax}=0,9 \mathrm{~T}$ $\mathrm{Bmax}=1,0 \mathrm{~T}+\mathrm{Bmax}=1,2 \mathrm{~T} \rightarrow \mathrm{Bmax}=1,4 \mathrm{~T}-\mathrm{Bmax}=1,5 \mathrm{~T} \diamond \mathrm{Bamx}=1,6 \mathrm{~T}$

Figura 54: Energia dissipada por histerese na região de alta indução em função da deformação real.

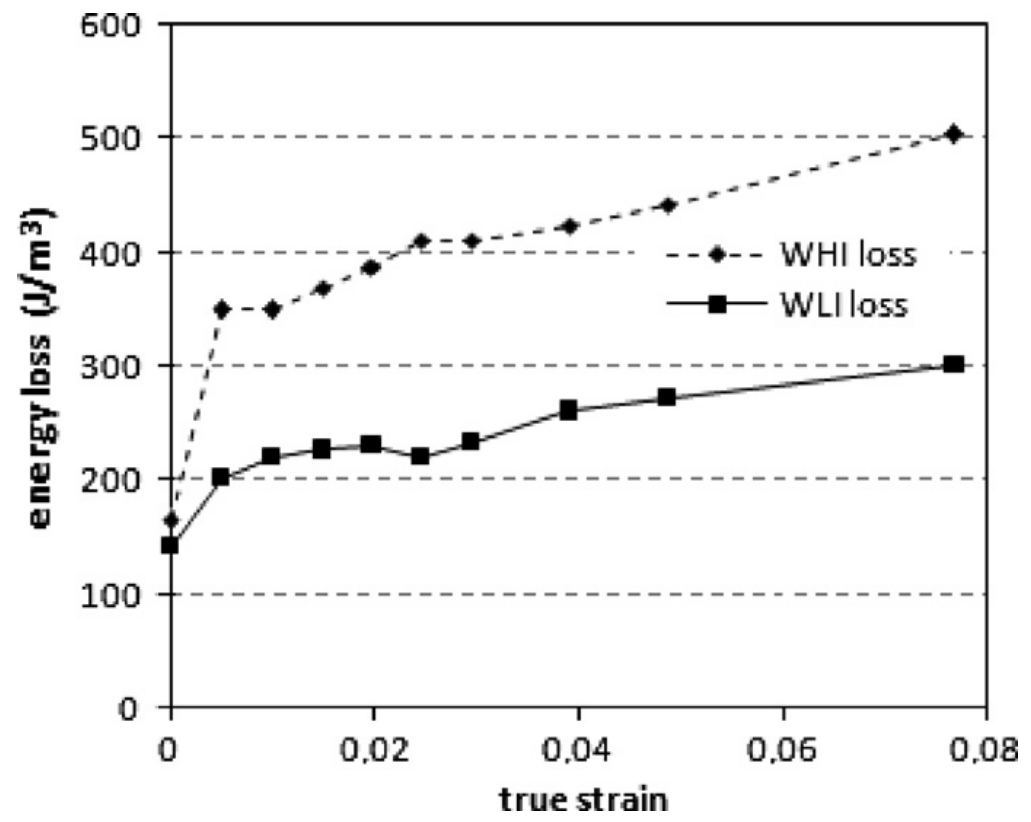

Figura 55: Efeito da deformação sobre as componentes da perda histerética [26]. 


\subsubsection{Ação da deformação plástica sobre o campo coercivo}

Assim como a energia dissipada por histerese, o campo coercivo também aumenta linearmente com a raiz da deformação real, conforme indica a Figura 56.

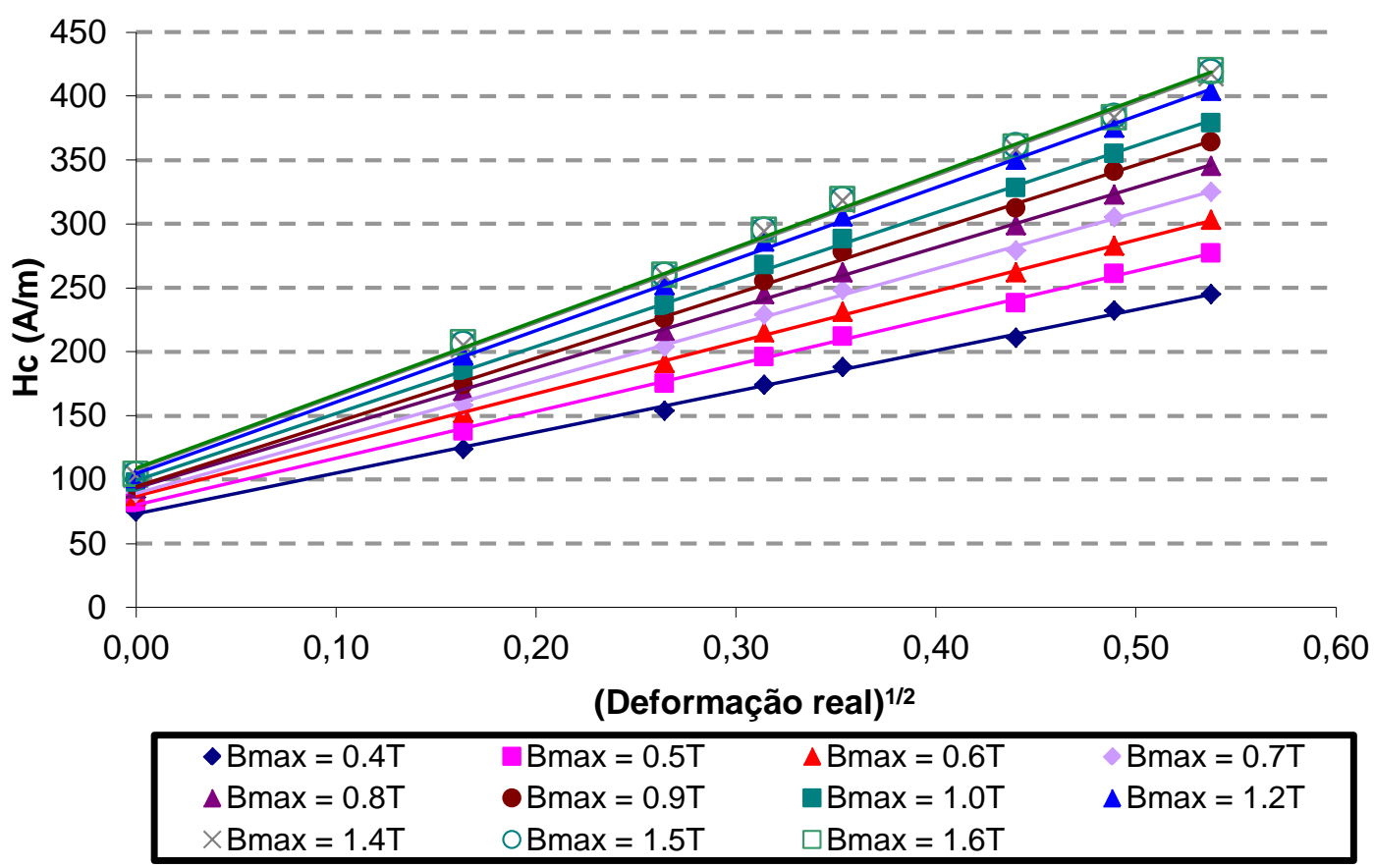

Figura 56: Gráfico do crescimento linear do campo coercivo com a raiz da deformação real para diferentes valores de indução.

O mecanismo de interação proposto por Kronmüller entre discordâncias (ou grupo de discordâncias) e paredes de domínio prevê uma relação onde o campo coercivo é proporcional à raiz da densidade de discordâncias. Os resultados indicados na Figura 57 apoiam essa lei de dependência. Dessa forma, embora as estruturas de discordâncias vistas em materiais deformados sejam mais complexas do que os arranjos assumidos por aquele autor, 0 modelo por ele proposto encontra correspondência com os resultados aqui observados. 


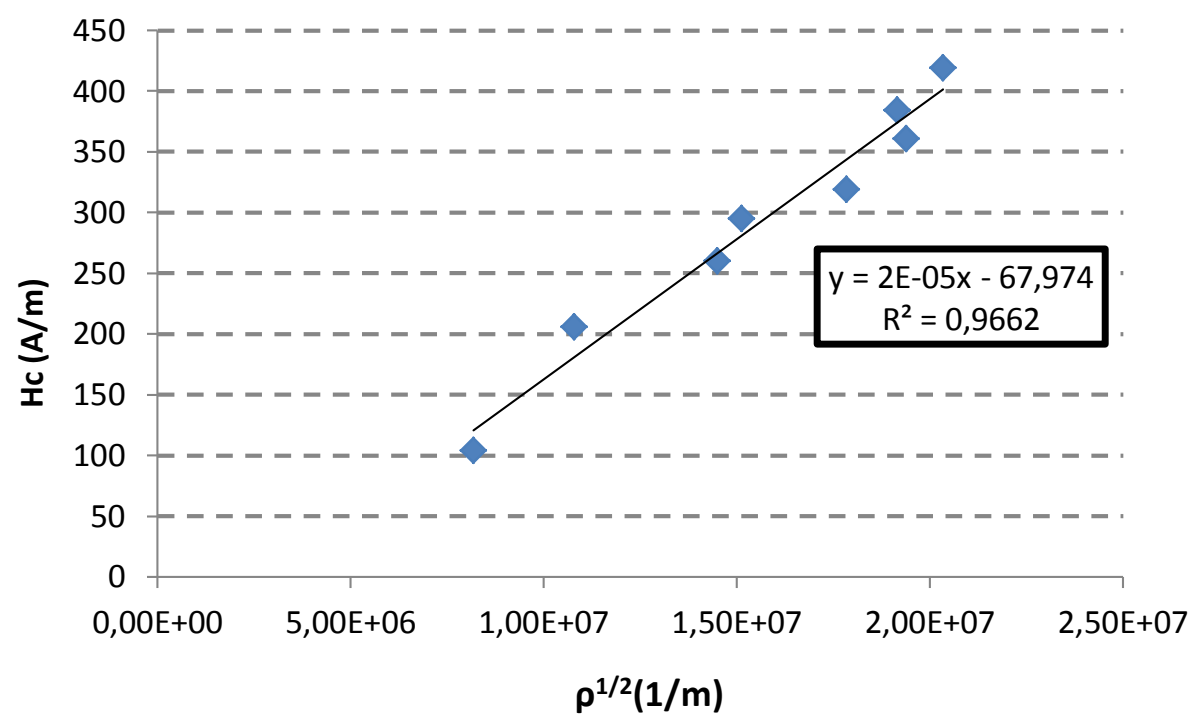

Figura 57: Crescimento linear do campo coercivo medido em regime quase estático em indução máxima de $1,5 \mathrm{~T}$ com a raiz da densidade de discordância estimada por raios X.

\subsection{Importância da frequência de excitação}

As perdas parasitas clássicas observadas diminuem com a redução da espessura seguindo a Equação 2. Alterações na resistividade elétrica em razão da deformação plástica são desprezíveis. Todos os conjuntos de amostras exibiram um crescimento linear das perdas totais com o aumento da frequência. No entanto os dados correspondentes ao material não laminado têm maior inclinação conforme relata a Figura 58. Este fato indica o efeito relativo da frequência se torna menor com o aumento da deformação. 


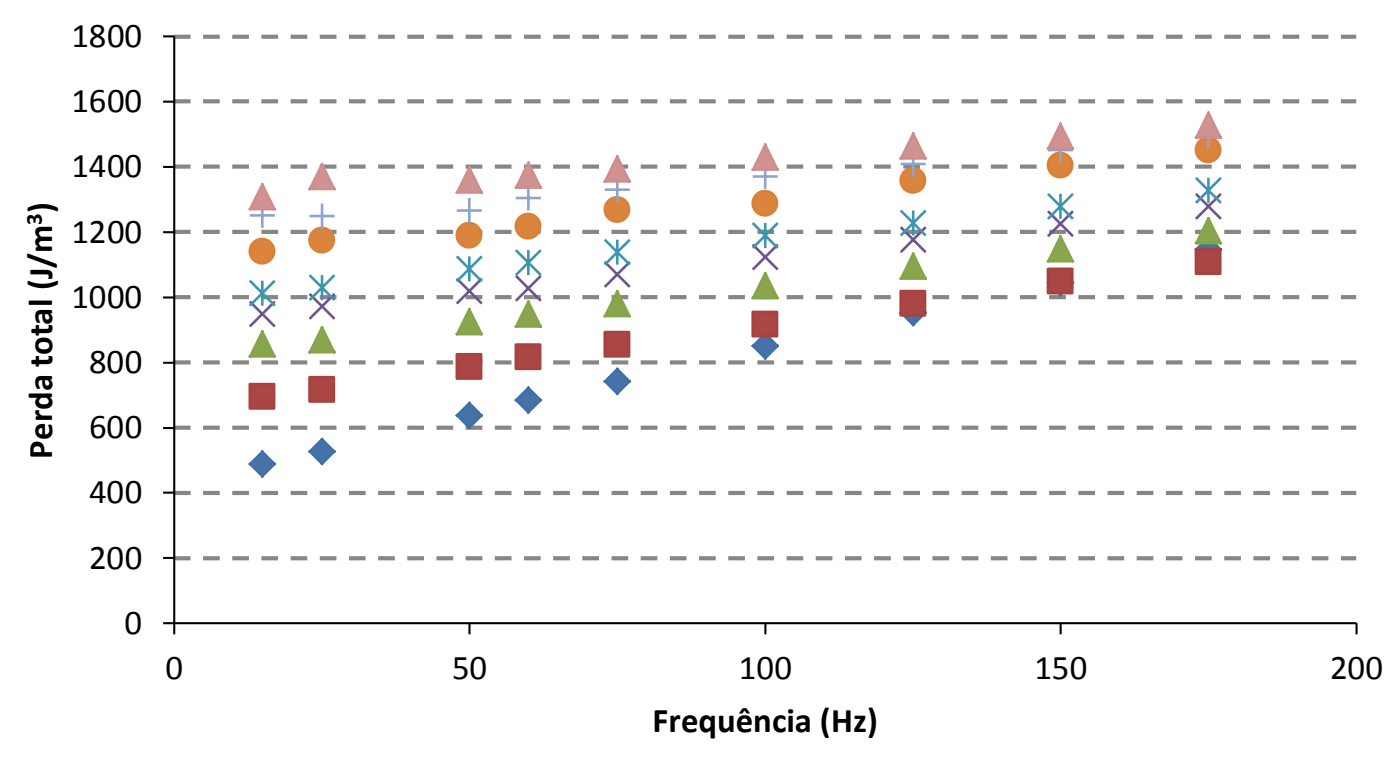

$\diamond \mathrm{S} / \mathrm{lam} \quad 0,03 \quad \Delta 0,07 \quad \times 0,1 \quad * 0,12 \quad 0,19 \quad+0,24 \quad \Delta 0,29$

Figura 58: Gráfico mostrando a perda total em função da frequência para as amostras deformadas

É sabido pelos resultados aqui apresentados, que a parcela histerética da perda sempre aumenta com a deformação. Dessa forma, a menor influência da frequência no desempenho das amostras mais deformadas deve ser explicada pela análise das demais parcelas. A Figura 59 obtida através da Equação 2 indica menor participação da perda parasita nas amostras mais deformadas. Assumindo-se que a deformação a frio não implica alterações significativas na resistividade do material, fica claro que ocorre efeito da espessura sobre a inclinação das retas indicadas Figura 58. Tomando-se como referência a amostra sem laminação e a amostra mais deformada (deformação real 0,29), observa-se que a diferença entre a energia dissipada a $175 \mathrm{~Hz}$ entre esses dois casos é de aproximadamente $400 \mathrm{~J} / \mathrm{m}^{3}$. Tal diferença não pode ser explicada apenas pela perda parasita (para este caso a diferença é de apenas $200 \mathrm{~J} / \mathrm{m}^{3}$ ). Dessa forma, o melhor desempenho das amostras deformadas mediante a alta frequência de excitação se deve também à perda de excesso. 


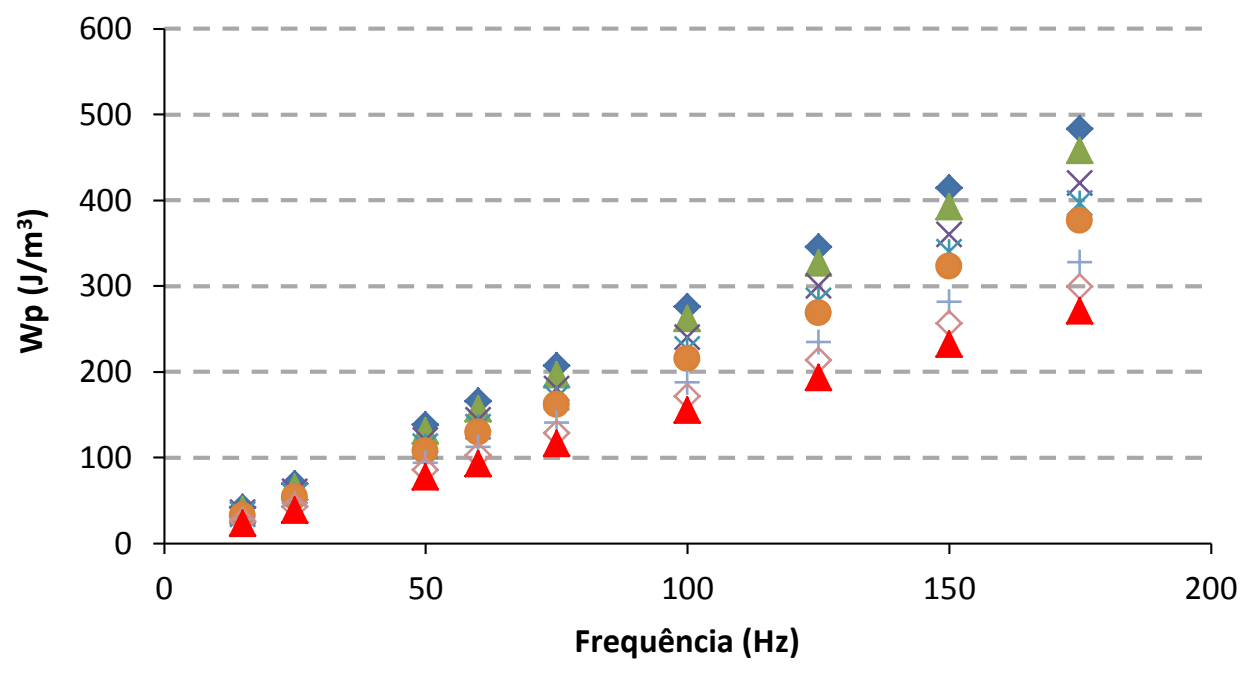

$\diamond \mathrm{S} / \mathrm{lam} \quad \Delta 0,03 \quad \times 0,07 \quad * 0,10 \quad 0,12 \quad+0,19 \quad \supset 0,24 \quad \Delta 0,29$

Figura 59: Gráfico indicando a variação da energia dissipada na forma de perda parasita (Wp) em função da frequência para as amostras deformadas.

Examinando a dependência das perdas de excesso com relação à frequência (Figura 60), nota-se que essa parcela da perda aumenta para a amostra não deformada enquanto as perdas de excesso diminuem para valores desprezíveis nas amostras laminadas (os pequenos valores negativos observados na figura estão dentro do erro experimental de aproximadamente $\left.20 \mathrm{~J} / \mathrm{m}^{3}\right)$.

Uma relação entre a perda anômala e uma característica microestrutural (tamanho de grão, Gs) é descrito pela Equação 15 [66], onde c é uma constante experimentalmente observada e f é a frequência. É possível inferir através da equação que a perda anômala é consequência da estrutura de domínios do material e de transformações que esta pode sofrer ao longo do processo de magnetização. Este cálculo assume que, para o estado desmagnetizado (ou com polarização distante da saturação) a distância média entre domínios é proporcional a $\mathrm{G}^{1 / 2}$. O número de paredes de domínio 
também é descrito pelos autores como proporcional a $\mathrm{f}^{1 / 2}$. Contudo, o modelo impõe a condição onde a Equação 16 tenha valor $n$ >> 1. Sendo $D$, a distância entre paredes de domínio e "e" a espessura da chapa. Dessa forma, alterações microestruturais que provoquem aumento da quantidade de paredes por unidade de volume podem inviabilizar a relação entre perda anômala e frequência descrita na Equação 15. Torna-se razoável, portanto, a hipótese de que a laminação a frio possa provocar a diminuição da perda anômala em razão do refino da estrutura de domínios.

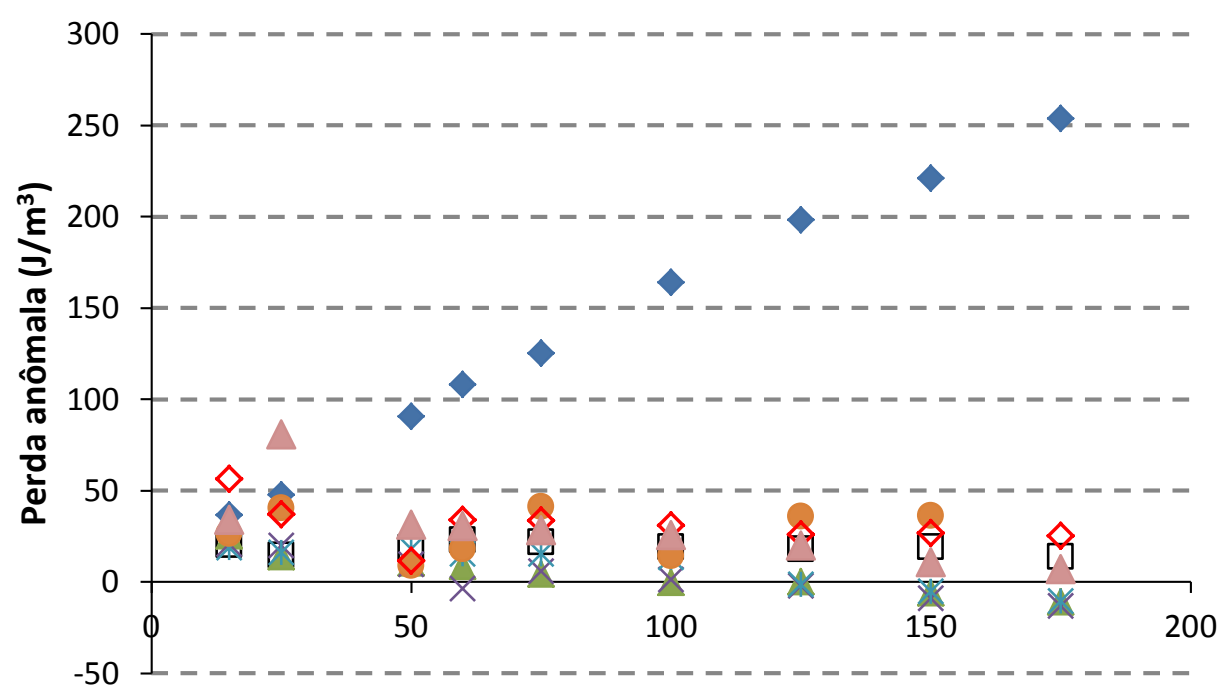

Frequencia $(\mathrm{Hz})$

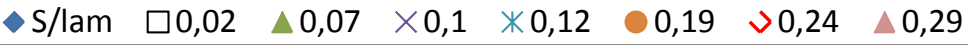

Figura 60: Evolução das perdas de excesso em função da frequência para amostras com diferentes quantidades de deformação.

$$
\begin{gathered}
P_{e}=c \cdot G s^{1 / 2} \cdot \frac{1}{\rho} \cdot e^{2} \cdot B_{\max }^{2} \cdot f^{3 / 2} \quad \text { Equação } 15 \\
n \cong 1,6 \times \frac{D}{e} \quad \text { Equação } 16
\end{gathered}
$$


Por meio de microscopia ótica por efeito Kerr, Takezawa [21] observou a estrutura de domínios na superfície de um dente de estator de motor elétrico. Essa peça foi produzida através de corte por puncionamento de uma chapa de aço GNO com 3 \% Si. São apontadas diferenças com relação à estrutura de domínios observada nos grãos próximos à borda de corte e a vista no restante da peça. $\mathrm{O}$ autor atribui tais diferenças à ação de tensões residuais. Estas tensões induziriam a formação de uma estrutura de domínios caracterizada pela alternância de faixas claras e escuras alinhas paralelamente à direção transversal à laminação (Figura 61). O artigo, contudo, não discute outras características microestruturais e não relaciona estrutura de domínios com os defeitos gerados pela deformação local.

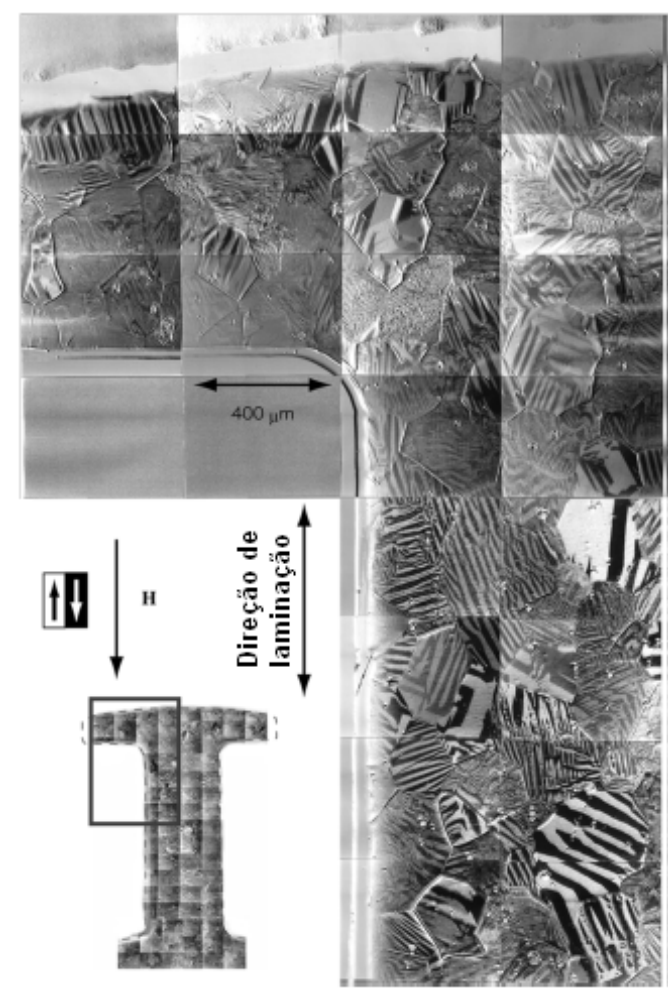

Figura 61: Imagem da estrutura de domínios ao longo da superfície de um dente de estator produzido por corte por puncionamento e sem recozimento posterior [21]. 
Swartzendruber [67] menciona a maior mobilidade das paredes de domínios em amostras não deformadas plasticamente. Também conclui que a quantidade de discordâncias tem influência sobre o campo coercivo. Sendo assim, os resultados da Figura 60 não podem ser explicados apenas em função de tensões residuais. O mesmo comportamento das perdas anômalas foi observado em amostras laminadas submetidas a tratamento térmico de recuperação [54]. Tal tratamento, conforme reporta o artigo, não foi capaz de promover recristalização do material. Portanto, embora tenha havido alguma aniquilação de discordância, uma microestrutura fragmentada pela deformação pode persistir.
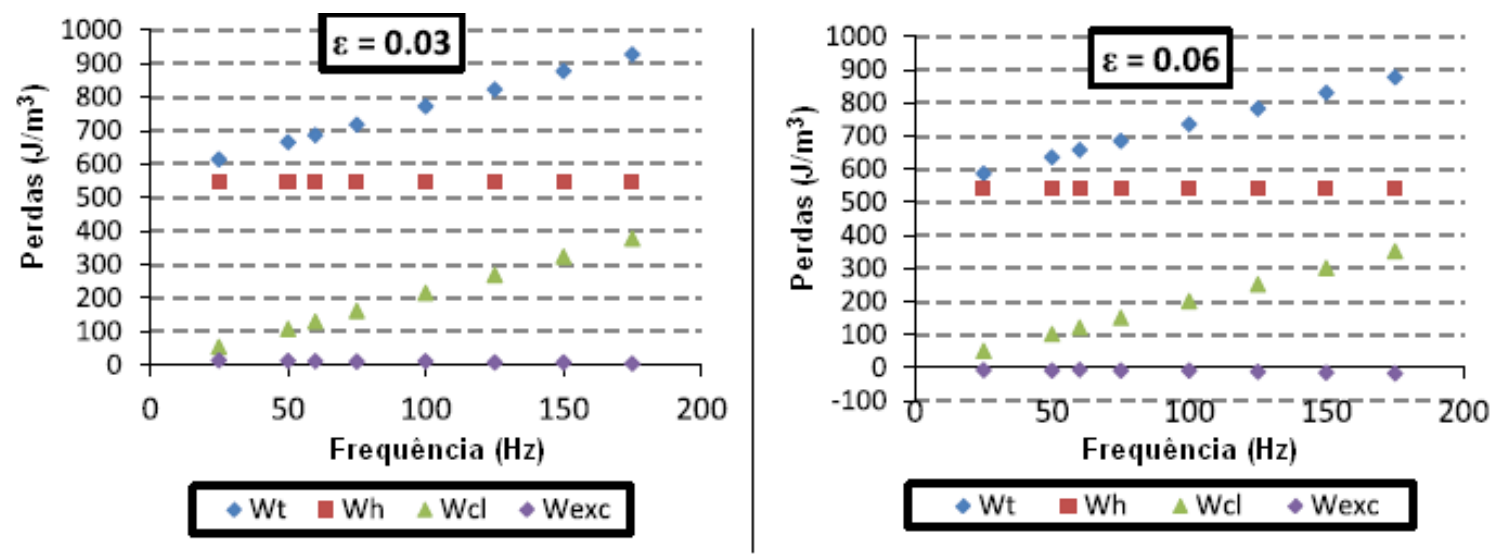

Figura 62: Processo de separação de perdas aplicado à amostras com deformação real (ع) 0,03 e 0,06 posteriormente recozidas a $500^{\circ} \mathrm{C}$ por 90 minutos [54].

A Equação 17 proposta em [68] descreve as perdas histeréticas em função do tamanho de grão $(\ell)$ e da indução máxima ( $\left.B_{\max }\right)$. A Figura 63 usa esta equação, juntamente com os dados da Figura 45, para fazer uma analogia entre o efeito da deformação a frio e a consequente redução do tamanho de grão pelo processo de fragmentação da microestrutura. Nota-se a redução do tamanho de grão calculado (TG calc.) com o aumento da deformação real. Os 
"novos grãos" oriundos da fragmentação podem ser associados aos blocos de célula visto que estes são separados por contornos de alto ângulo compostos por emaranhados de discordâncias.

$$
W_{h}=96 \times B_{\max }^{2}+\frac{3224 \times B_{\max }^{1.4}}{\ell} \quad \text { Equação } 17
$$

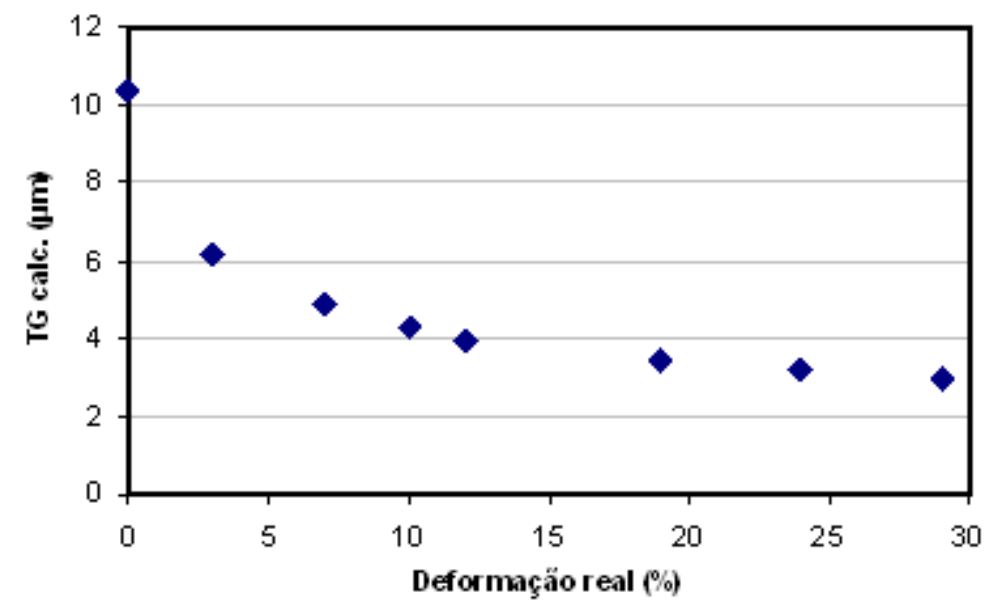

Figura 63: Gráfico do tamanho de grão calculado através da Equação 17 em função da deformação real.

O comportamento da perda anômala, observado na Figura 60, pode ser explicado frente a uma queda na mobilidade das paredes do domínio. Uma possível causa pode ser a interação entre essas paredes e estruturas de deformação. Outro fator se deve ao aumento da quantidade de paredes por unidade de volume. O mapa de EBSD (Figura 64) para a amostra mais deformada $(\varepsilon=0,29)$ mostra existência de variações de orientação no interior de grãos. Estes desvios de orientações decorrem de rotações ocasionadas pelo acomodamento de deformações. Porém, a imagem não relata uma estrutura onde um grão aparece subdividido em regiões distintas. Pelo contrário, as alterações ocorrem de maneira gradual. Nota-se, ainda que de maneira sutil, a presença de linhas paralelas cruzando o interior dos grãos. 
Essas linhas se apresentam em ângulos semelhantes às bandas observadas na micrografia da Figura 36.

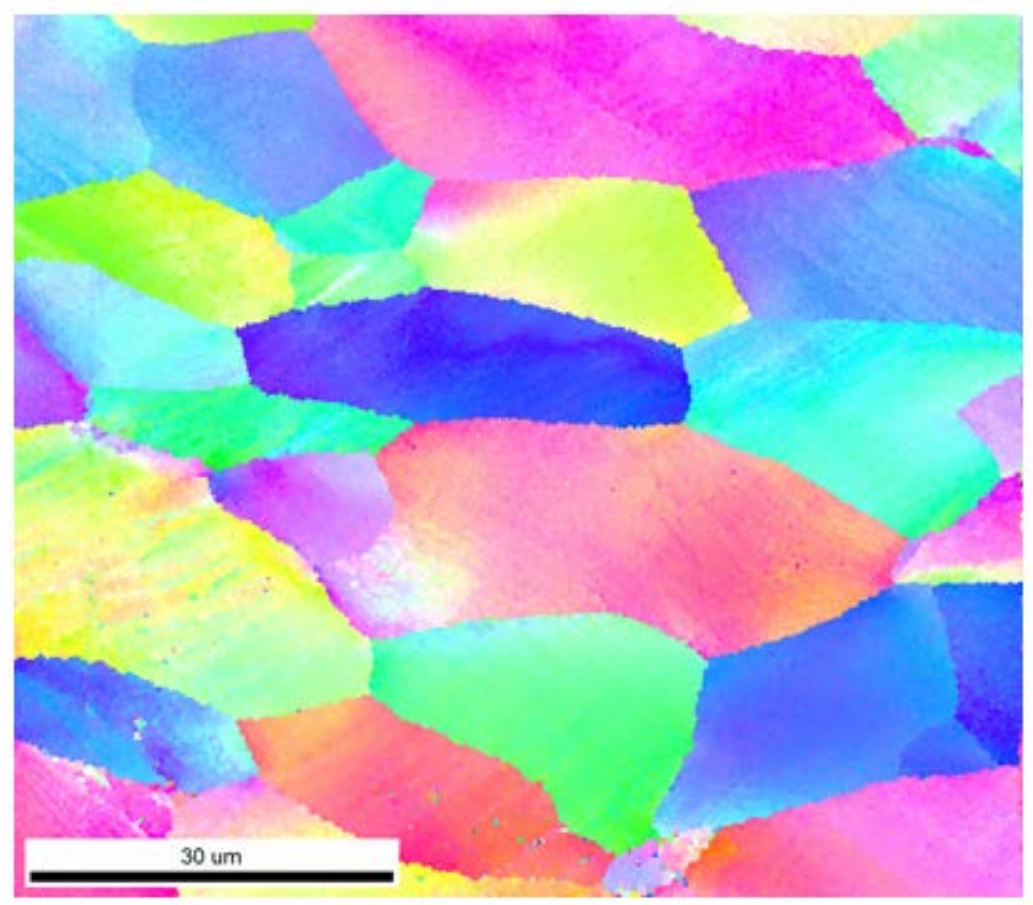

Iron - Alpha

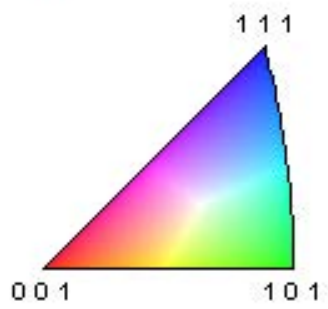

Figura 64: Mapa de EBSD/OIM para uma amostra de aço laminada a frio com deformação real 0,29.

O mapa de misorientações da Figura 65 realça as diferenças de orientação no interior dos grãos. Torna-se mais nítido que regiões próximas a contornos de grão apresentam maior misorientação. Isto denota a característica heterogênea da deformação. As linhas paralelas aparecem de maneira mais intensa. São vistas em todos os grãos destacados na imagem, porém, separam regiões onde a misorientação entre elas é pequena (inferior a $10^{\circ}$ ). Ainda assim caracterizam a presença de uma estrutura de deformação organizada e periódica ao longo de todo o grão. 


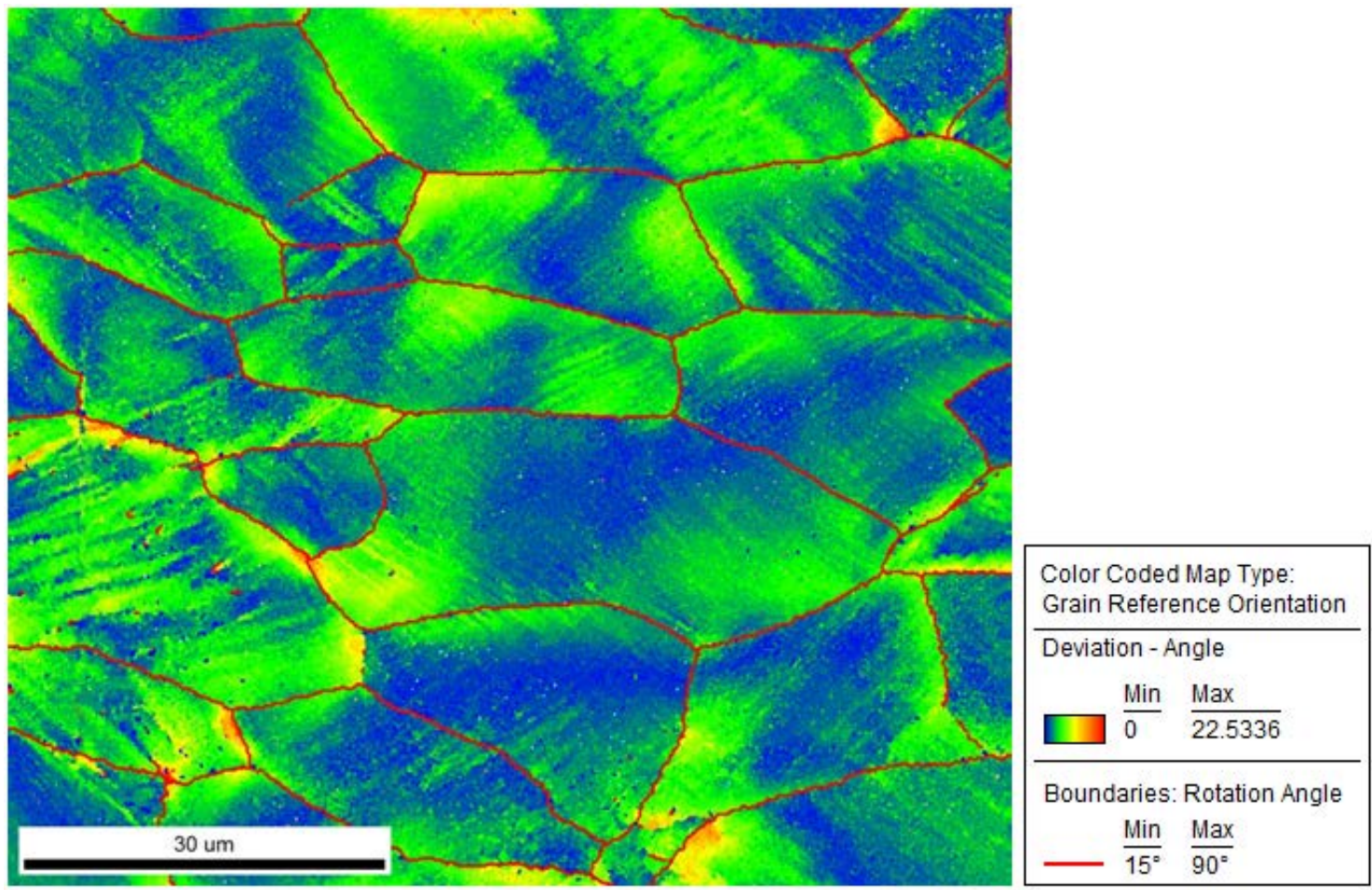

Figura 65: Micrografia indicando a variação dos ângulos de misorientação na microestrutura de uma amostra com 29\% de deformação real.

Visando-se observar as alterações que o tratamento térmico de recuperação provocaria sobre uma estrutura deformada, foi executado sobre uma amostra de deformação 0,29 um recozimento a $500^{\circ} \mathrm{C}$ durantente uma hora. Este procedimento foi realizado em atmosfera inerte de $\mathrm{N}_{2}$. O mapa de orientações é descrito na Figura 66. Nota-se que mesmo após o tratamento térmico algumas características da estrutura de deformação persistem. Os grãos permanecem alongados. Observa-se também que ainda ocorrem variações de orientação no interior dos grãos. Isso evidencia a existência de uma estrutura que permanece fragmentada pela deformação. 


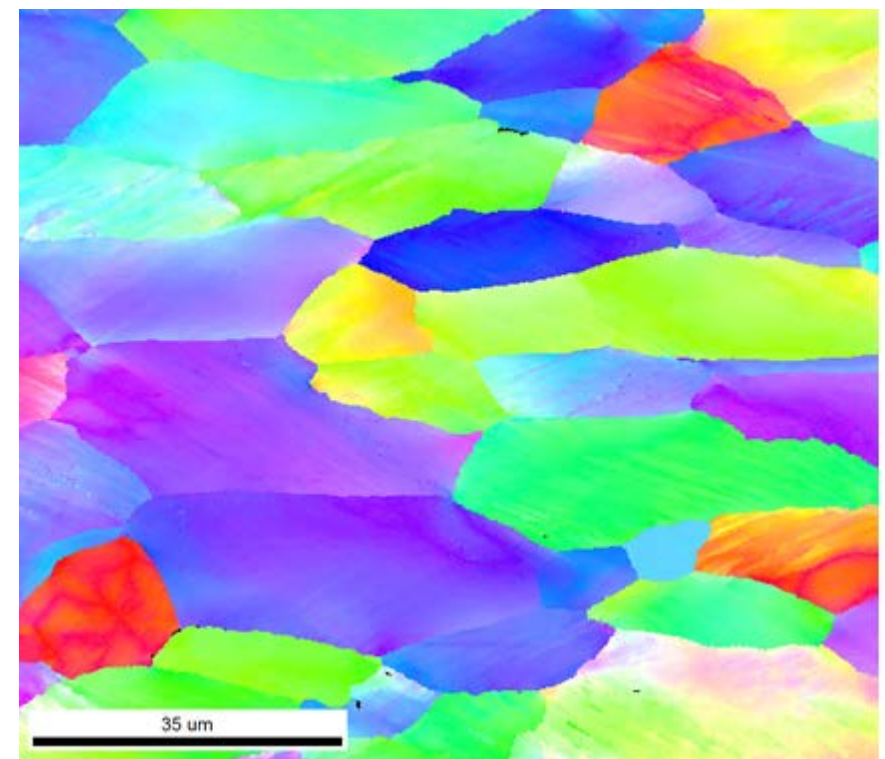

Color Coded Map Type: Inverse Pole Figure [001] Iron (Alpha)

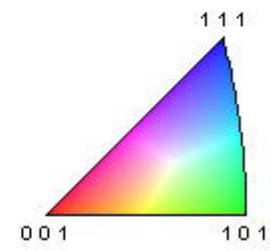

Figura 66: Mapa de orientações obtidas por EBSD em uma amostra com deformação 0,29 recozida a $500^{\circ} \mathrm{C}$ durante uma hora.

\subsubsection{Análise de ruídos de Barkhausen}

A Figura 67 mostra os resultados dos ensaios de medição de ruídos Barkhausen descritos pela envolvente do valor médio quadrático dos pulsos de Barkhausen. Para as medições, o campo magnético aplicado partiu de um valor máximo diminuindo para um valor mínimo. Os pulsos de Barkhausen estão distribuídos ao longo de uma faixa entre $+2500 \mathrm{~A} / \mathrm{m}$ e $-5000 \mathrm{~A} / \mathrm{m}$. O campo coercivo observado para essas amostras (mesmo para o maior grau de deformação em indução máxima de 1,6 T) não supera o valor de 450 A/m. Dessa maneira, a largura da curva descrita na Figura 67 se estende para além da movimentação de paredes de domínio de $180^{\circ}$ (que se espera ocorrer próximo do campo coercivo) para incluir a eliminação dos domínios de fechamento de $90^{\circ}$. A amostra como recebida apresenta dois picos de atividade Barkhausen enquanto as deformadas apresentaram único pico cuja amplitude aumenta com a deformação. 


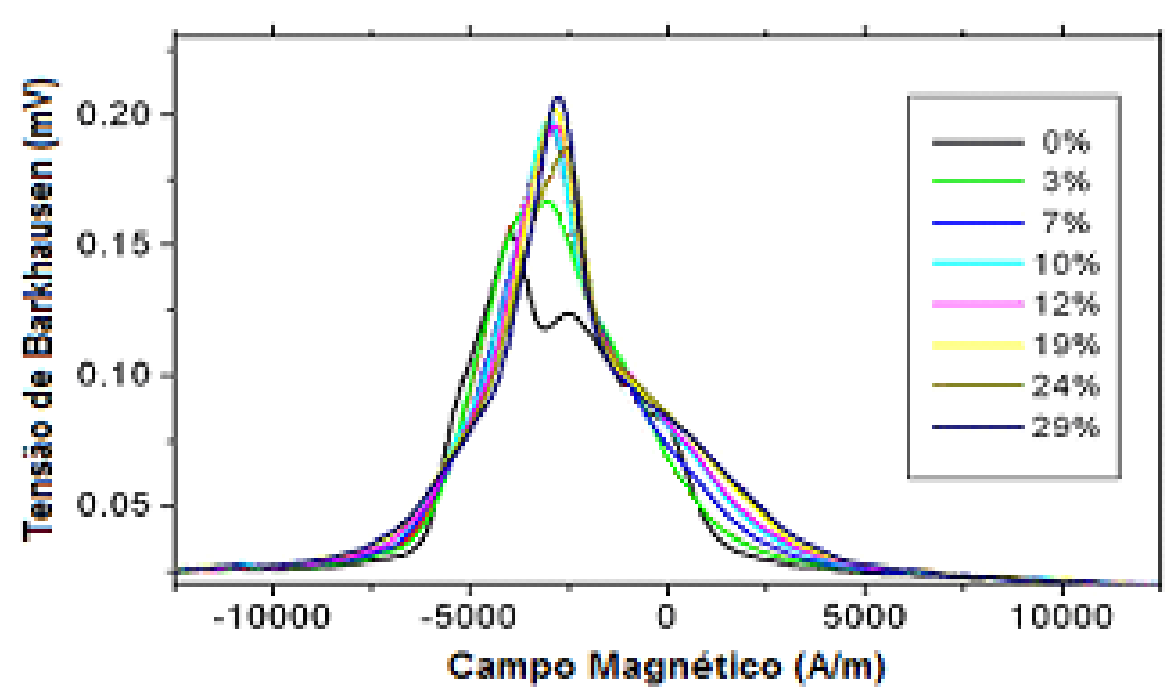

Figura 67: Tensão de Barkhausen em função do campo magnético para amostras com diferentes quantidades de deformação.

Um artigo recente [69] também relata uma estrutura de dois picos para amostra não deformada. Essa estrutura inicial teve sua forma modificada após pequenas deformações no sentido de se formar uma curva com um único pico para as deformações mais elevadas. Esse trabalho mencionou que microtensões poderiam exercer influência neste comportamento. Outros artigos [70] e [71] discutiram a presença da estrutura de dois picos em termos de dois mecanismos microestruturais: a nucleação e aniquilação de paredes de domínios de $90^{\circ}$ no contorno de grão e o salto das paredes de domínios de $180^{\circ}$ ancoradas por partículas de segunda fase.

Piotrowski [72] observou que uma pequena deformação (2 \%) provocou grande alteração no formato da envolvente em amostras de ferro Armco, conforme mostra a Figura 68. O autor citou que para as amostras livres de deformação os picos de atividade de Barkhausen se devem à nucleação/aniquilação de domínios e ocorrem em maiores campos. No entanto, afirma que a deformação eleva a quantidade de sítios de ancoramento à 
movimentação de paredes de domínio. Afirma ainda que isso se deve à criação de emaranhados de discordâncias. Isso explica o crescimento da atividade próxima ao campo coercivo. Dessa, forma o mecanismo principal a justificar o aumento de atividade é o movimento abrupto de paredes que se libertam de seus pontos de aprisionamento.

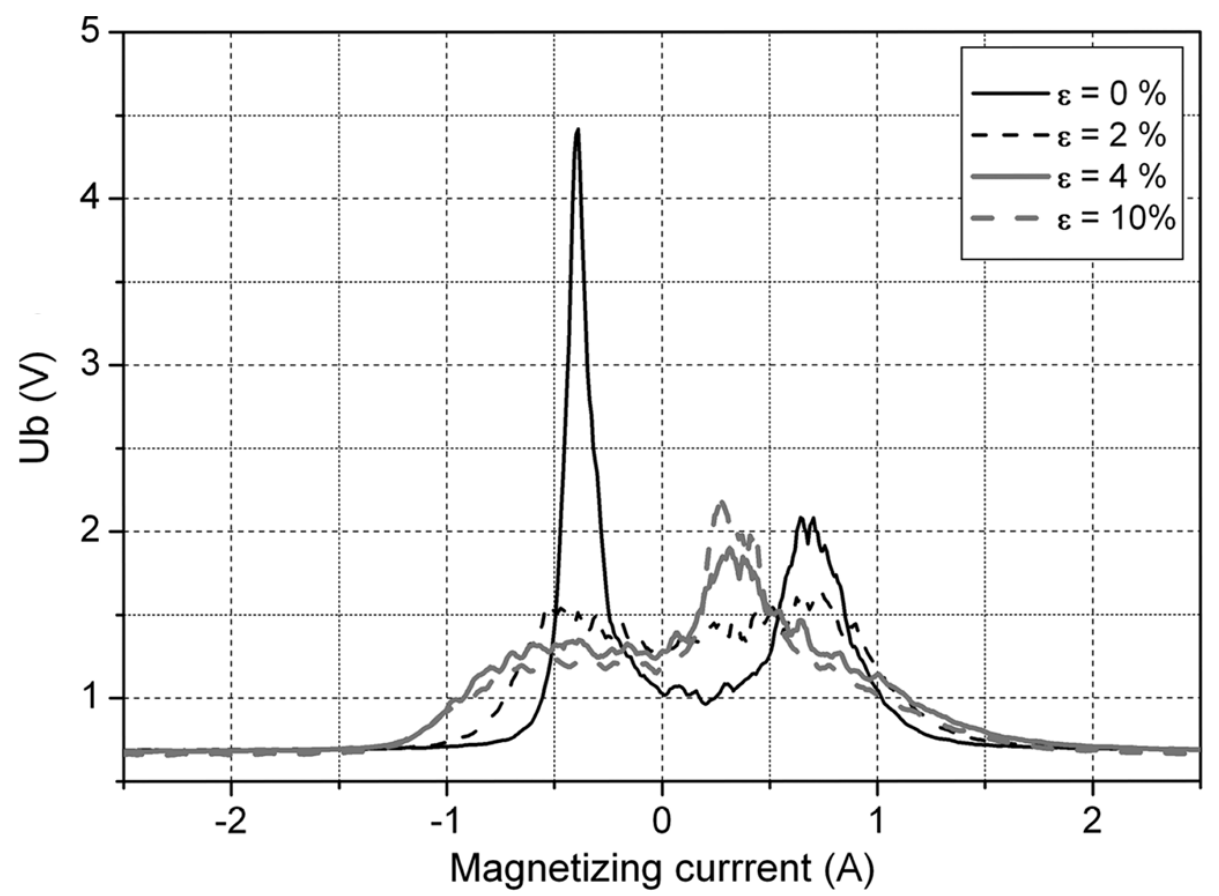

Figura 68: Envolventes do sinal de Barkhausen para amostras de ferro Armco submetidas a diferentes níveis de deformação a frio [72].

A importância desses dois mecanismos foi discutida por Sakamoto et al. [73]. A ação das paredes de $90^{\circ}$ no contorno de grão conduziria a uma contribuição no ruído de Barkhausen dependente do tamanho de grão e que pode levar a um aumento em $V_{\mathrm{RMS}}$. No entanto, não esperamos que modificações no tamanho de grão tenham efeito significante.

Outra característica da ação do processo de deformação é exibida na Figura 68 onde é mostrada a área integrada sob as curvas da tensão de Barkhausen da Figura 67 em função da deformação plástica. Há rápido 
aumento na área do pico de Barkhausen, conforme maior número de discordâncias são geradas para as menores deformações, seguido por saturação (assim que a substrutura de células começa a se formar). Esse comportamento é similar ao indicado pelos picos de difração da Figura 34 assim como o observado para um aço baixo carbono laminado a frio.

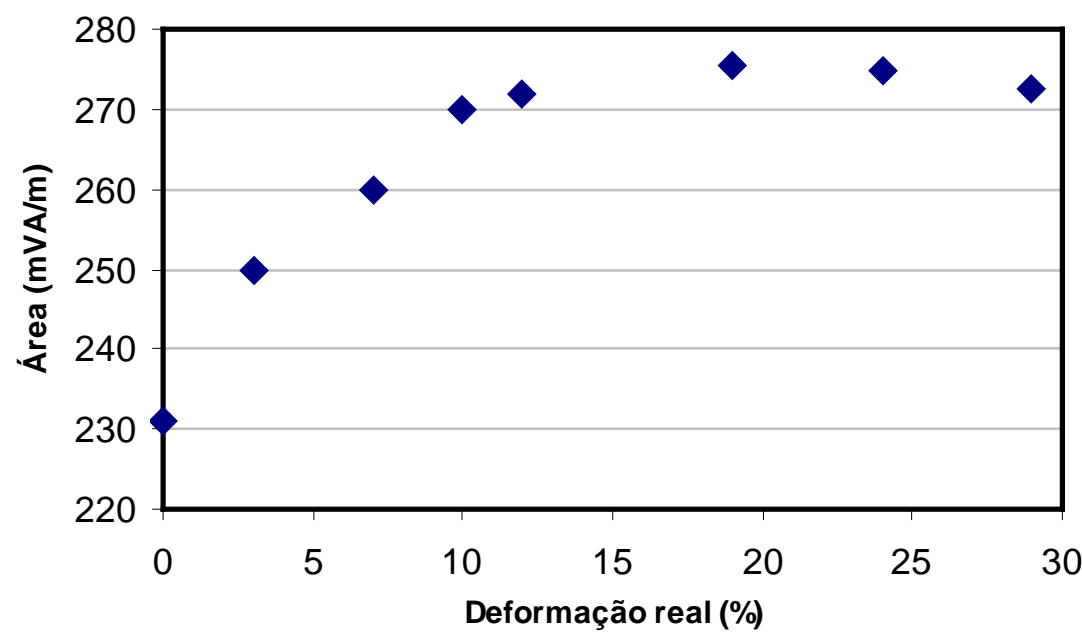

Figura 69: Área integrada dos picos de Barkhausen em função da deformação real.

O aumento nas áreas de Barkhausen se torna mais pronunciado se esses dados são corrigidos pela diminuição da espessura das amostras. Nota-se a partir da Figura 69 que a razão entre essas duas grandezas é sempre crescente com a deformação real não havendo saturação. Uma hipótese para essa relação reside no modo como as medições do ruído de Barkhausen são executadas. $\mathrm{O}$ fato de a bobina sensora envolver todo o corpo de prova torna a espessura do mesmo uma variável determinante do volume de material que está sob ensaio. 


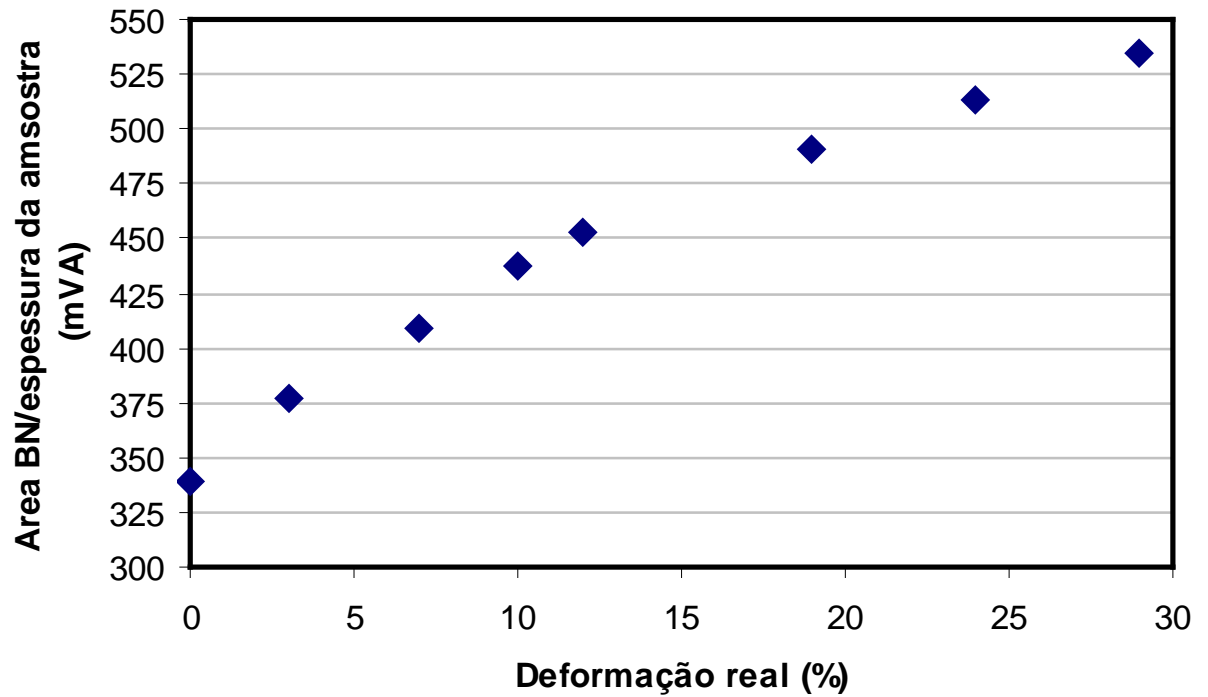

Figura 70: Gráfico mostrando a razão entre área integrada dos picos de Barkhausen e a espessura das amostras em função da deformação real. 


\section{Conclusões}

Este trabalho trata da ação da deformação sobre as propriedades magnéticas. Os resultados obtidos mostram forte degradação das propriedades magnéticas mesmo para o menor valor de deformação plástica.

Foi possível calcular a densidade de discordâncias em material laminado a frio através do ensaio de difração de raios $X$. Tal procedimento se deu através da análise da largura à meia altura dos picos de difração. Os resultados descreveram maior taxa de aumento da densidade de discordâncias para pequenas deformações e a partir de $12 \%$ de deformação real o incremento foi mínimo.

Os dados extraídos apontam para o fenômeno de fragmentação do grão como o principal fator a explicar a queda de rendimento energético do material quando submetido a ensaio em regime quase estático. O fato de duas grandezas, campo coercivo e energia dissipada em região de baixa indução, apresentarem crescimento linear com a raiz da densidade de discordância correlaciona as propriedades magnéticas com as estruturas de deformação.

A caracterização magnética conduzida em frequências mais elevadas trouxe à baila uma discussão sobre a estrutura de domínios magnéticos no material deformado. O procedimento de separação de perdas comprovou que a piora do desempenho se dá em função da parcela histerética. A parcela de excesso surpreendeu e foi a valores desprezíveis e pouco variou com a frequência nas amostras laminadas. Tal fato indica refino da estrutura de domínios provocado pela estrutura deformada. 
Os resultados dos ensaios de ruídos de Barkhausen indicam efeito da espessura sobre essa propriedade e efeito da deformação sobre os picos do espectro. Aparentemente a deformação promove o aumento da atividade de Barkhausen para campos próximos do campo coercivo indicando maior ação da densidade de discordâncias. 


\section{Referências}

[1] Disponível em: http://www.ogakiseiko.co.jp/e/products/03.html. Data de acesso 08 de dezembro de 2012.

[2] A.I.N. Press, Challenges in optimizing the magnetic properties of bulk soft magnetic materials, Journal of Magnetism and Magnetic Materials. 320 (2008) 2411-2422.

[3] M.C.A. Silva, Avaliaçao da textura e da microestrutura de deformação de um aços elétrico GNO com $1,25 \%$ de Si laminado a frio, Tese para a obteção do título de Doutor em Engenharia, 2007.

[4] W.E. Leithead, Wind energy., Philosophical Transactions. Series A, Mathematical, Physical, and Engineering Sciences. 365 (2007) 957-70.

[5] P. Waide, C.U. Brunner, Energy-Efficiency Policy Opportunities for Electric Motor-Driven Systems, Disponível em: http://www.iea.org/papers/2011/EE_for_ElectricSystems.pdf. Data de acesso: 08 de dezembro de 2012

[6] S. dos R. Melquíades, O efeito do carbono no aumento do tamanho de grão e nas propriedades magnéticas de aços elétricos semiprocessados após recozimento final, Tese de doutorado, 2006.

[7] A.J. Moses, Energy efficient electrical steels: Magnetic performance prediction and optimization, Scripta Materialia. 67 (2012) 560-565..

[8] F. Bohn, A. Gündel, A.M. Severino, F.J.G. Landgraf, R.L. Sommer, Propriedades magnéticas de aços elétricos de grão não-orientado, in: XVI Congresso Brasileiro de Engenharia E Ciência Dos Materiais, Porto Alegre - RS, 2004.

[9] J.J. Thomson, On the heat produced by eddy currents in an iron plate exposed to alternating magnetic field, The Electrician. 28 (1892).

[10] Disponível em:

http://efisica.if.usp.br/eletricidade/basico/inducao/correntes_foucault/. Data de acesso: 08 de dezembro de 2012.

[11] F.J.G. Landgraf, Nonoriented Electrical Steels, Jom. 64 (2012) 764-771.

[12] S.E. Zirka, Y.I. Moroz, P. Marketos, A.J. Moses, Loss Separation in Nonoriented Electrical Steels, IEEE Transactions on Magnetics. 46 (2010) 286-289.

[13] S.E. Zirka, Y.I. Moroz, P. Marketos, A.J. Moses, Evolution of the loss components in ferromagnetic laminations with induction level and 
frequency, Journal of Magnetism and Magnetic Materials. 320 (2008) e1039-e1043.

[14] J. Shilling, G.H. Jr, Magnetic properties and domain structure in grainoriented 3\% Si-Fe, IEEE Transactions on Magnetics. MAG-10 (1974) 195-223.

[15] S. Defoug, R. Kaczmarek, Measurements of local magnetization by Kerr effect on Si-Fe nonoriented sheets, Journal of Applied Physics. 79 (1996) $6036-6038$.

[16] Disponível em: http://www.doitpoms.ac.uk/tlplib/ferromagnetic/printall.php Data de acesso 08 de janeiro de 2013.

[17] A. Pulnikov, Modification of Magnetic Properties of Non Oriented Electrical Steels by the Production of Electromagnetic Devices, Tese de doutorado, 2004.

[18] D. Jiles, Introduction to magnetism and magnetic materials, Chapman \& Hall, 1991.

[19] P. Baudouin, Effect of laser and mechanical cutting on the magnetic properties of non-oriented electrical steels, Tese para a obtenção do título de Doutor, 2002.

[20] M. Takezawa, J. Yamasaki, T. Honda, C. Kaido, Domain structure of chemically thinned non-oriented electrical sheet, Journal of Magnetism and Magnetic Materials. 254-255 (2003) 167-169.

[21] M. Takezawa, K. Kitajima, Y. Morimoto, C. Kaido, Effect of Strain by Mechanical Punching on Nonoriented Si-Fe Electrical Sheets for a NineSlot Motor Core, IEEE Transactions on Magnetics. 42 (2006) 2790-2792.

[22] M.G. Lloyd, Magnetic hysteresis, The Journal of the Franklin Intitute. CLXX (1910) 1-25.

[23] J. Barros, J. Schneider, K. Verbeken, Y. Houbaert, On the correlation between microstructure and magnetic losses in electrical steel, Journal of Magnetism and Magnetic Materials. 320 (2008) 2490-2493.

[24] L. Dijkstra, C. Wert, Effect of inclusions on coercive force of iron, Physical Review. 79 (1950) 979-985.

[25] J. Makar, B. Tanner, The effect of plastic deformation and residual stress on the permeability and magnetostriction of steels, Journal of Magnetism and Magnetic Materials. 222 (2000) 291-304.

[26] F.J.G. Landgraf, M.F. de Campos, J. Leicht, Hysteresis loss subdivision, Journal of Magnetism and Magnetic Materials. 320 (2008) 2494-2498. 
[27] Z. Akase, Y.-G. Park, D. Shindo, T. Tomida, H. Yashiki, S. Hinotani, Magnetic Domain Structures in Electrical Steel Sheets Studied by Lorentz Microscopy and Electron Holography, Materials Transactions. 46 (2005) 974-977.

[28] F.J.G. Landgraf, M. Emura, M.F. de Campos, On the Steinmetz hysteresis law, Journal of Magnetism and Magnetic Materials. 320 (2008) e531-e534.

[29] M. Emura, F.J.G. Landgraf, Efeito da induçao máxima nas perdas magnéticas de aço 3\% Si. $57^{\circ}$ Congresso Anual Da ABM, 2002: pp. 932-945.

[30] D.L. Rodrigues-jr, F.J.G. Landgraf, S.A. Romero, Efeito da indução máxima sobre a energia dissipada por histerese em aços elétricos de grão não orientado. 69 Congresso anual da ABM, 2014 São Paulo.

[31] S. Foner, Versatile and Sensitive Vibrating-Sample Magnetometer, The Review of Scientific Instruments. 30 (1959) 548-557.

[32] C.S. Barret, L.H. Levenson, Structure of iron after compression, AIME. 135 (1939) 296-326.

[33] H.J. Kestenbach, Estudo de textura no microscópio eletrônico de transmissão, in: II Workshop Sobre Textura E Relações de Orientação, São Paulo, 2003.

[34] N. Hansen, Cold deformation microstructures, Materials Science and Technology. 6 (1990) 1039-1047.

[35] L. Delannay, Observation and modelling of grain interactions and grain subdivision in rolled cubic polycrystal, Tese de doutorado, 2001.

[36] R.D. Doherty, D. a. Hughes, F.J. Humphreys, J.J. Jonas, D.J. Jensen, M.E. Kassner, et al., Current issues in recrystallization: a review, Materials Science and Engineering: A. 238 (1997) 219-274.

[37] D. Kuhlmann-Wilsdorf, "Regular" deformation bands (DBs) and the LEDS hypothesis, Acta Materialia. 47 (1999) 1697-1712..

[38] F. Landgraf, M. Emura, K. Ito, P. Carvalho, Effect of plastic deformation on the magnetic properties of non-oriented electrical steels, Journal of Magnetism and Magnetic Materials. 216 (2000) 94-96.

[39] A.S. Keh, S. Weismann, Deformation substructure in body-centered cubic metals, in: G. Thomas, W. Jack (Eds.), Electron Microscopy and Strength of Crystals, Interscience Publishers, London, 1963: pp. 231299. 
[40] Y. Tomota, P. Lukas, S. Harjo, J.-H. Park, N. Tsuchida, D. Neov, In situ neutron diffraction study of IF and ultra low carbon steels upon tensile deformation, Acta Materialia. 51 (2003) 819-830.

[41] W.G. Johnston, J.J. Gilman, Dislocation Velocities, Dislocation Densities, and Plastic Flow in Lithium Fluoride Crystals, Journal of Applied Physics. 30 (1959) 129-144. doi:10.1063/1.1735121.

[42] M.F. de Campos, M.J. Sablik, F.J.G. Landgraf, T.K. Hirsch, R. Machado, R. Magnabosco, et al., Effect of rolling on the residual stresses and magnetic properties of a $0.5 \%$ Si electrical steel, Journal of Magnetism and Magnetic Materials. 320 (2008) e377-e380.

[43] H. Kronmüller, Magnetic techniques for the study of dislocations in ferromagnetic materials, International Journal of Nondestructive Testing. 3 (1972) 315-350.

[44] F.J.G. Landgraf, M. Emura, Losses and permeability improvement by stress relieving fully processed electrical steels with previous small deformations, Journal of Magnetism and Magnetic Materials. 242-245 (2002) 152-156.

[45] M. LoBue, C. Sasso, V. Basso, F. Fiorillo, G. Bertotti, Power losses and magnetization process in Fe-Si non-oriented steels under tensile and compressive stress, Journal of Magnetism and Magnetic Materials. 215216 (2000) 124-126.

[46] M. Emura, F.J.. Landgraf, W. Ross, J.. Barreta, The influence of cutting technique on the magnetic properties of electrical steels, Journal of Magnetism and Magnetic Materials. 254-255 (2003) 358-360.

[47] Disponível em: http://www.custompartnet.com/wu/sheet-metal-shearing Data de acesso 15 de novembro de 2012.

[48] H. Yashiki, T. Kaneko, Effect of alloying elements on response of non oriented electrical steels to stamping operations, Journal of Materials Engineering and Performance. 1 (1992) 29-34.

[49] F.J.G. Landgraf, Processo de tratamento térmico com recuperação magnética na fabricação de aço de grão não orientado, totalmente processado, para uso em máquinas elétricas, PI 9802711-5, 2006.

[50] R.W. Cahn, P. Haasen, Physical Metallurgy (Vol. 3), Fourth Edi, NORTHHOLLAND, Amsterdam, 1996.

[51] F.J. Humphreys, M. Hatherly, Recrystallization and related annealing phenomena, Pergamon, Oxford, 1996. 
[52] J. Kwiecinski, J.W. Wyrzykowski, The effect of recovery annealing after small plastic deformations on the yield strength of polycrystalline aluminium, Acta Metallurgica et Materialia. 41 (1993) 3089-3095.

[53] A. Martínez-de-Guerenu, K. Gurruchaga, F. Arizti, Nondestructive characterization of recovery and recrystallization in cold rolled low carbon steel by magnetic hysteresis loops, Journal of Magnetism and Magnetic Materials. 316 (2007) e842-e845.

[54] D. Rodrigues-Jr, T.S.P. Nishkawa, A.A. Almeida, F.J.G. Landgraf, R. V. Martin, The Effect of Recovery Annealing on the Magnetic and Mechanical Properties of Nonoriented Electrical Steels, IEEE Transactions on Magnetics. 50 (2014) 1-4.

[55] G.R. Stibitz, Energy and. Lattice Spacing in Strained Solids, Physical Review. 49 (1936) 862-863.

[56] M.F. de Campos, R. Machado, T.K. Hirsch, Tensões residuais em aços avaliadas por difração de raios-X: diferença entre micro e macro tensões residuais, in: III Workshop de Textura, São Paulo, 2006.

[57] A. Borbély, J. Driver, T. Ungár, An X-ray method for the determination of stored energies in texture components of deformed metals; application to cold worked ultra high purity iron, Acta Materialia. 48 (2000) 2005-2016.

[58] A. Moses, N. Derebasi, G. Loisos, A. Schoppa, Aspects of the cut-edge effect stress on the power loss and flux density distribution in electrical steel sheets, Journal of Magnetism and Magnetic Materials 216 (2000) 690-692.

[59] D.A. Hughes, N. Hansen, Plastic deformation structure, in: ASM Handbook Volume 9 - Metallography and Microstructures, ASM International, 2004: pp. 191-214.

[60] E. Hug, O. Hubert, M. Clavel, Some aspects of the magnetomechanical coupling in the strengthening of nonoriented and grain-oriented 3\% SiFe alloys, IEEE Transactions on Magnetics. 33 (1997) 763-771.

[61] M. Fukuhara, T. Yonamine, F.J.G. Landgraf, F.P. Missell, Evolution of magnetic properties and crystallographic texture in electrical steel with large plastic deformation, Journal of Applied Physics. 109 (2011) A325A325-3.

[62] C. Hou, S. Lee, Effect of rolling strain on the loss separation and permeability of lamination steels, IEEE Transactions on Magnetics. 30 (1994) 212-216.

[63] S. Thompson, B. Tanner, The magnetic properties of specially prepared pearlitic steels of varying carbon content as a function of plastic 
deformation, Journal of Magnetism and Magnetic Materials. 132 (1994) 71-88.

[64] B.. Cullity, Introduction to magnetic material, 1 sd, Addson-Wesley, New York, 1972.

[65] M. Fukuhara, Subdivisão das perdas histereticas em aços elétricos deformados e recozidos, Universidade Federal do Rio de Janeiro, 2010.

[66] M.F. de Campos, J.C. Teixeira, F.J.G. Landgraf, The optimum grain size for minimizing energy losses in iron, Journal of Magnetism and Magnetic Materials. 301 (2006) 94-99.

[67] L.J. Swartzendruber, G.E. Hicho, H.D. Chopra, S.D. Leigh, Effect of plastic strain on magnetic and mechanical properties of ultralow carbon sheet steel, Journal of Applied Physics. 81 (1997) 4263-4265.

[68] D.L. Rodrigues-Jr, J.R.F. Silveira, F.J.G. Landgraf, E. Politécnica, U.D.S. Paulo, S. Paulo, Combining Mager and Steinmetz: The Effect of Grain Size and Maximum Induction on Hysteresis Energy Loss, IEEE Transactions on Magnetics. 47 (2011) 2179-2183.

[69] R. Baiotto, G. Gerhardt, M. Fukuhara, T. Yonamine, F.P. Missell, Barkhausen Noise and Magnetic Properties of Plastically Deformed Silicon Steels, IEEE Transactions on Magnetics. 46 (2010) 294-297.

[70] X. Kleber, A. Vincent, On the role of residual internal stresses and dislocations on Barkhausen noise in plastically deformed steel, NDT \& E International. 37 (2004) 439-445.

[71] J. Pérez-Benitez, J. Capó-Sánchez, J. Anglada-Rivera, L.R. Padovese, A model for the influence of microstructural defects on magnetic Barkhausen noise in plain steels, Journal of Magnetism and Magnetic Materials. 288 (2005) 433-442.

[72] L. Piotrowski, B. Augustyniak, M. Chmielewski, E. V. Hristoforou, K. Kosmas, Evaluation of Barkhausen Noise and Magnetoacoustic Emission Signals Properties for Plastically Deformed Armco Iron, IEEE Transactions on Magnetics. 46 (2010) 239-242.

[73] H. Sakamoto, M. Okada, M. Homma, Theoretical analysis of Barkhausen noise in carbon steels, Magnetics, IEEE Transactions on. 23 (1987) 2236-2238. 


\section{Apêndice}

São mostrados nessa seção os dados extraídos a partir dos ensaios de difração de raios-X.

\subsection{Apêndice 1: Resultados obtidos por difração de raios-X}

\section{Amostra sem laminação}

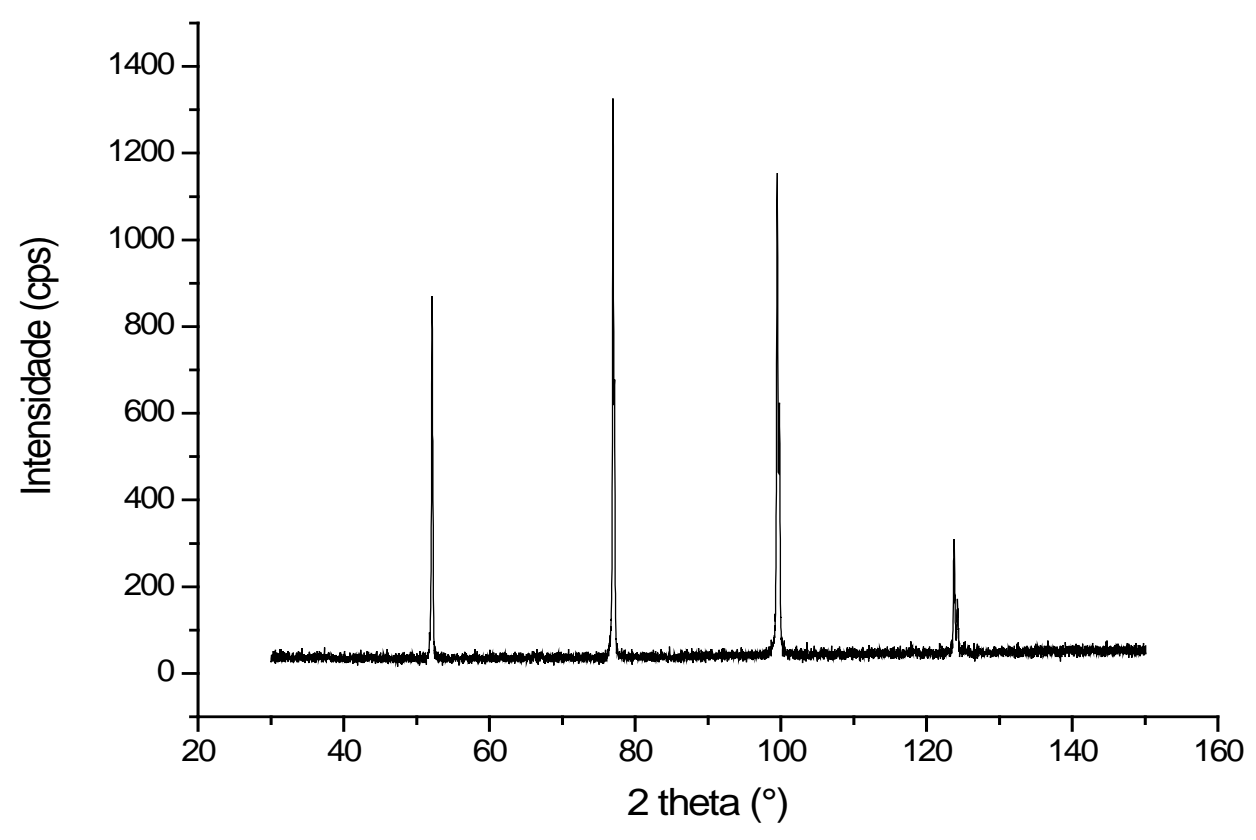


Amostra com 0,03 de deformação real

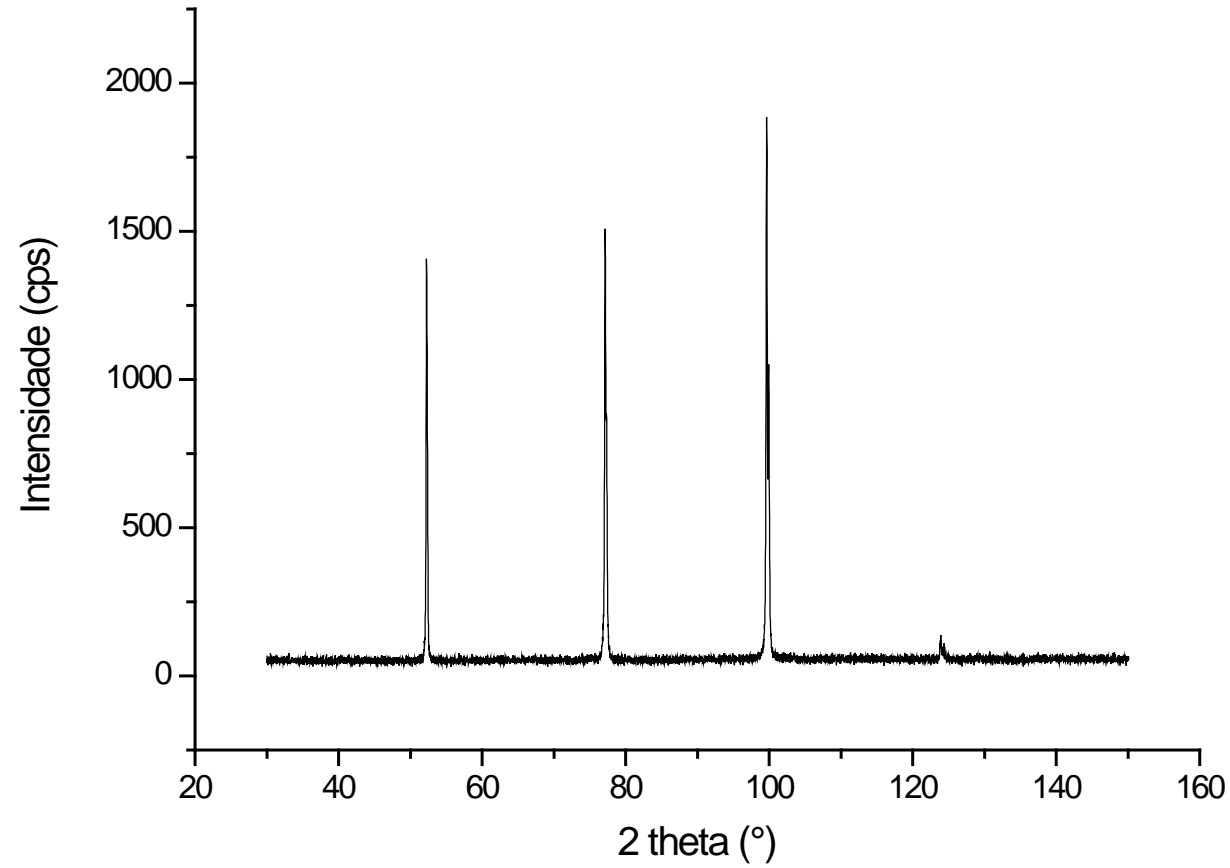

Amostra com 0,07 de deformação real

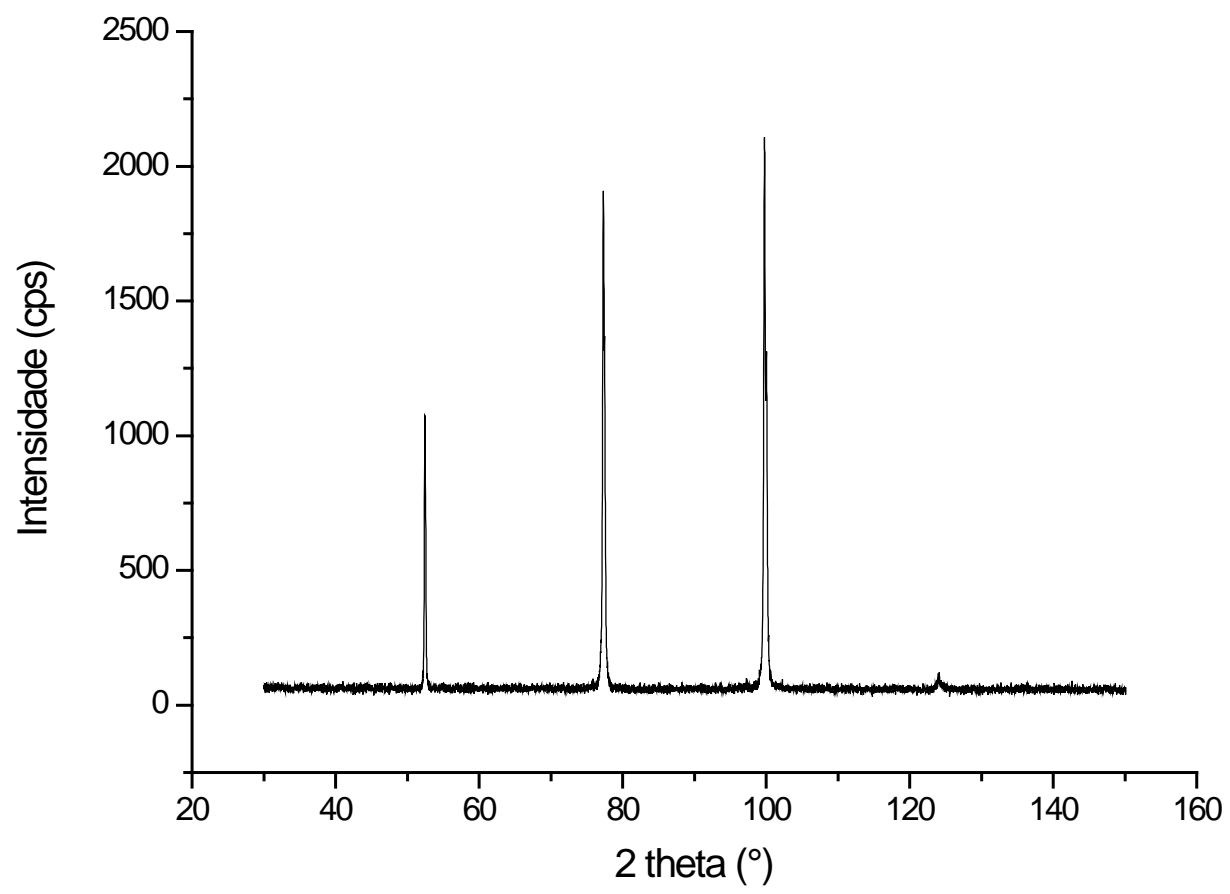


Amostra com 0,10 de deformação real

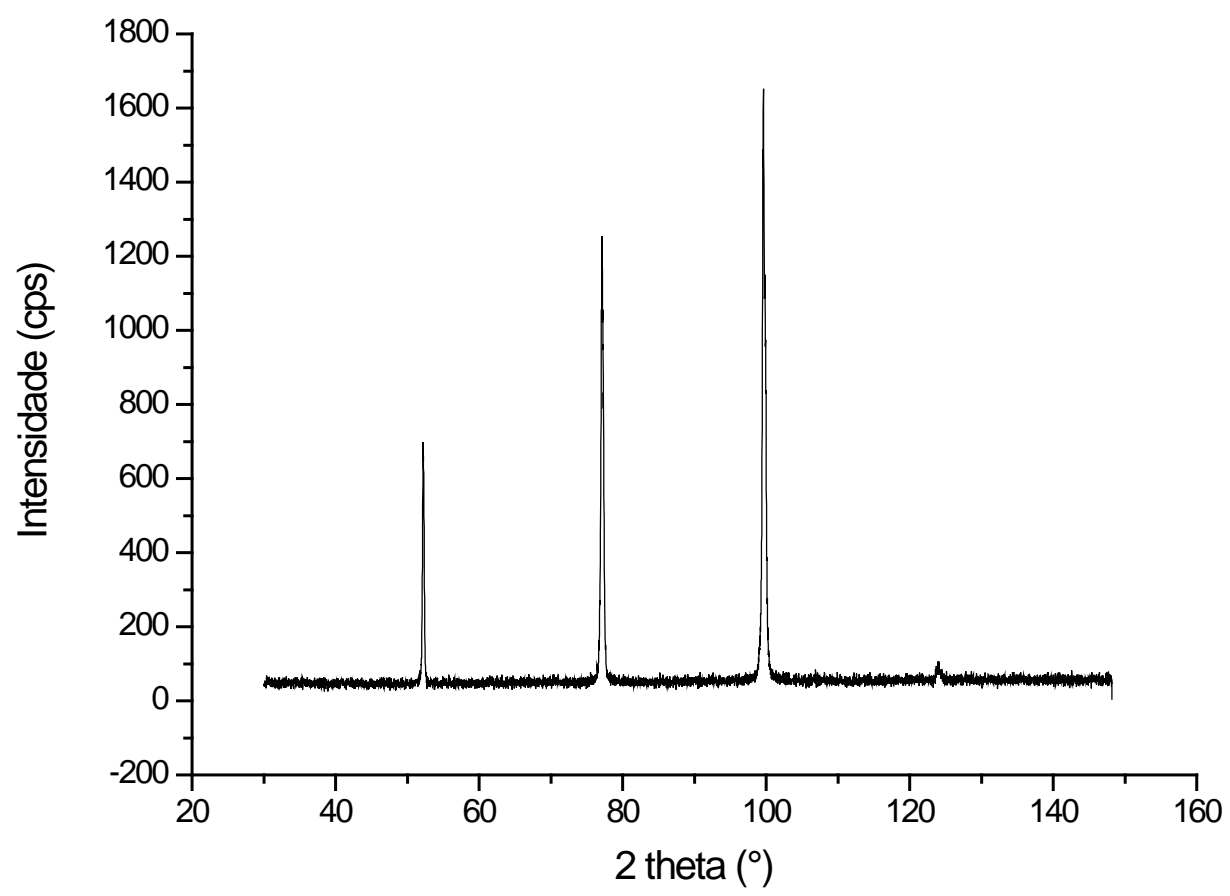

Amostra com 0,12 de deformação real

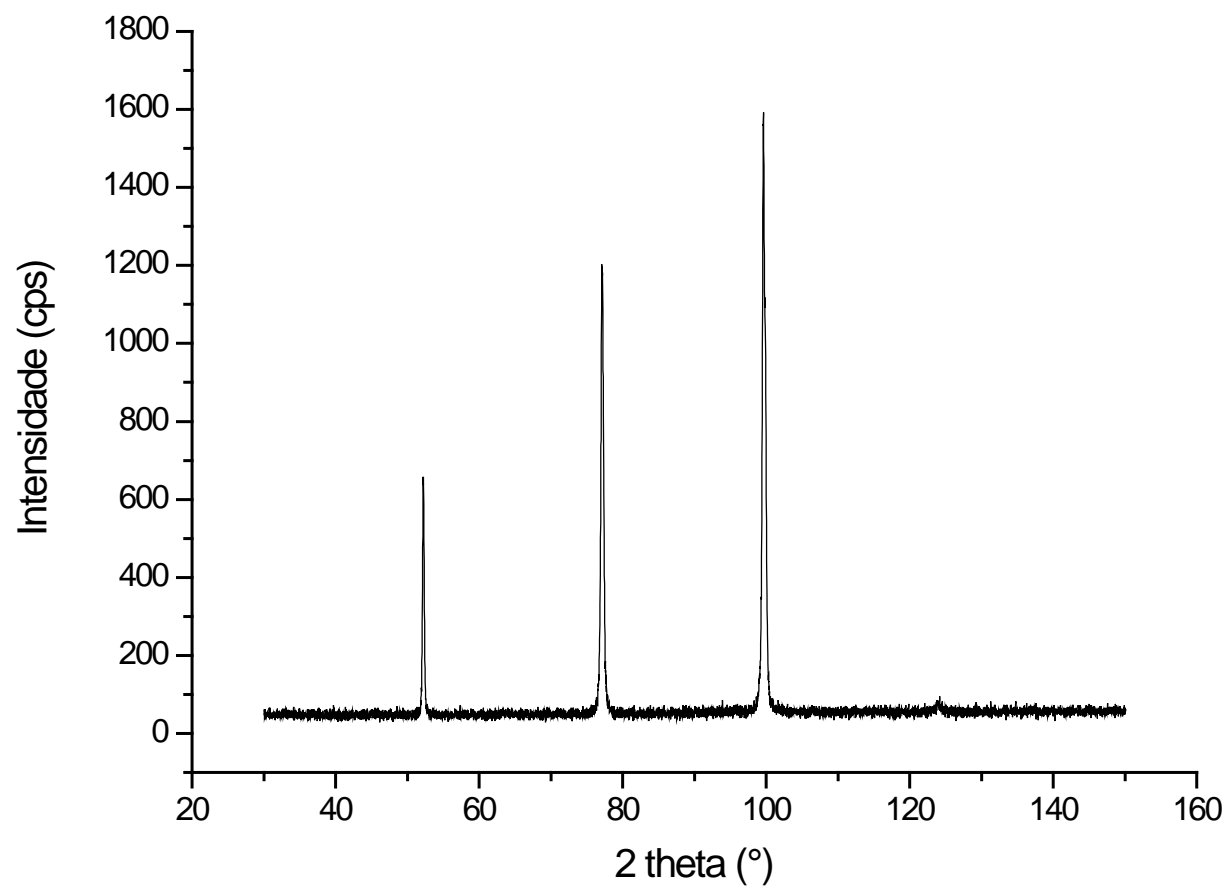


Amostra com 0,19 de deformação real

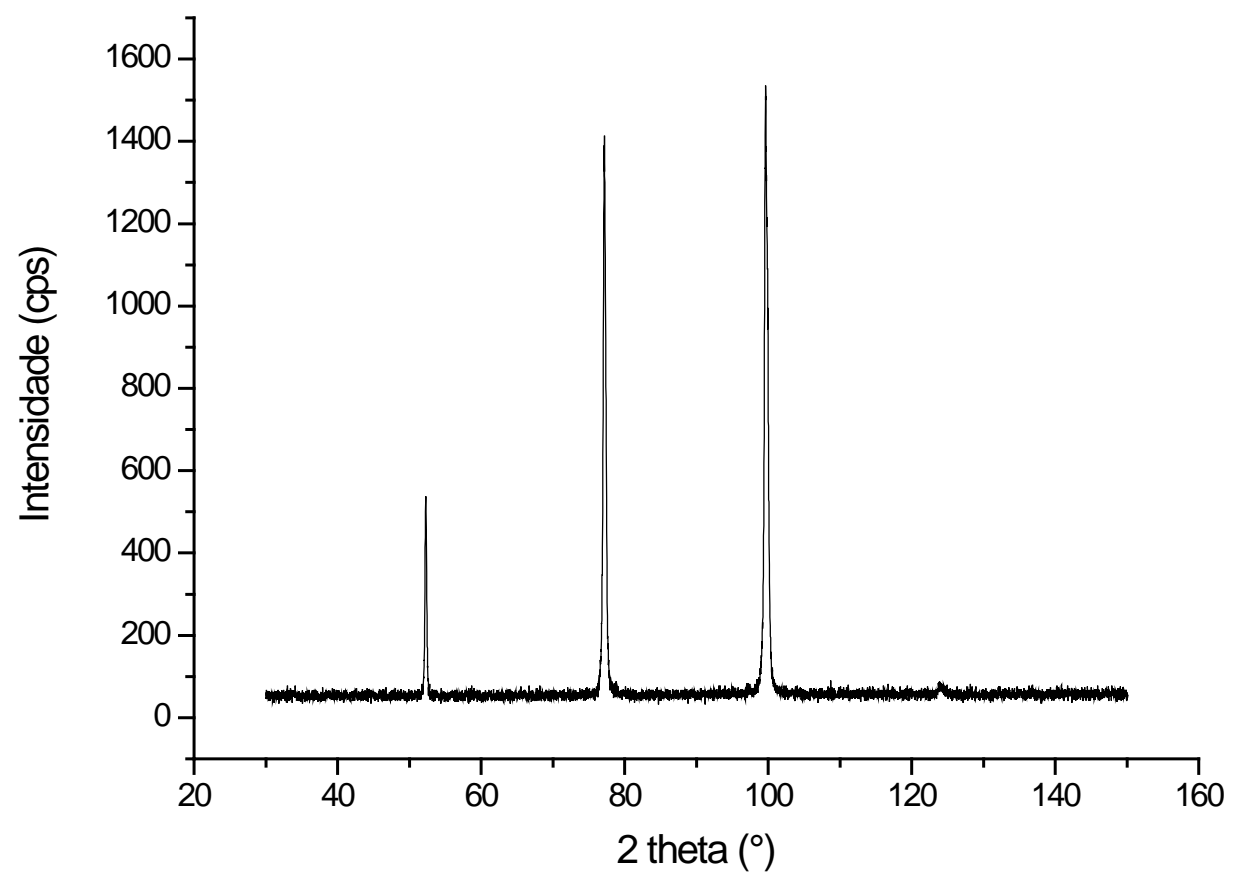

Amostra com 0,24 de deformação real

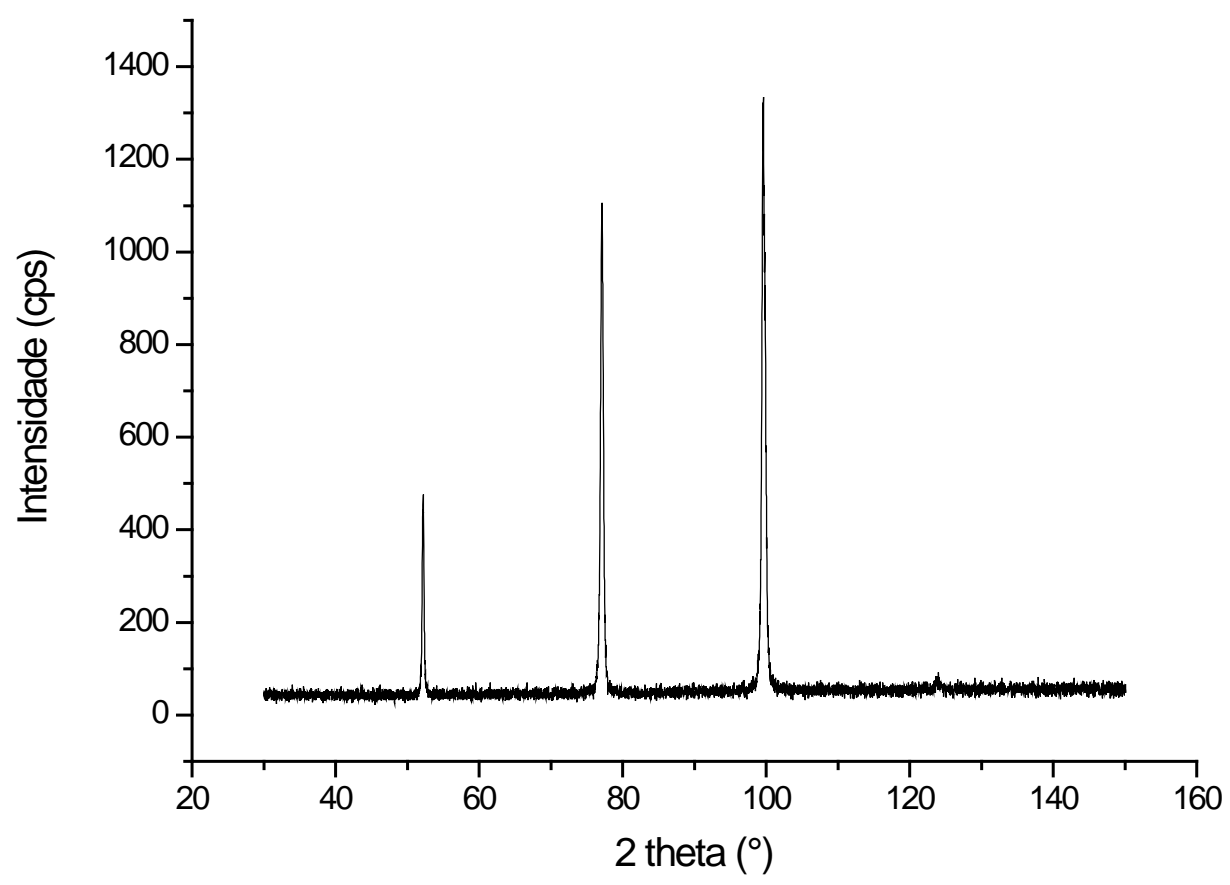


Amostra com 0,29 de deformação real

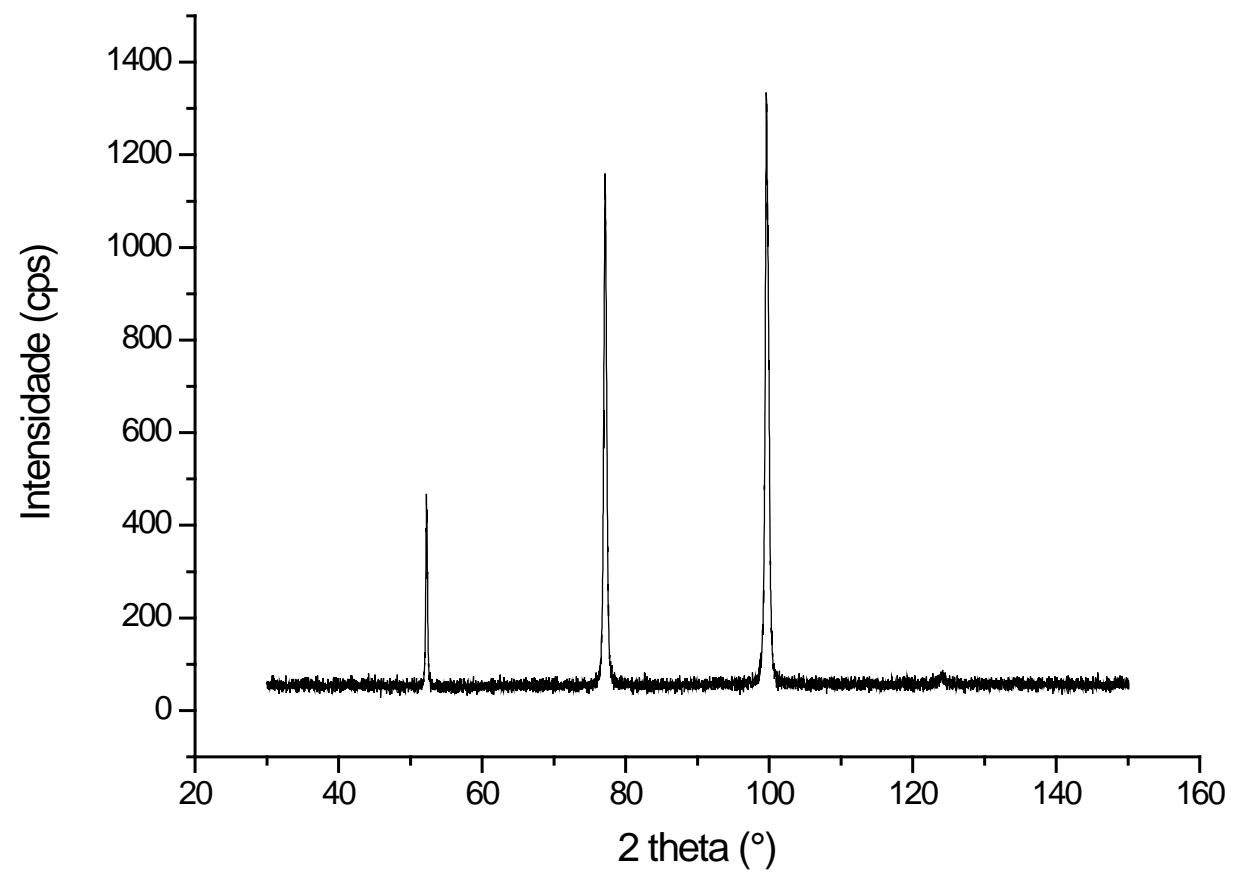

